Universidad de Lima

Facultad de Comunicación

Carrera de Comunicación

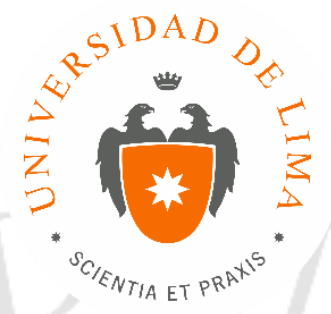

\title{
CRUZ ANCLA:
}

\section{PROGRAMA DE RADIO ONLINE}

Trabajo de Suficiencia Profesional para optar el Título Profesional de Licenciado en

Comunicación

\section{Daniela Padilla Collomp}

Código 20112947

\author{
Asesor \\ Carlos Rivadeneyra Olcese \\ Lima - Perú




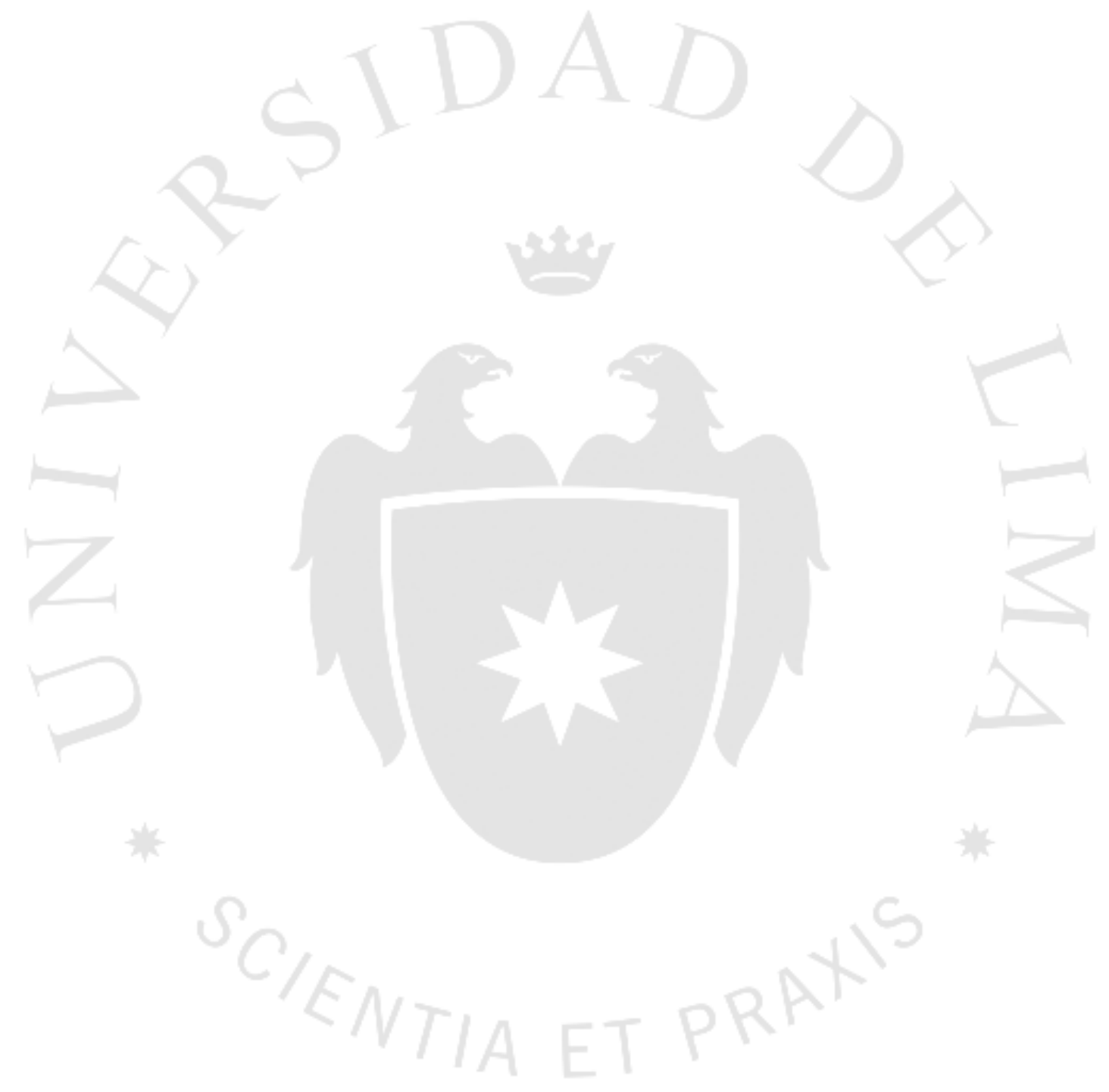




\section{CRUZ ANCLA:}

\section{PROGRAMA DE RADIO ONLINE}




\section{TABLA DE CONTENIDO}

I. DIRECCIÓN ELECTRÓNICA DEL TRABAJO ................................ 2

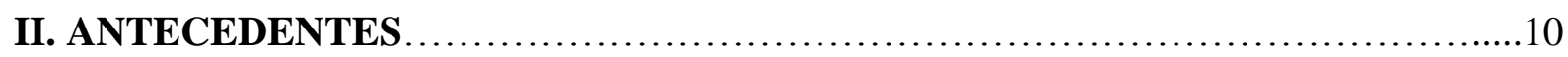

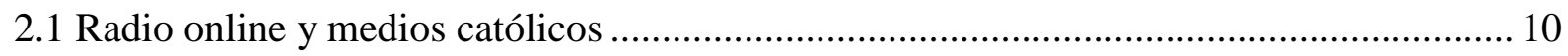

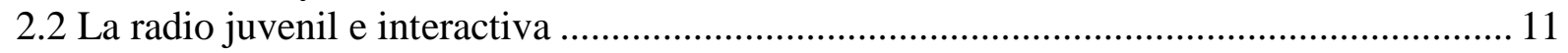

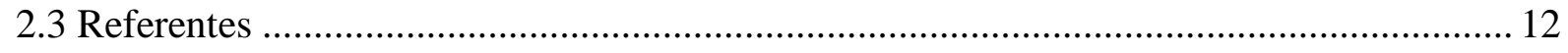

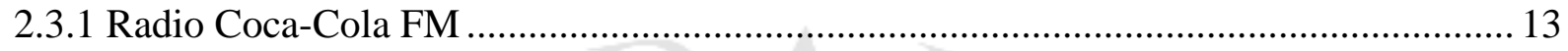

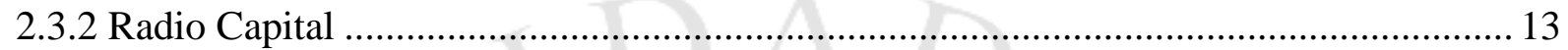

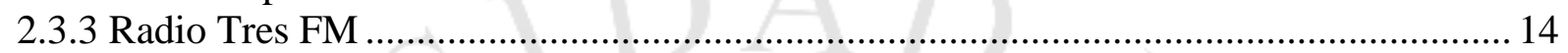

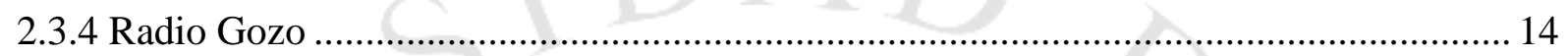

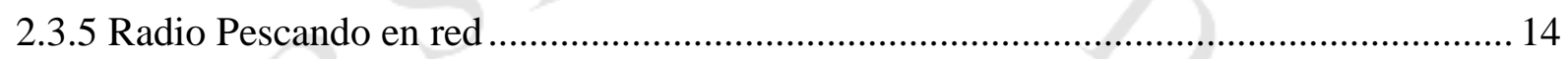

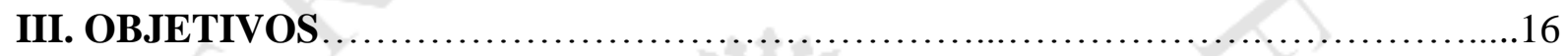

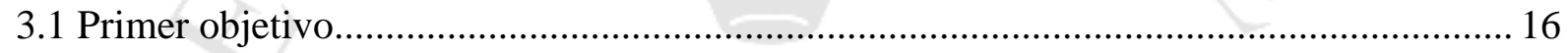

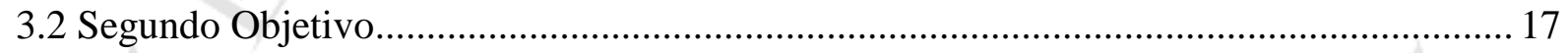

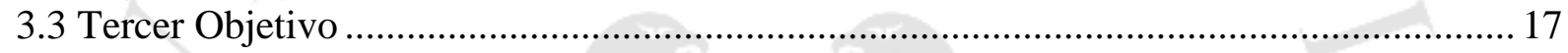

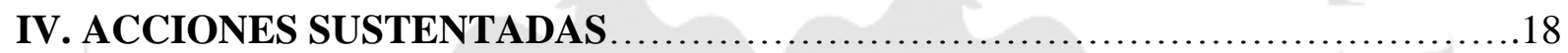

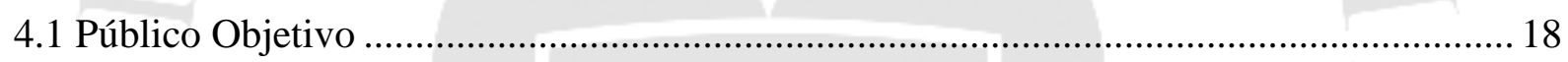

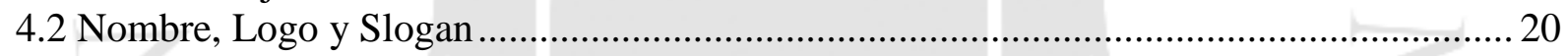

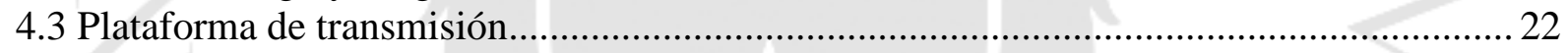

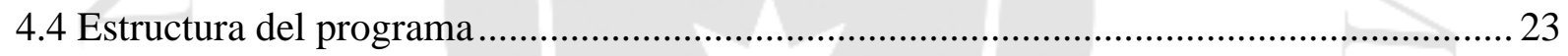

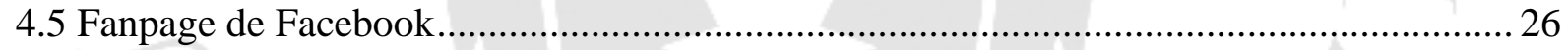

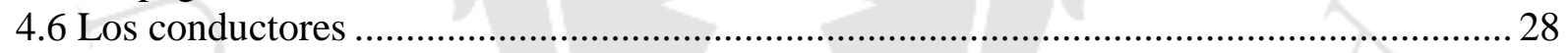

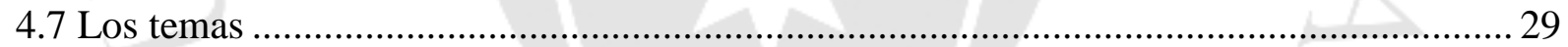

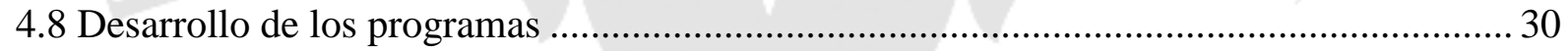

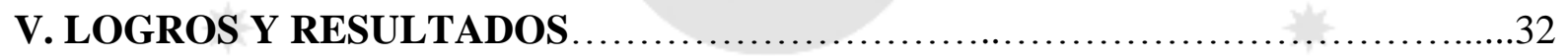

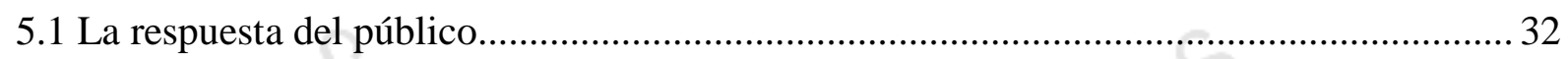

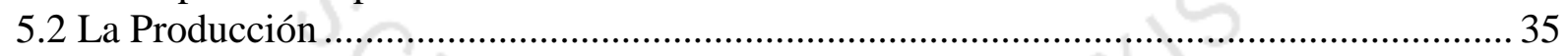

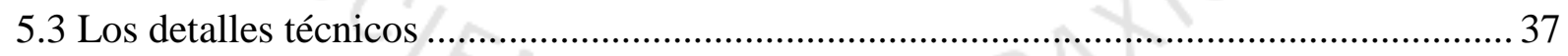

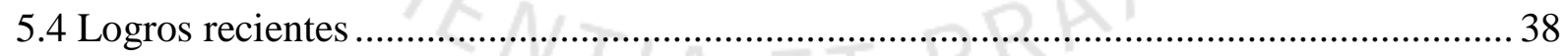

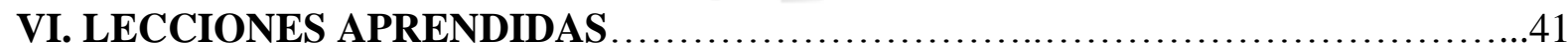

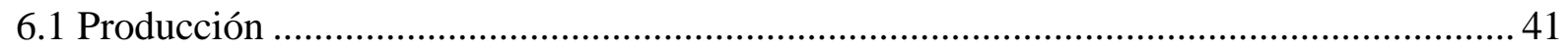

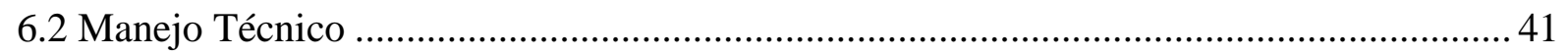

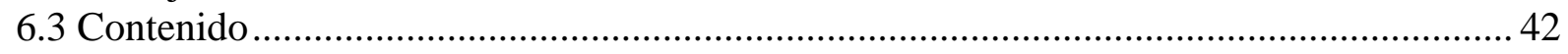

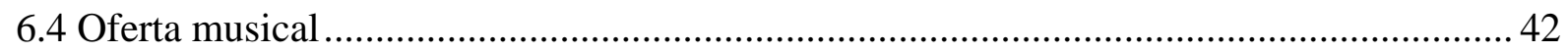

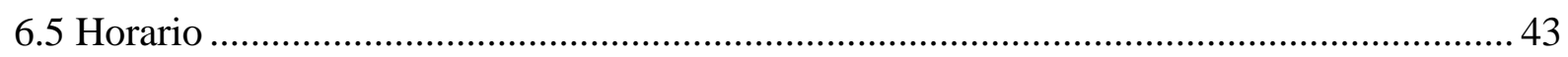

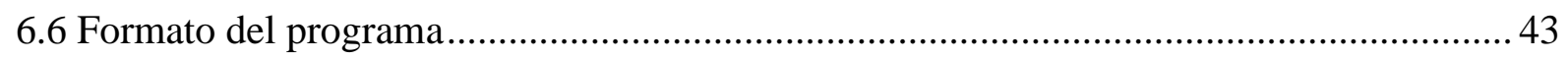

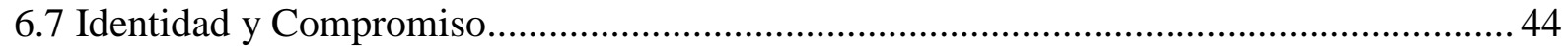

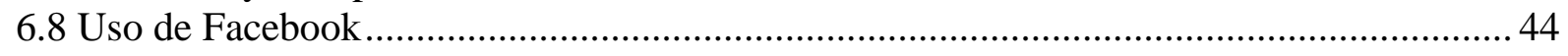


ANEXOS. .48

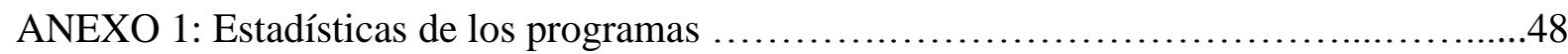

ANEXO 2: Pautas radiales de los programas .........................................59

ANEXO 3: Resultados de la encuesta de validación del proyecto........................109

ANEXO 4: Links relacionados 


\section{ÍNDICE DE GRÁFICOS}

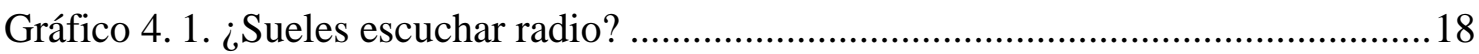

Gráfico 4. 2. ¿Con qué frecuencia escuchas radio? ..................................................... 18

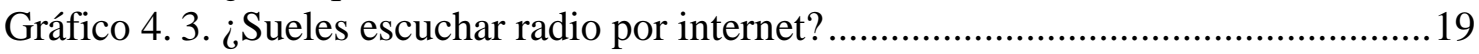

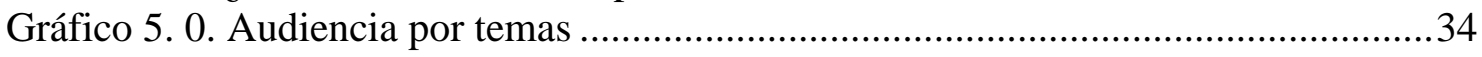

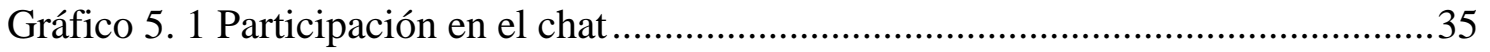




\section{ÍNDICE DE FIGURAS}

Figura 4. 1. Logo del Movimiento de Vida Cristiana .................................................... 19

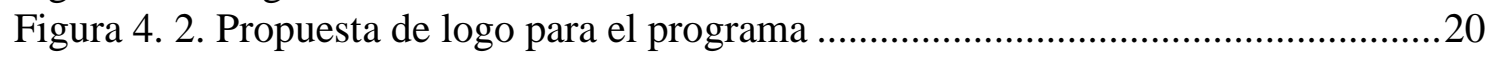

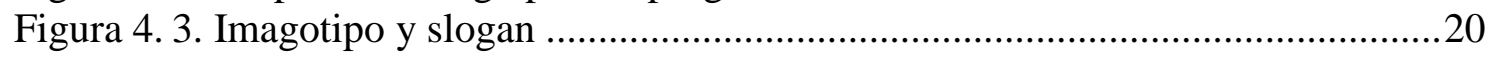

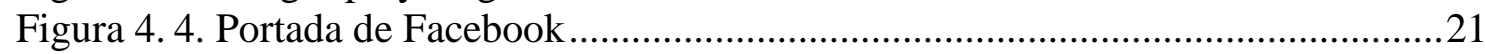

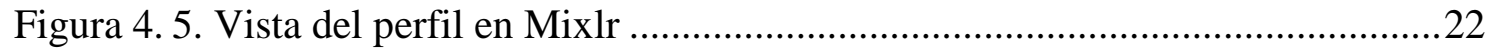

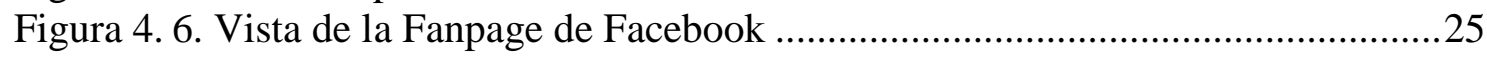

Figura 4. 7. Publicación de Facebook sobre el primer programa....................25

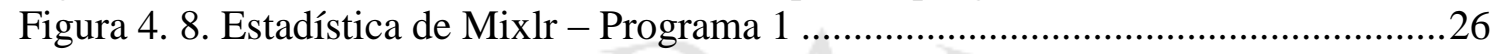

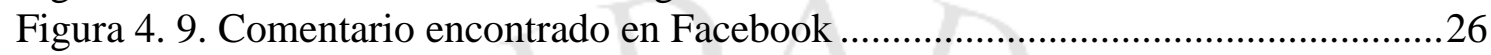

Figura 5. 1. Estadísticas del segundo programa según Mixlr ..........................................30

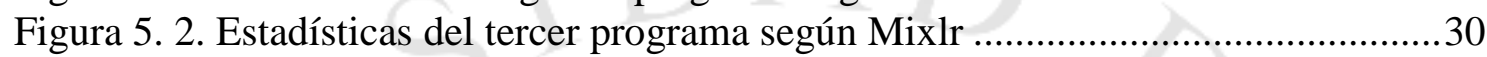

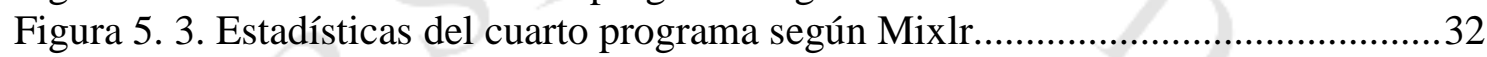

Figura 5. 4. Estadísticas del quinto programa según Mixlr .........................................33

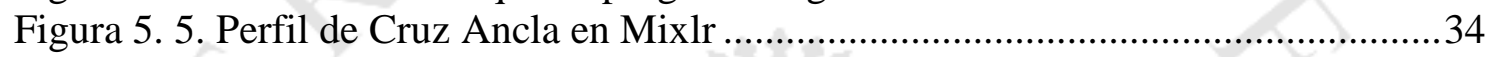

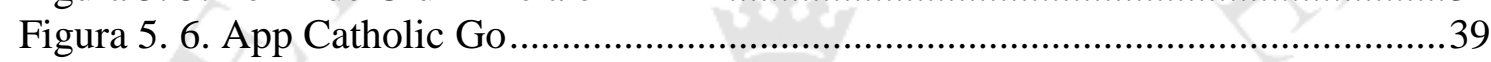

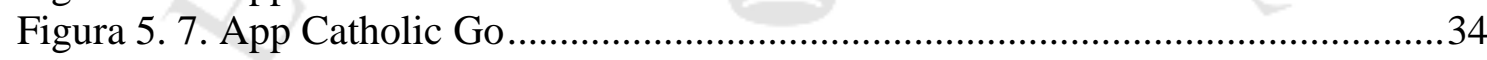

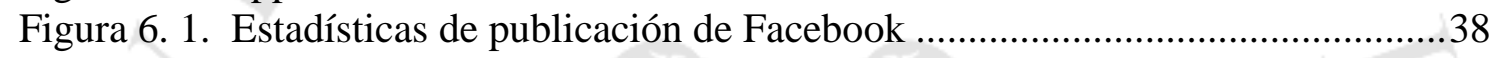

Figura 6. 2. Estadísticas de publicación de Facebook …................................................ 41

Figura 6. 3. Estadísticas de publicación de enlace en Facebook ..................................42 


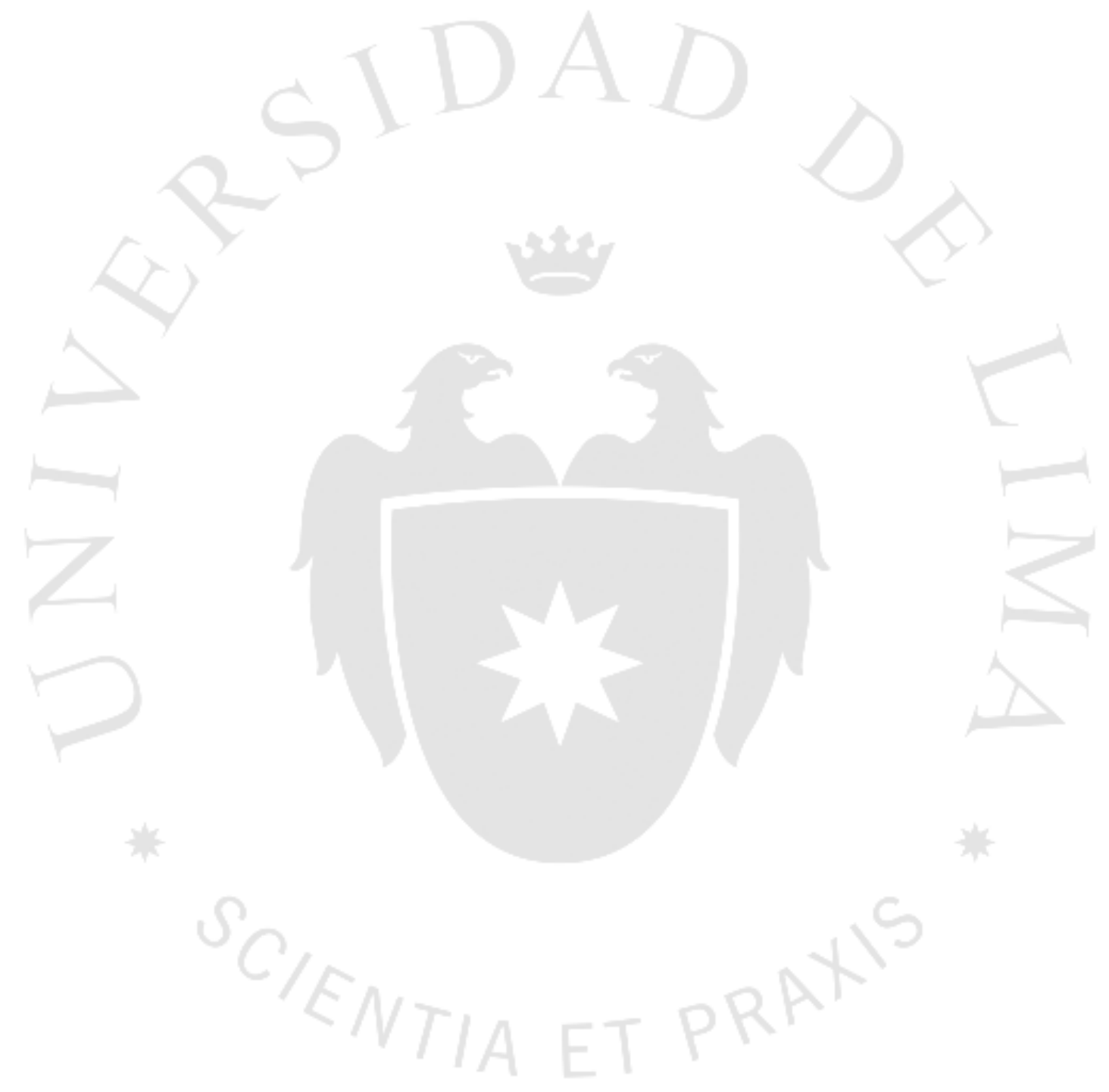




\section{DIRECCIÓN ELECTRÓNICA DEL TRABAJO}

Página en Mixlr:

WWW.mixlr.com/cruz-ancla

Página de Facebook:

$\underline{\text { www.facebook.com/cruzancla }}$

Programas transmitidos:

http://mixlr.com/cruz-ancla/showreel/ 


\section{ANTECEDENTES}

\subsection{Radio online y medios católicos}

La radio se ha transformado con el paso de los años. Hoy en día se ha dejado de lado el uso de tecnologías análogas para la producción radial y los medios de distribución se han multiplicado. En el Perú, las frecuencias más conocidas son la Frecuencia Modulada (FM) y la Amplitud Modulada (AM). Pero vale la pena detallar los diversos medios existentes para tener el panorama completo.

Según Rivadeneyra (2013), por un lado, tenemos la Radio Digital Terrestre (RDT) mediante el cual se usa el espectro radioeléctrico para transmitir señales digitales, donde se agrupa la información correspondiente al sonido comprimido en algún formato digital. También tenemos la radio digital satelital, que consta principalmente de servicios pagados, generalmente ligados a servicios de cable, en muchos casos.

Otro de los medios de distribución de la radio es Internet. La llegada del internet y, en general, la constante evolución tecnológica, ha llevado a muchos medios como la radio, a adaptarse y reinventarse constantemente, lo cual le atribuye un gran potencial, sobre todo si hablamos de radio online. Según Aurora García (2013), la radio siempre se ha caracterizado por ser un medio accesible, que no requiere de tantos recursos para su producción en comparación a otros; tiene la posibilidad de variar el contenido y el formato en que este se presenta; y, además, es íntimo y cercano. Con las tecnologías como el Internet, todo esto se potencia.

La radio en Internet o ciber-radio en la actualidad tiene tres formas de uso diferentes. Por un lado, tenemos la radio en Internet de forma literal: las emisoras de radio convencionales colocaron la misma señal de la emisora en vivo, a través de su página web, de manera que la señal de la radio se pueda encontrar online. Por otro lado, surgieron las Radios online o Radios web, que son emisoras que solo se pueden encontrar en Internet. Finalmente, existe en la actualidad el Podcasting, que consiste en la publicación de audios, llamados Podcasts, a los que se accede por demanda, en el momento que se desee. 
En la actualidad, en el Perú, casi todas las radios convencionales han optado por tener la radio en Internet, de forma que se puede escuchar la misma transmisión convencional, pero a través de internet, de forma digital. Podemos confirmar esto en páginas como www.radios.com.pe o www.radiosenvivodeperu.com donde encontramos varias listas de las radios peruanas que se pueden escuchar por Internet.

Además, en páginas como www.enlaradio.pe vemos que ya existen muchas radios que se trasmiten solo a través de internet y éstas han ido aumentando. Según un artículo publicado en el portal web Puro Marketing (2015) las radios online han tenido éxito en relación a la audiencia, sobre todo con los jóvenes e incluso, hay muchos especialistas que sostienen que en el futuro todas las radios se transmitirán a través de internet.

Por otro lado, internet ofrece acceso a múltiples programas y plataformas que permiten transmitir libremente programas de radio, lo cual hace que cualquier persona que lo desee pueda crear su propio programa de radio, y con menos costos en comparación a la radio tradicional. Aurora García (2009) menciona varios de los obstáculos que puede tener una emisora tradicional: "Obstáculos que pueden ser de naturaleza económica, si hay que pagar una licencia de radio, de carácter burocrático, si es necesaria una autorización oficial, o de naturaleza política" (p. 137).

Es por todo esto que optamos por realizar un programa de radio online, con el objetivo de plantear un concepto nuevo para un público objetivo específico, con características muy definidas, de manera que pudiéramos realizar un programa especial para ellos. Por esto decidimos realizar un programa para jóvenes miembros del Movimiento de Vida Cristiana, movimiento eclesial al que pertenecemos.

Además, pudimos ver que dentro del Movimiento de Vida Cristiana (MVC), si bien existe el uso de diversos medios digitales, sobre todo las redes sociales, no existe una radio online, por lo que se trata de un medio que podría tener gran acogida al ser algo nuevo y diferente, sobre todo para los jóvenes. Además, es un lugar donde estos podrán escuchar la música del MVC, incluso algunas canciones que no se escuchan con frecuencia ni son fáciles de encontrar en internet. 


\subsection{La radio juvenil e interactiva}

Una de las características de la radio es la posibilidad de interactuar con los oyentes, ya sea a través de llamadas telefónicas, comentarios en la página web o través de redes sociales, donde se les permite comentar o enviar mensajes, e incluso audios a través de WhatsApp. Este elemento es un atributo que resulta atractivo y es muy valorado por los oyentes. Además, brinda mucho dinamismo al programa de radio y permite generar un espacio de diálogo muy rico que agrega valor, sobre todo para los jóvenes (López Vidales, Gómez Rubio, \& Redondo García, 2014).

Así lo afirma Elizabeth Rodríguez Montiel: "Los usuarios están deseosos de que los medios tradicionales interactúen con ellos y que sean capaces de crear productos dinámicos adecuados al contexto complejo en el cual están inmersos”. Esto mismo es lo que plantea la radio online, que es capaz de ser mucho más cercana y generar interacción, sin dejar de ser un medio de referencia como la radio tradicional (Montiel, 2011).

Sabemos que en la actualidad los jóvenes realizan múltiples actividades a la vez, y la radio es un medio que permite esto, ya que uno puede escucharla en segundo plano, mientras realiza otras actividades. Esto permite tenerla siempre cerca, incluso en el auto, y en estos días en que la mayoría tiene un Smartphone en la mano y, además, uno con casi constante acceso a Internet, las posibilidades de tener a la radio, incluso la radio por internet, como compañera constante, son muchas. Esto lo podemos verificar en el último reporte de Osiptel (diciembre 2016), donde vemos que el 59\% de la población del Perú accede al servicio de Internet Móvil, de los cuales, el 58.6\% lo hace a través de su Smartphone (Osiptel, 2016). Por otro lado, según el último informe de IPSOS (enero 2017), el 56\% del Perú urbano cuenta con Internet en casa y el Smartphone es el dispositivo más usado por los internautas peruanos para acceder a Internet (IPSOS, 2017).

Por otro lado, la cantidad de medios a los que tenemos acceso, obligan a la radio a competir para no perder atención, y la posibilidad de adaptarse y ser interactiva y participativa, incluso individualizada, es una forma en la que esta puede evolucionar para no quedarse sin audiencia (Gonzáles, 2013). 


\subsection{Referentes}

Como parte del trabajo previo a la realización del programa de radio, en el año 2015, se buscó radios de referencia, con dos características principales: por un lado, buscamos radios que tuvieran como público objetivo a los jóvenes, o que tuviesen como característica la interacción con el público. Por otro lado, buscamos radios católicas que se escuchen en Perú y que tengan un corte o algunos programas juveniles.

\subsubsection{Radio Coca-Cola FM}

Es una radio online dirigida a jóvenes que está directamente enlazada a la promoción de la famosa bebida. Encontramos que en su página web: http://www.coca-cola.fm/ se describe como "una plataforma interactiva en línea que abre un espacio de radio que impulsará diferentes propuestas alternativas e independientes de la esfera musical mundial. Con esta iniciativa, la marca evoluciona para ofrecer un componente de contenido que buscará inspirar experiencias positivas en los jóvenes".

Esta radio online que tiene un fin principalmente comercial, ya que está asociada a la marca de gaseosa y constantemente se habla de esta en los programas. Es una radio juvenil bastante similar a algunas radios peruanas que tienen el mismo público objetivo.

Nos interesa esta radio ya que tiene como público objetivo a los jóvenes y busca ser una radio interactiva, dinámica, fresca y juvenil, lo cual es similar a lo que nosotros queremos. Por otro lado, también nos llama la atención que tiene la característica de haber ido cambiando para adecuarse al público.

\subsubsection{Radio Capital}

Es una radio convencional que también se puede escuchar por Internet Nos interesa porque su principal característica es la interacción con el público. Dado que su eslogan es "Tu opinión importa", se trata de una radio que da espacio durante sus programas para que los oyentes puedan llamar a la radio y dar sus opiniones sobre el tema del que se está 
hablando, les permiten opinar, contar anécdotas, experiencias y hasta proponer soluciones a la problemática de la sociedad.

Esto lo vemos claramente plasmado en el slogan con el que CAPITAL 96.7 FM se incorporó al espectro radial es "Tu Opinión Importa", una frase que encierra la diversidad de ideas que se acogerán en la emisora, siempre en el marco de un debate alturado y respetuoso.

Esta radio nos llama la atención sobre todo por la participación que tienen los oyentes en ella. Nos agrada lo abiertos que están para recibir llamadas y comentarios y cómo con libertad los dejan salir al aire y el debate o las conversaciones que esto permite. Nos interesa particularmente estas características, ya que nos gustaría lograr bastante interacción y cercanía con nuestros oyentes.

\subsubsection{Radio Tres FM}

Es una radio online católica colombiana que se caracteriza por ser de corte juvenil. Entre los bloques, pasan todo tipo de música, desde Shakira hasta Juan Luis Guerra, incluida la música católica, por supuesto. Esta radio tiene diversos programas, en algunos se habla de temas de fe católica, en otros temas de actualidad, se comenta el evangelio de día, etc.

Es una de las radios católicas que hemos encontrado más llamativa, sobre todo porque está muy bien producida, y es bastante dinámica. Nos llamó la atención el hecho de que la música sea variada y no se limiten a pasar solo música católica.

Link: http://www.tres.fm./

\subsubsection{Radio Gozo}

Es una radio católica que tiene la característica de tener locutores que provienen de distintos países y que participan de la radio en vivo desde el país donde viven, tienen programas de reflexión, informativos, etc. En este caso, el público objetivo son los católicos en general, no sólo jóvenes y transmiten durante todo el día, tiene varios programas dirigidos por diversas personas y con diferente temática. 
En la actualidad ya no transmiten en su página, pues están iniciando el uso de su propia app llamada RadioGozo.net.

http://radiocatolicainternacional.org/

\subsubsection{Radio Pescando en red}

Esta es una radio online católica peruana, que busca promover la música católica contemporánea. Es dirigida por el conocido cantante católico Luis Enrique Ascoy y se puede escuchar desde su propia página.

Según lo que se describe en su página, esta radio "busca transmitir un mensaje de evangelización adaptado a las nuevas generaciones a través de un amplio contenido interactivo que implica programas en vivo, segmentos de evangelización y música católica contemporánea”. (Misión, 2015)

Link: http://luisenriqueascoy.com/\# 


\section{OBJETIVOS}

Cruz Ancla es un programa de radio online dirigido a jóvenes pertenecientes al Movimiento de Vida Cristiana, que trata temas relacionados a este movimiento eclesial. La idea es que sea interactivo y que motive la participación de los oyentes a través de redes sociales. Lo que buscamos es generar un espacio de diálogo presentado de una forma fresca y juvenil intercalando bloques musicales.

Buscamos lograr una propuesta diferente a las radios católicas, como Tres FM o Radio María, que ya existen que en muchos casos no tiene una línea gráfica bien trabajada ni propuestas dinámicas o temas interesantes. Además, para nuestro público objetivo que es un movimiento eclesiástico con determinadas características, estas radios católicas particularmente no resultan tan llamativas.

La idea es que esto quede como un medio que permita a los emevecistas estar más conectados y conocer más sobre nuestra fe, sobre la Iglesia y sobre nuestra música y nuestra proyección es que esto pueda crecer en alcance y que llegue más allá del Perú y también como una radio que tenga varios programas con distinta temática y para distintos públicos.

\subsection{Primer Objetivo}

El programa busca promover la identidad emevecista en los jóvenes, así como generar más compromiso en las actividades, que puedan conocer más sobre el MVC y que se generen espacios de diálogo y reflexión en torno a determinados temas de interés.

Dado que se trata de una radio que busca la participación de los oyentes y, además, no cuenta con una ubicación fija, y se puede escuchar desde cualquier lugar del mundo, queremos que se genere un espacio donde se puedan encontrar personas de distintos 
lugares y que todos se unan más al pertenecer al mismo movimiento y puedan ver que se viven las mismas experiencias y tienen los mismos anhelos, alrededor de Lima, del Perú y del mundo.

Además, podrá acercar a los emevecistas y ayudarlos a estar al tanto de las actividades que se realizan en los diferentes lugares donde está presente el MVC.

\subsection{Segundo Objetivo}

Consideramos que son los jóvenes los que conforman una gran parte de la población y los que buscan siempre formas más dinámicas de conocer su fe. Por ello tenemos como objetivo, que nuestro programa radial llame la atención de los jóvenes y dé que hablar.

Queremos generar debate, abrir un espacio de diálogo y sobre todo que permita compartir vivencias y opiniones. Nos interesa abrir un espacio para que los Jóvenes del MVC puedan compartir sus experiencias con los demás y también sentirse escuchados y comprendidos por otros que viven lo mismo.

\subsection{Tercer Objetivo}

Buscamos promover la música del MVC y la música católica en general. Hemos notado que el MVC cuenta con una gran cultura musical, muchas canciones propias que solemos cantar y muchas otras que no son tan conocidas. Muchas de estas canciones no se encuentran en Internet, por lo que solo se pueden escuchar en actividades, eventos y/o Misas. Por ello, queremos dar un espacio donde se pueda escuchar estas canciones más seguido.

Por otro lado, también vemos que, al tener tanta música de esta familia espiritual, no se conoce mucho la música y los artistas que son muy conocidos para otros movimientos o parroquias dentro de la Iglesia Católica. Por ello nos parece importante también incluir estas canciones en la radio, para que los emevecistas puedan conocer la riqueza musical de la Iglesia. 


\section{ACCIONES SUSTENTADAS}

\subsection{Público Objetivo}

Empezamos a construir la idea del programa, definiendo el público objetivo al que se dirigiría, para esto quisimos establecer un perfil. Para empezar, quisimos dirigirnos al público católico juvenil, pero vimos que ya existen muchas radios católicas, así que buscamos algo que nos diferencie. Por otro lado, vimos que, dentro del grupo al que pertenecemos, el Movimiento de Vida Cristiana, no escuchan mucho las radios católicas existentes. Por ello decidimos que nuestro programa estará dirigido a los jóvenes pertenecientes al MVC.

Para empezar, definimos bien nuestro público a investigar un poco más. Definimos que serían jóvenes de 15 a 25 años, que pertenezcan al Movimiento de Vida Cristiana, de nivel socioeconómico $\mathrm{AB}$ y que participen de las actividades del MVC. Estos son agrupados o vinculados al movimiento, que tienen interés en escuchar y compartir experiencias, conocimientos y opiniones. Además, les gusta estar conectados a través de redes sociales y les gusta la música del MVC.

Para conocer mejor el público al que nos enfrentaríamos, recurrimos a algunos datos tomados del INEI: Al 30 de junio de 2014, la población joven de lima (de 15 a 29 años de edad) alcanzaría 2 millones 383 mil 30 habitantes y representarían el 27,2\%. Por otro lado, $86 \%$ de la población de 12 a 70 años, de los NSE A, B, C, D y E de Lima Metropolitana que escucha radio al menos una vez por semana. (Ipsos 2013)

* Datos del año 2011:

- El $61 \%$ de los entrevistados escuchan radio todos los días.

- El 81\% de encuestados suele escuchar una emisora radial en su hogar. 
- Entre los que afirman haber entrado a páginas web de emisoras radiales, la principal actividad que suelen realizar es escuchar radio a través de Internet

Además, preguntando a los líderes del MVC y obtuvimos el dato de que, en Lima, en el año 2015, había alrededor de 700 jóvenes pertenecientes a este movimiento.

Para obtener datos sobre el consumo de radio online, realizamos una encuesta a 60 jóvenes miembros del Movimiento de Vida Cristiana. A continuación, mostramos algunos de los resultados:

Gráfico 4.1

\section{¿Sueles escuchar radio?}

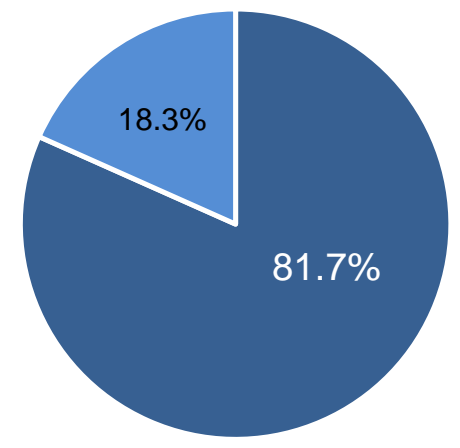

- Sí escucha radio - No escucha radio

Fuente: Elaboración propia

Gráfico 4.2

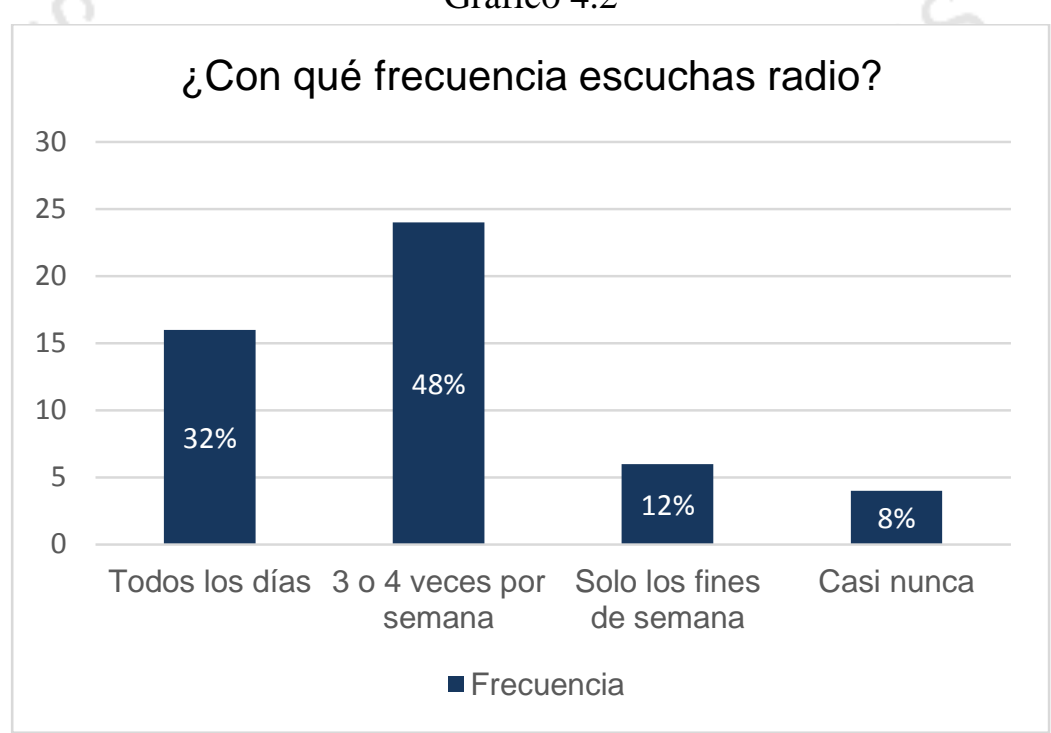


Fuente: Elaboración propia

\section{Gráfico 4.3}

¿Sueles escuchar radio por internet?

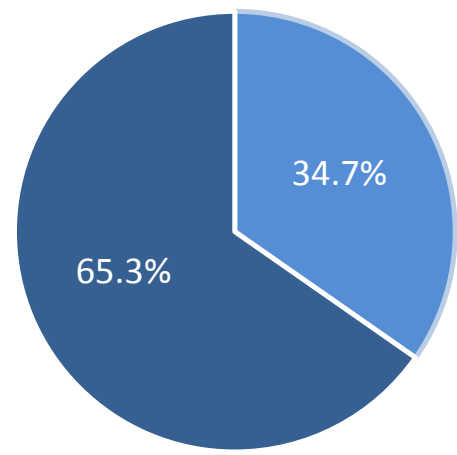

Si $\square \mathrm{No}$

Fuente: Elaboración propia

Mediante esta misma encuesta, se definió el horario y la duración del programa. Este se transmitió, al inicio, todos los sábados a las $12 \mathrm{~m}$. y tenía una duración de 1 hora. Más adelante se cambió a un horario en el que era más fácil para nosotros poder realizar el programa, y también fue bueno para los oyentes, que fue los viernes a las 5pm.

\subsection{Nombre, Logo y Slogan}

Para elegir el nombre y el logo del programa, pensamos en el logo del Movimiento de Vida Cristiana que es una cruz con forma de ancla, y este símbolo representa a todo el MVC. Entonces por ello pensamos que "Cruz Ancla" funcionaría como nombre, además de que suena bien.

Figura 4.1 


\section{Movimiento de}

Para el logo, estas fueron las ideas iniciales:

Figura 4.2

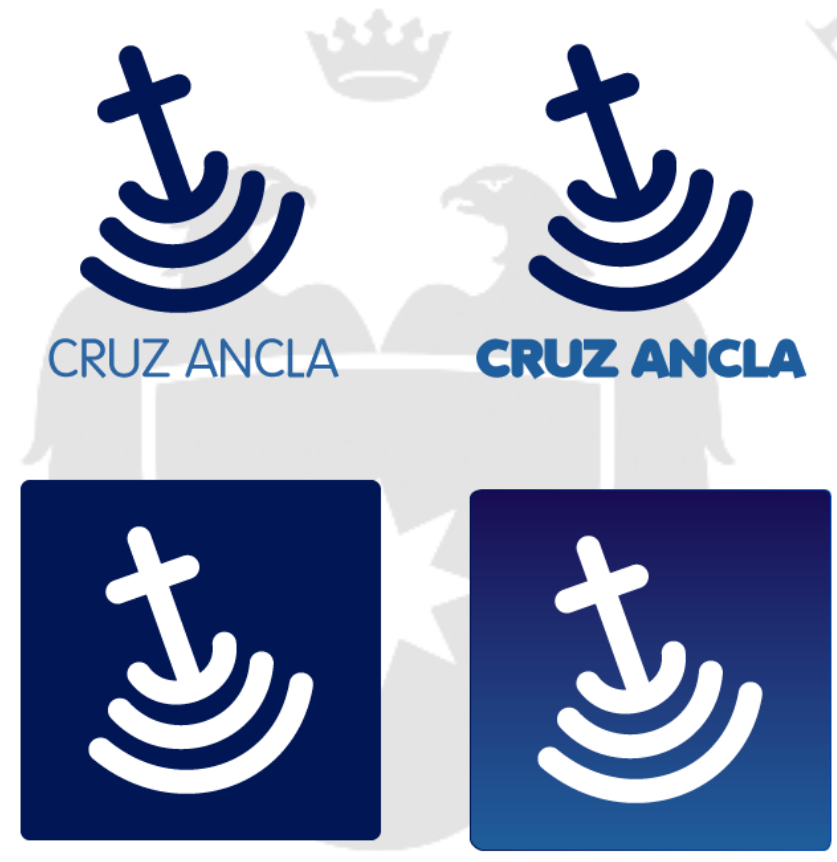

El logo es precisamente una cruz ancla con dos semicírculos más que hacen referencia a las ondas del sonido, las ondas radiales o también las ondas del Wi-Fi. Los colores son azul marino y celeste, ambos son colores similares a los del manual de identidad del MVC. El logo guarda relación con el logo del MVC, con el fin de que sea claro que la radio está hecha para emevecistas.

Antes de salir al aire, un diseñador le dio unos retoques finales de color y tipografía, y finalmente la gráfica del programa quedó así: 
Figura 4.3

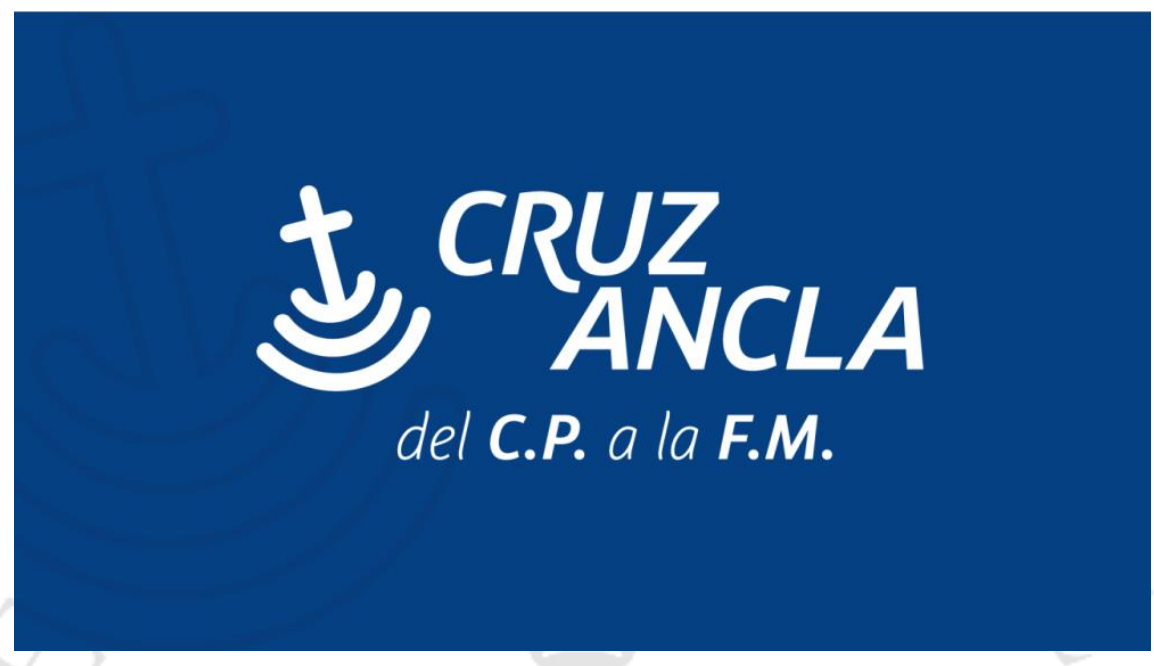

Para crear el slogan del programa, nos reunimos con los colaboradores del proyecto, con los conductores y otros amigos que ofrecieron su ayuda, e hicimos una lluvia de ideas. Finalmente, uno de ellos fue el que dio la idea de este slogan: "Del CP a la F.M". Este hace referencia a que somos los agrupados, que siempre nos reunimos en el CP (Centro Pastoral) los que hemos entrado a la radio, que somos los emevecistas los que hacemos este programa para emevecistas. Y usamos el término Fm para dar a entender que estamos en la radio, a pesar de no transmitir por FM.

Figura 4.4

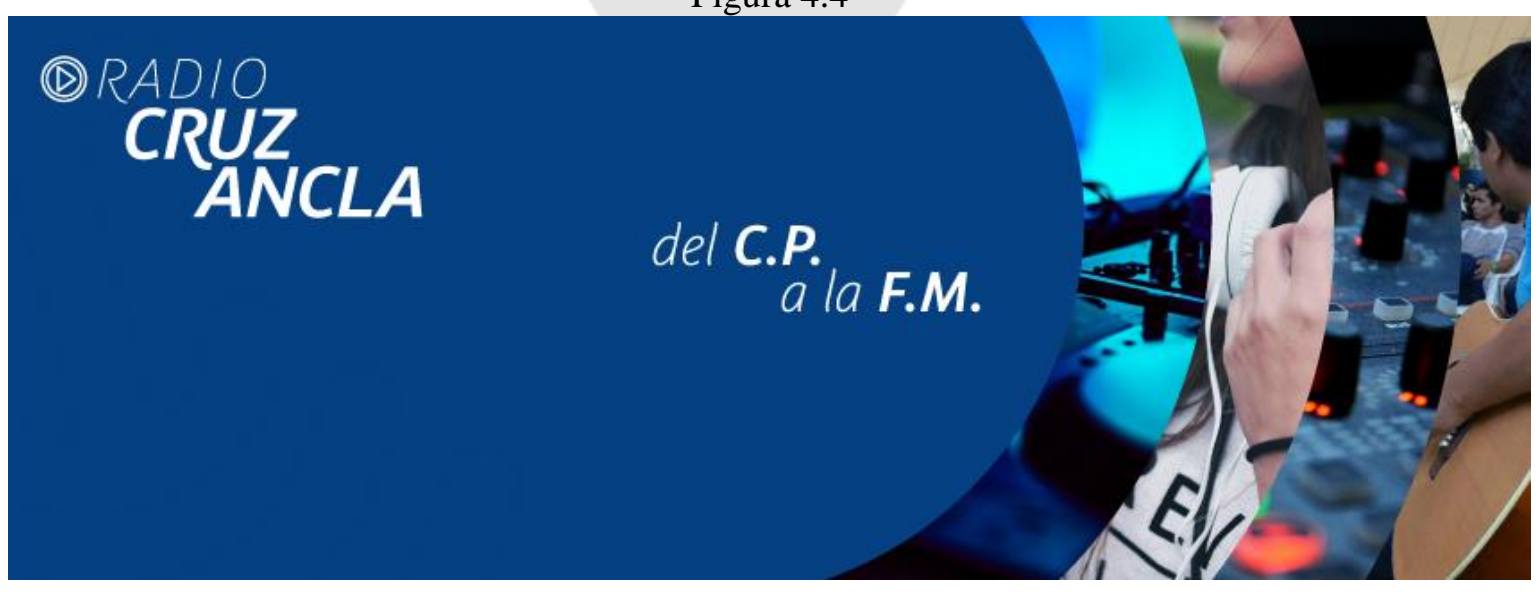




\subsection{Plataforma de transmisión}

Decidimos usar Mixlr, que es un programa que permite transmitir radio online en vivo durante una hora, de forma gratuita y con una muy buena calidad. Esta plataforma incluso da facilidades como un perfil con un chat donde los oyentes pueden comentar el programa en vivo, y el uso de Skype para que otras personas participen del programa. Además, esta plataforma permite ser insertada en páginas web, lo cual es un beneficio si es que quisiéramos hacer una página web a futuro.

Para trabajar con ella, se descarga el programa en la computadora, y desde allí se pueden poner las canciones e incluso conectar una mezcladora o un micrófono directamente a la laptop. Para acceder a la transmisión, se debe ingresar a la página de Mixlr y luego al perfil de la radio.

El link desde donde se puede escuchar el programa es este:

https://mixlr.com/cruz-ancla

Así es como se ve esta página cuando se entra al link y desde ahí se puede escuchar la radio:

Figura 4.5 


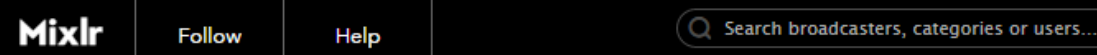

Prueba 1

0 hearts 零

CRUZ ANCLA

- 00:01:22

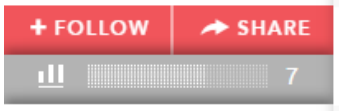

You're listening to:

Prueba 1

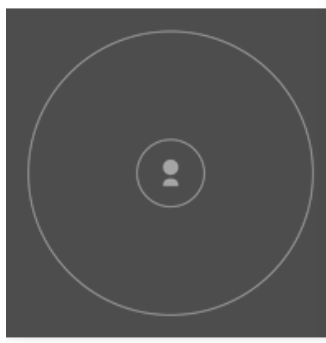

@: 0 Followers

$\checkmark$ Read more

Welcome to chat!

Be the first to start the conversation.

Now Playing :

No pares by Julio Cañas

Join the chat now

\subsection{Estructura del programa}

En base a las encuestas que realizamos, decidimos iniciar con un programa de una hora de duración, que se transmitiera una vez por semana. Dado que nuestra intención era tener un programa dinámico y entretenido, decidimos dividirlo en cuatro bloques, separados por bloques de dos o tres canciones. El primer bloque la bienvenida y presentación de los conductores y también la introducción al tema o los temas de los que se va a hablar durante el programa.

El segundo bloque es el desarrollo del tema. Idealmente, tratamos de tener al menos un invitado que de sus comentarios sobre el tema. Dependiendo del tema, se trata de un especialista o de personas relacionadas que puedan dar su opinión o comentar sus experiencias al respecto. La idea es que mientras más personas comentan sobre el tema, se vuelve más ameno y entretenido.

El tercer bloque es la continuación del mismo tema, o, en algunos casos, se pasa a comentar sobre algún proyecto solidario o actividad, para lo cual se entrevista a algún 
encargado o participante. Esto se planteó de esta manera, para que no se hiciera demasiado largo el programa. Vimos que muchos de los temas que queríamos abordar, eran entretenidos, pero no como para hablar durante dos bloques. Entonces decidimos hablar de dos temas, uno en cada bloque, y que los temas sean de distinto tipo, por ejemplo: un tema puede ser de formación en la fe y el otro sobre un proyecto solidario o uno sobre experiencias en alguna actividad y el otro sobre una fecha del calendario litúrgico.

En el cuarto y último bloque se lee el "Calendario emevecista" donde se mencionan las próximas actividades que se van a realizar en el MVC o en la Iglesia tanto del Perú, como de otros países. Decidimos incluir este "Calendario emevecista" ya que vimos que el programa es una gran oportunidad para dar a conocer diversas actividades que son muy buenas, pero que no siempre todos se enteran a tiempo, sobre todo cuando se trataba de las actividades fuera del MVC, entonces es bueno incluso para que los oyentes estén al tanto de lo que ocurre en otros movimientos y en otros países.

Esta fue la propuesta de programa piloto:

$\underline{\text { Programa Piloto }}$

Tema: Misiones

\section{PAUTA RADIAL}

PROGRAMA RADIAL: Cruz Ancla

HORARIO: Sábados $11 \mathrm{am}$

DURACIÓN: 1 hora

\begin{tabular}{|c|c|c|}
\hline BLOQUE & CONTENIDO & TIEMPO \\
\hline $\begin{array}{c}\text { PRIMER } \\
\text { BLOQUE: } \\
\text { PRESENTA } \\
\text { CIÓN }\end{array}$ & $\begin{array}{l}\text { - Bienvenidos al nuevo programa: Cruz Ancla, un programa hecho } \\
\text { especialmente para todos los jóvenes emevecistas, para los agrupados, } \\
\text { que quieren escuchar algo diferente. Hablaremos de temas diferentes, de } \\
\text { las cosas que nos pasan como agrupados, de las cosas que tenemos en } \\
\text { común, de temas de actualidad y de temas también relacionados a } \\
\text { nuestra espiritualidad. } \\
\text { - Yo soy Raúl Gonzáles } \\
\text { - Yo Soy Valentina Cáceres } \\
\text { - Esto es Cruz Ancla y hoy hablaremos sobre un tema que nos entusiasma } \\
\text { a muchos. } \\
\text { - Así es, en estas vacaciones de medio año en nuestros centros pastorales } \\
\text { nos hemos ido de misiones } \\
\text { - Las misiones son una experiencia para todos muy enriquecedora y } \\
\text { difícil de olvidar así que les pedimos que compartan con nosotros a } \\
\text { través de Facebook y twitter sus anécdotas más divertidas de misiones. } \\
\text { - Sí, y además el día de hoy nos acompañan agrupados de distintos }\end{array}$ & $5 \min$ \\
\hline
\end{tabular}




\begin{tabular}{|c|c|c|}
\hline & $\begin{array}{l}\text { - ventros que han venido para compartirnos sus experiencias en misiones. } \\
\text { experiencia en Facebook y twitter. Los dejamos con una canción que } \\
\text { todos hemos alguna vez cantado a todo pulmón: "No nos basta". }\end{array}$ & \\
\hline MÚSICA & 3 CANCIONES & $10 \mathrm{~min}$ \\
\hline $\begin{array}{c}\text { SEGUNDO } \\
\text { BLOQUE }\end{array}$ & $\begin{array}{l}\text { - Ya estamos de vuelta en Cruz Ancla, esa canción fue "Tu Misión" de } \\
\text { Julio Cañas y ya estamos listos para empezar a compartir nuestras } \\
\text { anécdotas de misiones. } \\
\text { - Pero antes de escuchar las anécdotas queremos comentarles un poco } \\
\text { sobre misiones universitarias, que son básicamente las mismas misiones } \\
\text { del MVC, pero para universitarios de diversos lugares. Y para } \\
\text { comentarnos sobre esto, Gustavo, encargado de misiones universitarias, } \\
\text { nos ha mandado un audio, vamos a escucharlo. } \\
\text { - Ahora queremos comentar un poco nuestras anécdotas, para eso nos } \\
\text { acompaña Fiorella Valenzuela. Cuéntanos, ¿Qué es lo más particular } \\
\text { que vieron en el pueblo donde fueron? } \\
\text { - Ahora vamos a leer algunas de las cosas que nos han escrito en } \\
\text { Facebook... } \\
\text { - No se olviden de darle like a nuestra página Cruz Ancla en facebook y } \\
\text { seguirnos en twitter también nos encuentran como @ CruzAncla } \\
\text { - Ahora vamos a escuchar a Takillakkta con "Somos convocados". }\end{array}$ & $10 \mathrm{~min}$ \\
\hline MÚSICA & 2 CANCIONES & $8 \min$ \\
\hline $\begin{array}{l}\text { TERCER } \\
\text { BLOQUE }\end{array}$ & $\begin{array}{l}\text { - Seguimos con Cruz Ancla y ahora quiero preguntarles ¿Cuál fue el } \\
\text { momento que más les gustó? } \\
\text { - ¿Por qué creen que es importante hacer este tipo de viajes? } \\
\text { - Decir la hora. Ya volvemos con Cruz Ancla } \\
\text { - Ahora vamos con una canción que fue el himno de las primeras } \\
\text { misiones a las que fui: "La mies del Señor" del grupo Siervas }\end{array}$ & $12 \mathrm{~min}$ \\
\hline MÚSICA & 2 CANCIONES & $10 \mathrm{~min}$ \\
\hline $\begin{array}{c}\text { CUARTO } \\
\text { BLOQUE } \\
\text { Calendario } \\
\text { emevecista } \\
\text { y } \\
\text { Despedida }\end{array}$ & $\begin{array}{l}\text { CUÑA: ¡Calendario emevecista! } \\
\text { R: Y bueno hoy es el rosario por el año de la Misericordia en todos los } \\
\text { centros pastorales } \\
\text { en el Centro Apostólico NSR después del rosario habrá una jornada de } \\
\text { Adviento } \\
\text {-En Jesús María tienen "Star entre Hermanos" que se ve que va a estar } \\
\text { genial, así que no se lo pierdan. } \\
\text {-Y el martes } 8 \text { es la Misa de Aniversario del Sodalicio de Vida Cristiana a } \\
\text { las } 12 \text { y luego tendremos el almuerzo pro fondos de Jesús María, vamos a } \\
\text { comer un rico pollo a la brasa } \\
\text {-Y eso es todo por ahora, esto ha sido el Calendario emevecista } \\
\text {-Ha llegado el momento de despedirnos, ha sido un gusto estar con } \\
\text { ustedes, Esto fue CRUZ ANCLA!! }\end{array}$ & $5 \mathrm{~min}$ \\
\hline & TIEMPO TOTAL: & $60 \mathrm{~min}$ \\
\hline
\end{tabular}




\subsection{Fanpage de Facebook}

Para dar a conocer el programa y que así la gente nos escuche, se creó una página de Facebook dos meses antes, para hacer una campaña de intriga y así generar expectativa. Desde el lanzamiento de la Fanpage en Facebook, el 26 de agosto del 2015, se tuvo muy buena acogida. Esto lo sabemos ya que, antes del estreno del programa, ya habíamos llegado a tener 300 Me Gusta en la página y las primeras publicaciones contaban con un promedio de 50 likes y varios compartidos. Muchos de los seguidores de la Fanpage mostraron interés y hubo bastante expectativa y entusiasmo por la idea de la radio.

Figura 4.6

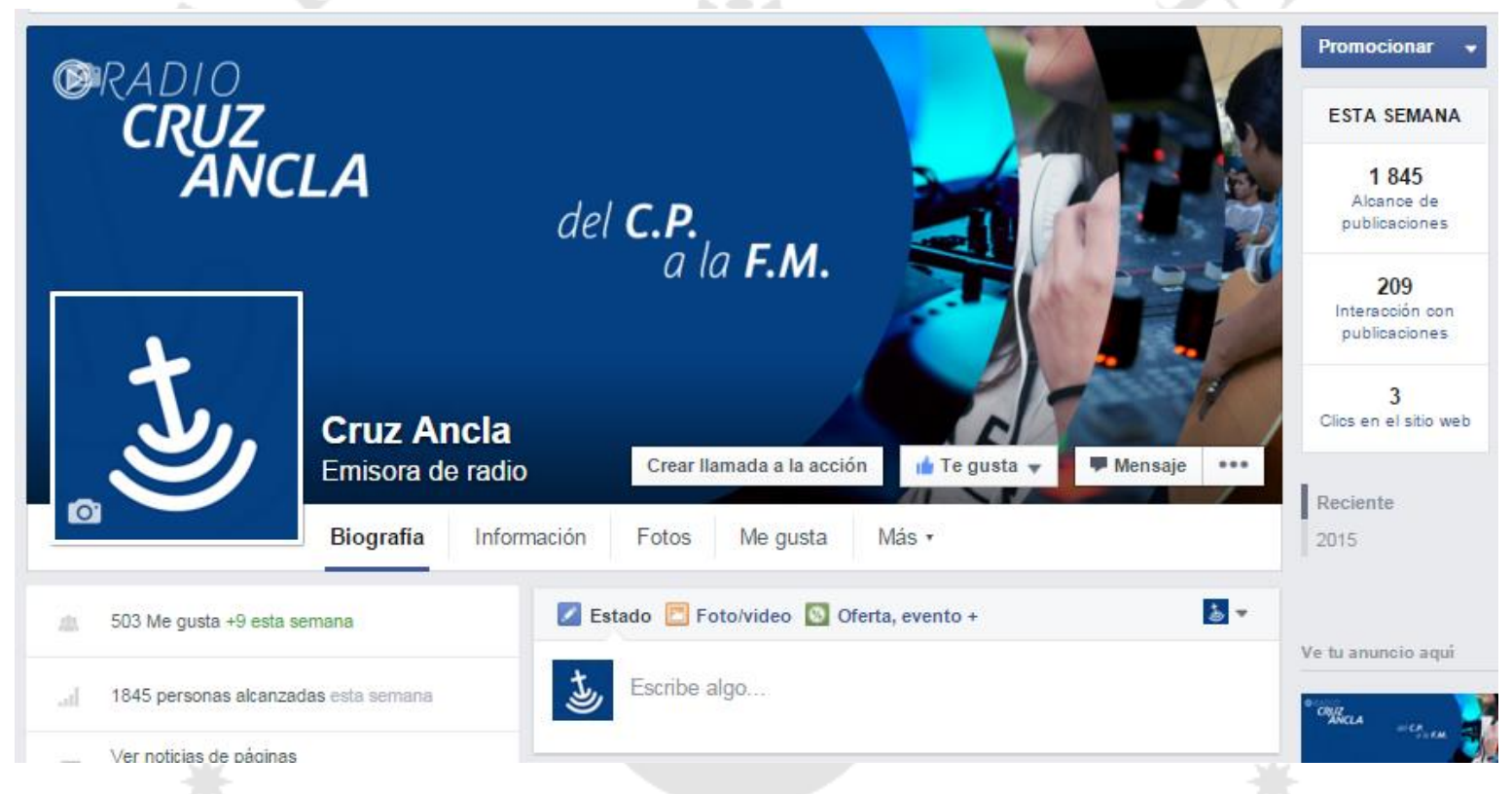

Figura 4.7 


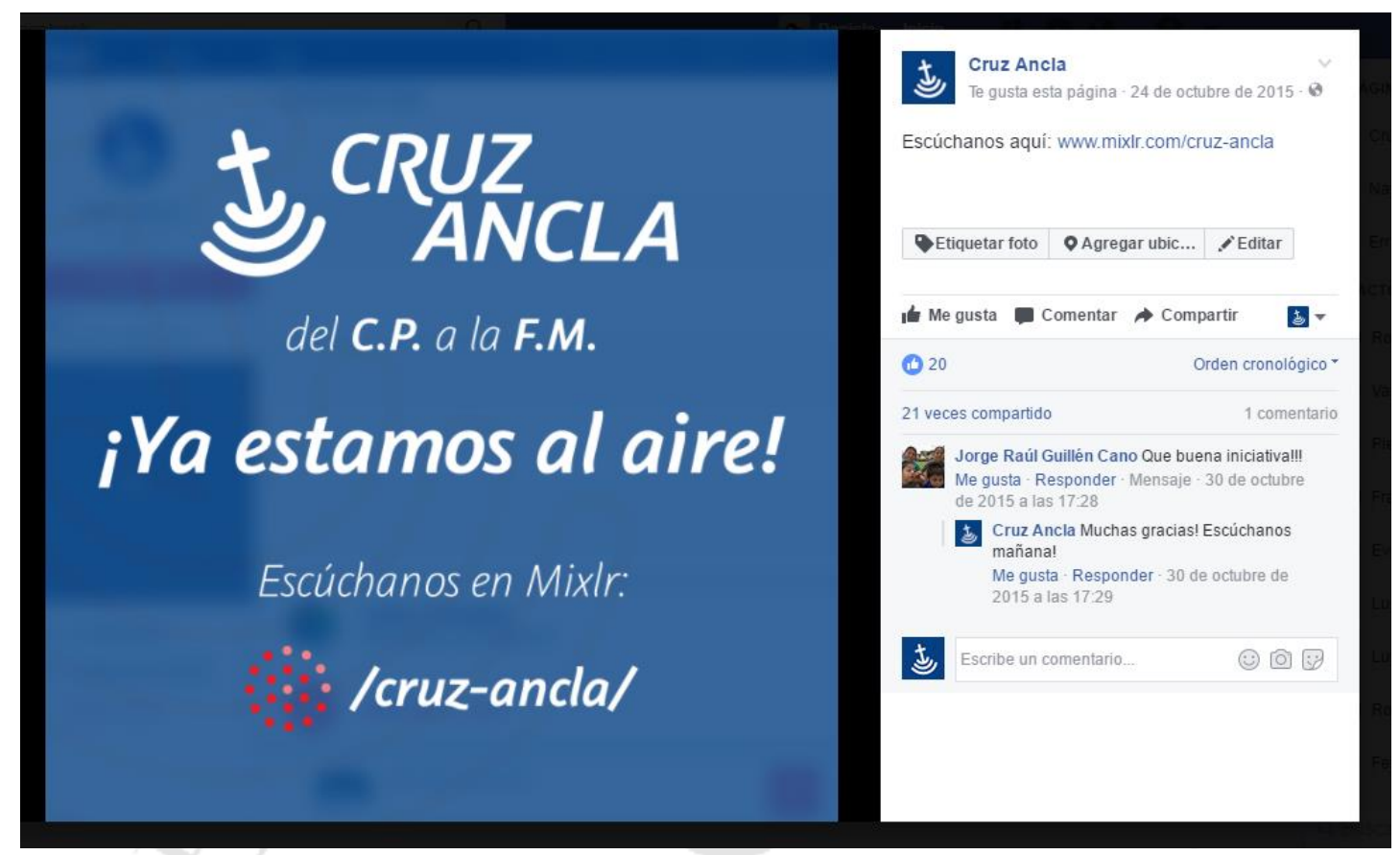

Para el primer programa, creamos un evento en Facebook, con el fin de difundir el programa y así lograr que la gente lo escuche. Ese día llegamos a tener 67 personas escuchando el programa y comentando sobre el mismo.

Figura 4.8

\section{Mixir}

Dear Cruz Ancla,

Congratulations! Your broadcast "Primer Programa" has been saved. You broadcast live for $1 \mathrm{~h} 0 \mathrm{~m}$.

- Listen: Listen back to your broadcast now

- Export: Export this broadcast to SoundCloud, Dropbox and more

- Delete: Delete this broadcast for ever

New feature: Change the audio quality of your broadcast on the fly. Learn more

Stats for this broadcast

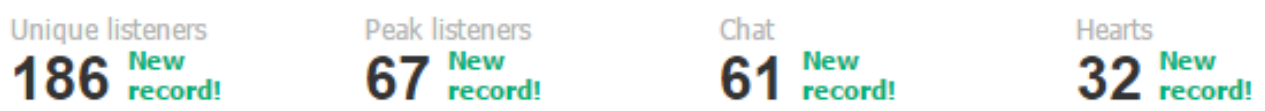

What are these statistics? More info.

Una vez iniciadas las transmisiones, hemos tenido muy buena acogida, tenemos un promedio de 30 personas que escuchan Cruz Ancla cada sábado y además vemos bastante 
respuesta en redes, sobre todo en Facebook. Y Además los oyentes suelen compartir y comentar con sus amigos sobre la radio y los invitan a escucharla.

Desde el 24 de octubre del 2015 hasta el 24 de junio del 2016 realizamos 31 programas donde desarrollamos diversos temas con muy buena acogida del público. Algunos de ellos fueron pregrabados y otros en vivo. Hemos ido mejorando sobre todo en el área de producción y en los aspectos técnicos, sobre todo en la calidad del audio que fue algo en lo que fallamos al inicio.

Figura 4.9

Mara Alcedo + CP SMR Callao

$14 \mathrm{~h}$ - 䧃

Hola a todos, para los que todavia no saben, hace poco se ha lanzado Cruz Ancla, un programa de radio por internet que transmite musica y temas del MNC, el programa son todos los sabados a las 12pm, aqui les dejo el link de su pagina en Facebook: https://www. facebook.com/CruzAncla/?ref=ts\&fref=ts

Y les comparto que el dia de ayer, Alvaro Aldama, agrupado del centro, fue entrevistado en este programa, hablando sobre el apostolado en la música. AQUI LES COMPARTO EL LINK DEL PROGRAMA DE AYER PARA QUIENES NO PUDIERON ESCUCHARLO... : :) http://mixlr.com/cruz-a.../showreel/la-musica-y-el-apostolado/ Buena Chan! ::)

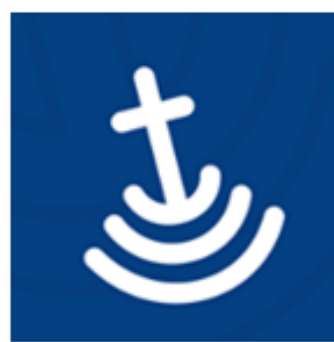

Cruz Ancla

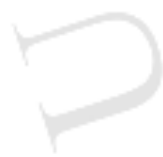

Guardar

Ine gusta Comentar $\Rightarrow$ Compartir

A Paola Tapia de Ossio, Jeremy Sánchez y 17 personas más les gusta esto.

Adrian Chirre Muy bueeena radio! (:):

Me gusta-Responder-31-14 h

Fatima Bazalar Buenísima!! *

Me gusta - Responder - 13 - $13 \mathrm{~h}$

Elisa Herrera me encanta porque la música es uno de los mejores medios

para el apostolado, felicitaciones

Me gusta - Responder - $12 \mathrm{~h}$ 


\subsection{Los conductores}

Hacia fines de setiembre iniciamos las reuniones con los conductores y con algunos amigos que ofrecieron su ayuda para sacar adelante el programa. De estas reuniones salieron muchas ideas sobre los temas y la dinámica que tendría Cruz Ancla.

Tuvimos dos reuniones de ensayo con los conductores la semana previa a la grabación del primer programa. Decidimos hacer el primer programa grabado para poder manejar mejor algunas variables, principalmente lo relacionado a los aspectos técnicos que aún no manejábamos al $100 \%$.

Elegimos a los conductores de Cruz Ancla en base a cualidades que habíamos visto en ellos. Se trata de amigos nuestros, miembros del MVC, con habilidades para dirigir eventos, hablar en público, etc. En el caso de Carlos Cruzalegui, él tiene experiencia animando eventos y también ha trabajado en radio, por lo que me pareció idóneo. Luego está Raúl Gonzáles, que nos manifestó su interés en participar y además tiene también mucha capacidad para hablar de temas a veces densos o de contenido, pero de forma dinámica y entretenida. Además, habíamos visto antes a Carlos y a Raúl dirigiendo y animando un evento juntos y lo hicieron muy bien. Esa química muy divertida nos pareció perfecta para la radio. Por otro lado, a Valentina Cáceres también la hemos escuchado conduciendo radio y nos pareció que lo haría muy bien. Cuando les mencionamos la idea, los tres se mostraron muy entusiasmados por ayudar y desde el inicio dieron ideas para el desarrollo del programa.

\subsection{Los temas}

Respecto a los temas, decidimos tocar diversos temas de interés, entre actividades y experiencias propias del MVC y también temas de fe y formación. Estos se eligen según la coyuntura o el calendario litúrgico. Estos han tenido buena acogida, sobre todo aquellos temas que no son los típicos de las charlas o pláticas que suele haber en el MVC, por ejemplo, el de la vocación a la familia o de la música y el apostolado.

Sobre todo, la participación de diversos invitados ha ayudado mucho y ha sido bien acogida por los oyentes, sobre todo porque en muchos casos son sus amigos los que están 
en la radio y eso lo hace especial. Los oyentes se entusiasman por escuchar a sus amigos y muchas de las cosas que ellos dicen, luego, fuera de la radio, son comentadas, recordadas y compartidas por aquellos que lo han escuchado.

En este link se pueden escuchar todos los programas transmitidos hasta ahora: http://mixlr.com/cruz-ancla/showreel/

Por otro lado, buscamos los permisos para pasar las canciones de diversos grupos y artistas, para evitar problemas a futuro con los derechos de autor. Conseguimos los permisos para pasar las canciones del grupo Siervas, de Julio Cañas, Navis, del grupo ecuatoriano Vox Lumini, de la artista argentina Athenas, y quedó en trámite el permiso de la Asociación Cultural Ictys, que cuenta con los derechos de varias canciones de distintos artistas católicos.

\subsection{Desarrollo de los programas}

El primer programa salió al aire el 24 de octubre del 2015 y hablamos principalmente del mismo. Se explicó de qué se trataba, que estaba dirigido a los agrupados, que son los jóvenes miembros del MVC, y para dar énfasis en esta idea, se habló de lo que significa para nosotros ser agrupado y se incluyó comentario y audios de agrupados que comentaban sobre lo que es ser agrupados para ellos. Este programa fue grabado el sábado 17 en la cabina de radio de la Universidad de Lima. Ese día la voz femenina del programa, Valentina Cáceres, no pudo asistir, por lo que se grabó el programa solo con Carlos y Raúl. Una vez grabado se editó un poco algunos detalles y salió al aire el 24 de octubre.

En los primeros programas tuvimos algunos problemas en los controles por falta de práctica, a veces nos demorábamos en poner la música o teníamos problemas con los volúmenes, pero con el tiempo y la práctica, fuimos mejorando. Además, en uno de los programas, el tercero, tuvimos problemas con el audio, que no se escuchaba bien, y luego nos dimos cuenta de que era porque el cable que conecta la consola con la computadora estaba desconectado y esto no lo habíamos notado por más que llamamos a un técnico para que nos ayude. Eso generó problemas en el tercer programa, pero en el siguiente se solucionó. 
En algunas ocasiones tuvimos inconvenientes ya que los invitados cancelaban a último minuto, pero hemos sabido manejarlo y a veces por esos detalles o por cuestiones de tiempo nos hemos visto obligados a improvisar un poco pero siempre con buenos resultados.

Con respecto a la plataforma Mixlr, no hemos tenido problemas, ha sido de gran ayuda hasta el momento y es fácil de usar, además de que es muy bueno poder tener un chat en vivo con los oyentes y ver cuántas personas nos están escuchando durante la transmisión. 


\section{LOGROS Y RESULTADOS}

\subsection{La respuesta del público}

Desde el momento en que se planteó la idea de un programa de radio dirigido al MVC, la respuesta fue positiva. Cuando se lanzó la página de Facebook, tuvimos muchos comentarios y likes, y pudimos ver que las personas estaban con mucha expectativa por escuchar el primer programa. Incluso tuvimos algunos amigos que se ofrecieron a ayudar a sacar el proyecto adelante y algunas personas que, por iniciativa propia, empezaron a invitar a otros a que lo escuchen.

\section{Figura 5.1}

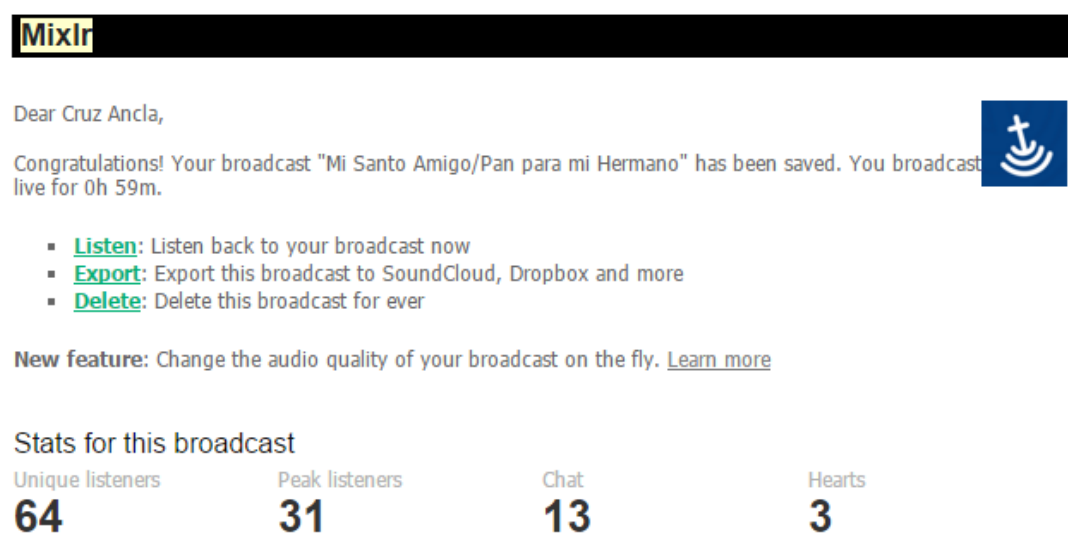

En los siguientes programas tuvimos bastante acogida, a la gente le gustaron mucho las entrevistas, con lo cual vimos que a los oyentes les gusta tener más contenido, personas especializadas, además de las opiniones de los jóvenes.

Figura 5.2

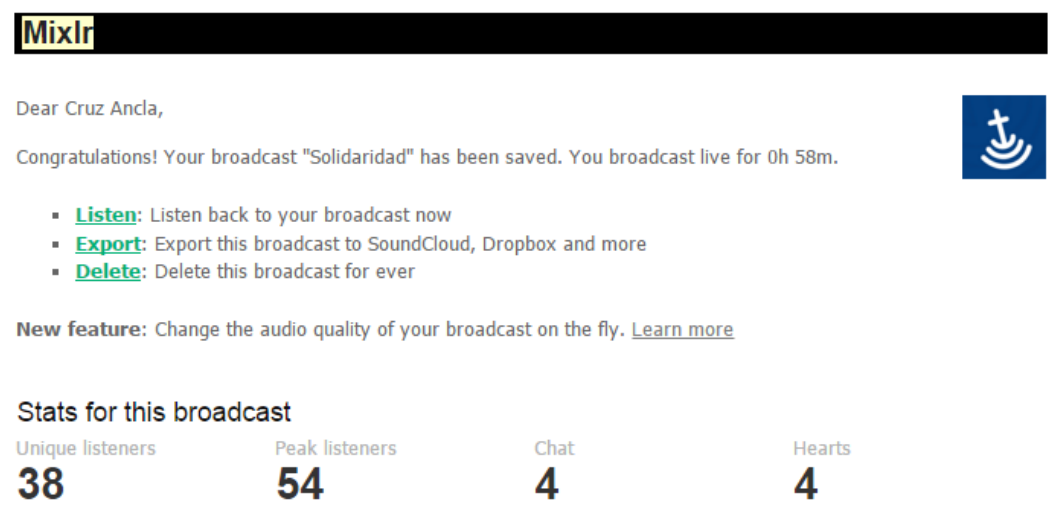


Consideramos que uno de los aciertos fue lograr presentar el programa como algo novedoso, de manera que logramos llamar la atención y muchas personas querían escucharlo. Por ello obtuvimos una gran respuesta al inicio, fueron muchos los que se enteraron del programa y que al inicio lo escuchaban con expectativa.

Otro factor que fue muy bueno, fue que logramos en varios de los programas que los oyentes comenten tanto en el chat de Mixlr, como en el Facebook y ellos valoraban mucho cuando se leía en vivo estos comentarios. Otro elemento que aprovechamos fue la posibilidad de que nos envíen audios a través de WhatsApp, con experiencias o comentarios relacionados al tema del programa. Estos se incluían y eran comentados por los conductores durante el programa y motivaba mucho que las personas nos siguieran escuchando, además de que lo hacía mucho más dinámico.

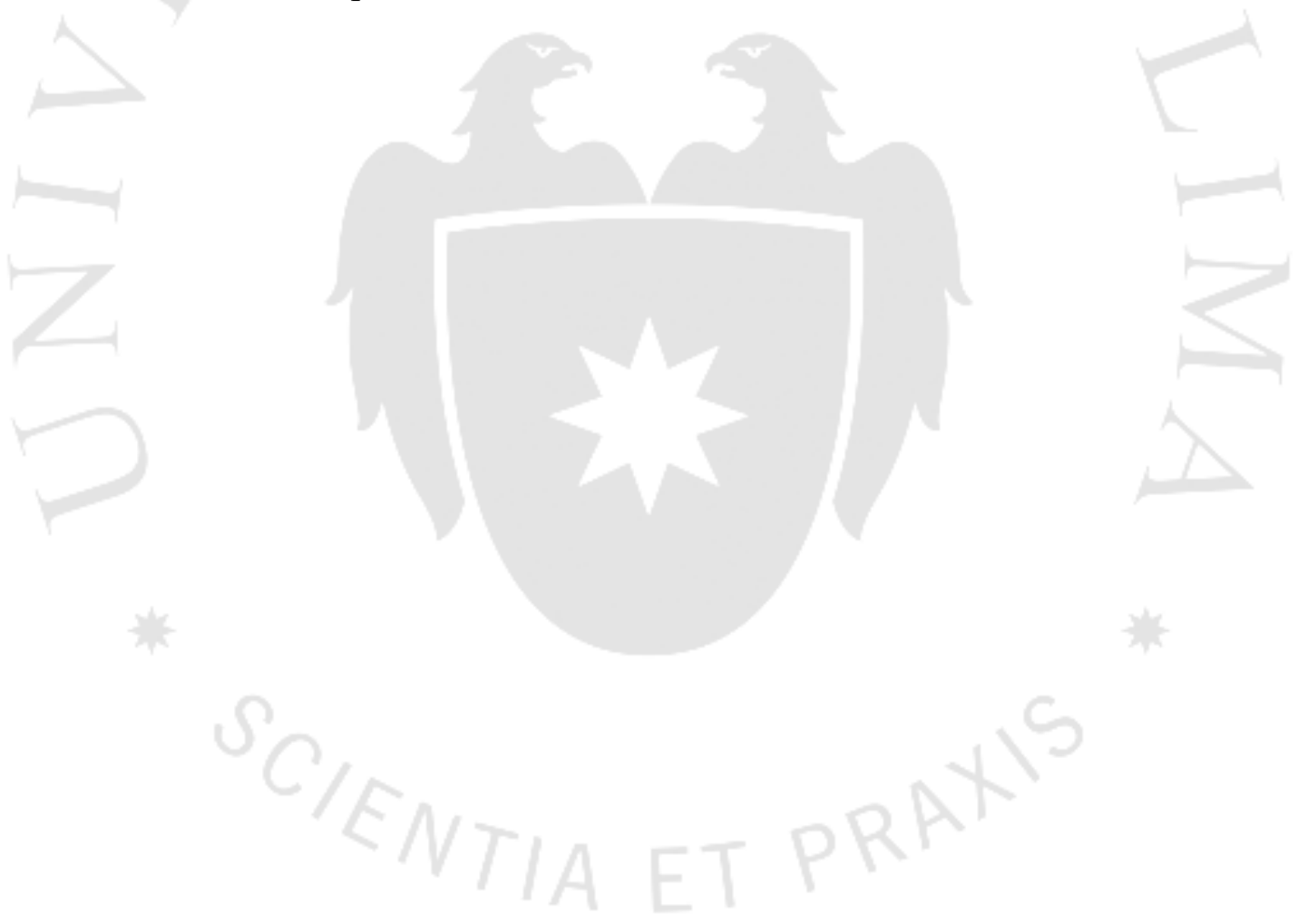


Gráfico 5.0

\section{Audiencia por temas (Unique listeners)}

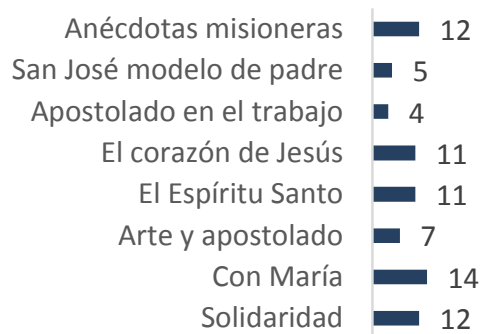

Aniversario del CP Jesús María Entrevistas

Navis en Cruz Ancla Ser Católico en la Universidad Semana Santa

La mujer en la Iglesia El apostolado y mi carrera

Signo de Contradicción Entrevista a Mauricio Alen Cuaresma MVC Miércoles de Ceniza Julio Cañas y Anécdotas de Agrupación

La confirma y Cruz Blanca

El Apostolado en la Familia El Bautismo ¡Felices Fiestas! Navidad Adviento Navidad es Jesús La música y el apostolado

La familia y la vocación Mi santo amigo y Pan para mi hermano Primer programa
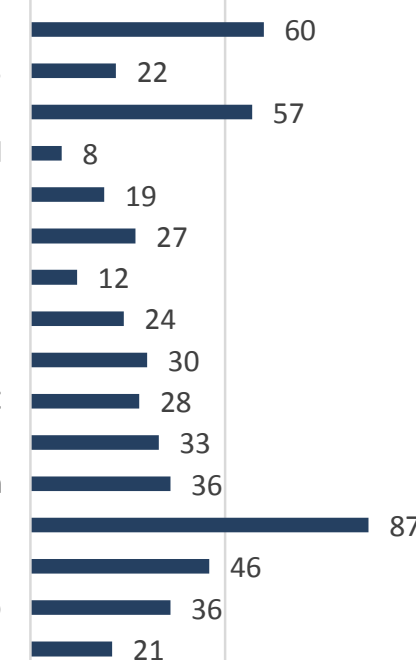

- 3
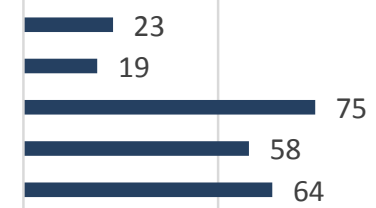

0

50

100

150

Fuente: Elaboración Propia 


\section{Gráfico 5.1}

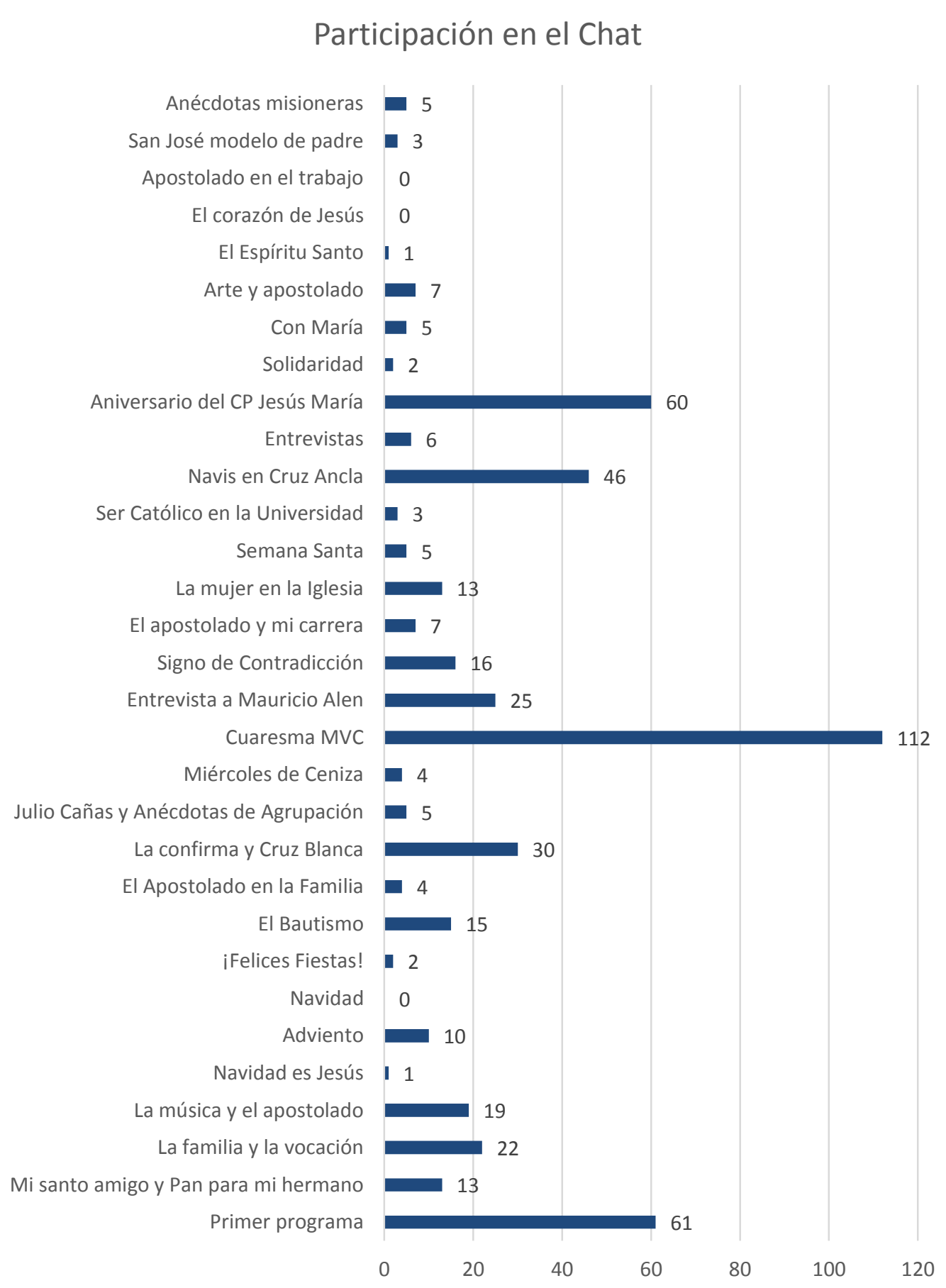

Fuente: Elaboración Propia

Como podemos ver en el gráfico 4.4, durante 6 meses logramos mantener un promedio de 30 oyentes cada programa, esto sin contar a aquellos que escucharon el programa luego de que fuera transmitido. En algunos programas como el del 12 de febrero del 2016, donde 
desarrollamos el tema de la Cuaresma, se generó gran participación en el chat de Mixlr, lo cual nos ayudó a ver qué temas generaban más participación.

\subsection{La Producción}

El primer programa salió al aire el sábado 24 de octubre del 2015, este fue pre grabado, lo cual nos ayudó a tener una buena calidad de audio ya que pudimos editar los audios grabados y tuvimos una muy buena acogida, hubo más oyentes de los esperados, casi 70 personas.

El siguiente programa se realizó el 31 de octubre. Dado que fue el primer programa en vivo, tuvimos algunos problemas para sincronizar la música, por lo que a veces entraba un poco tarde y hubo algunos silencios. Entonces decidimos practicar un poco más con los equipos para mejorar en este aspecto.

Figura 5.3

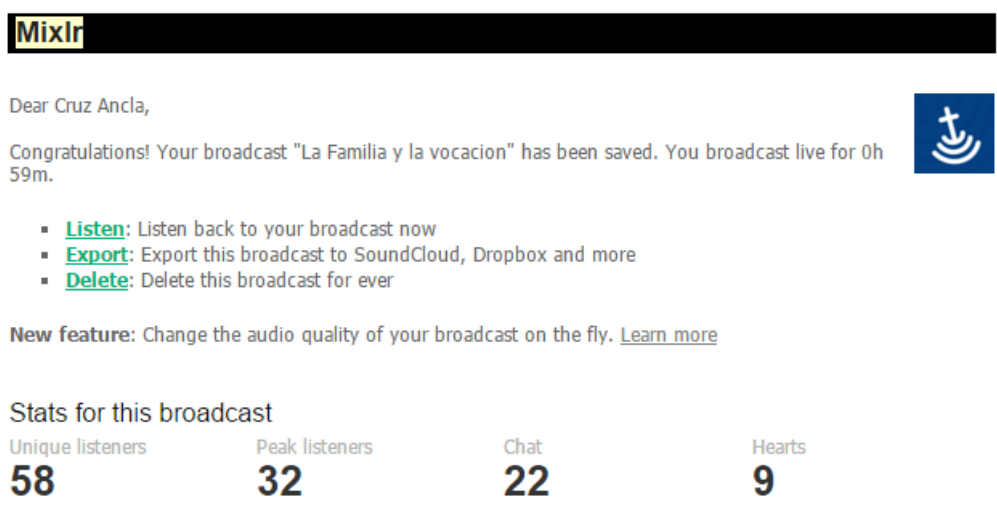

Para el cuarto programa, que se transmitió el 14 de noviembre, logramos disminuir los errores de sincronización con las canciones y los micrófonos. Logramos aprender cómo conectar bien todos los cables de la cabina y ya con la experiencia no tuvimos errores con los micrófonos.

Figura 5.4

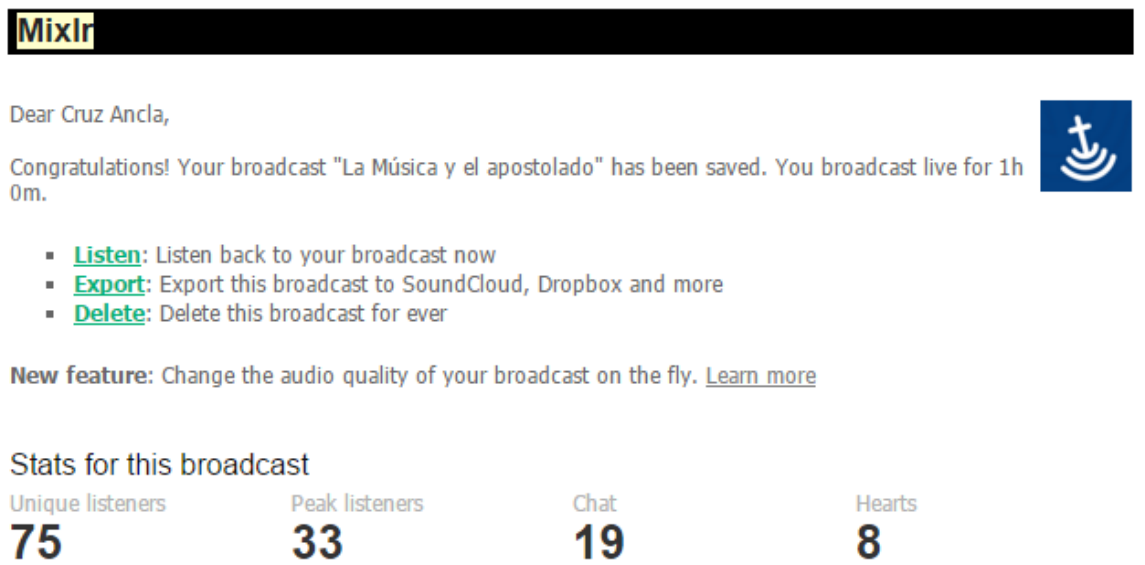


Dado que vimos que no aportaba mucho el hacer el programa en vivo y, por el contrario, nos complicaba bastante ya que muchas veces no lográbamos estar listos para salir al aire a las 12 en punto y además nos era complicado coordinar con los invitados, decidimos hacer los siguientes programas grabados y ya no en vivo. A pesar de ello, pedíamos a varios de los oyentes que nos envíen sus audios comentando sobre el tema del programa, con algunos días de anticipación, de forma que seguíamos teniendo la participación de otras personas en el programa.

\subsection{Los detalles técnicos}

Los primeros tres meses tuvimos la posibilidad de transmitir desde la cabina de radio de la universidad, lo cual nos ayudó mucho ya que teníamos todos los equipos técnicos para poder tener una transmisión de calidad. Al inicio nos demorábamos en conectar todo y probar que el audio fuera correcto, y nos costó un poco manejar bien los equipos al momento de poner música o apagar y encender los micrófonos, pero con el tiempo fuimos aprendiendo hasta que no tuvimos problemas.

Más adelante logramos conseguir una pequeña mezcladora de cinco canales y un par de micrófonos de manera que podíamos transmitir o grabar con un poco más de libertad sin tener que depender de que nos presten la cabina.

Al inicio nos esforzamos porque los programas fueran en vivo, ya que eso nos permitía tener mayor interacción con el público, los invitábamos a enviarnos sus comentarios y los leíamos en vivo, lo cual les gustaba mucho. Pero más adelante se nos hizo muy complicado esto ya que muchas veces los entrevistados no podían asistir a la hora del programa y para nosotros también a veces era difícil poder estar todos los días a determinada hora. Por ello los últimos 14 programas fueron grabados.

Por otro lado, algunos de los conductores que participaban al inicio del programa más adelante no pudieron continuar, ya que estaban cortos de tiempo. Se optó por buscar otras personas que los puedan reemplazar, pero en algunas ocasiones solo Raúl Gonzáles fue quien dirigió el programa. 
Finalmente, realizamos 31 capítulos en total 15 en vivo y 16 grabados, y transmitimos regularmente durante 8 meses. Logramos obtener 832 Me Gusta y 827 seguidores en Facebook hasta ahora. Tenemos 89 seguidores en nuestro perfil de Mixlr y el programa ha sido escuchado 3431 veces en total.

Figura 5.5

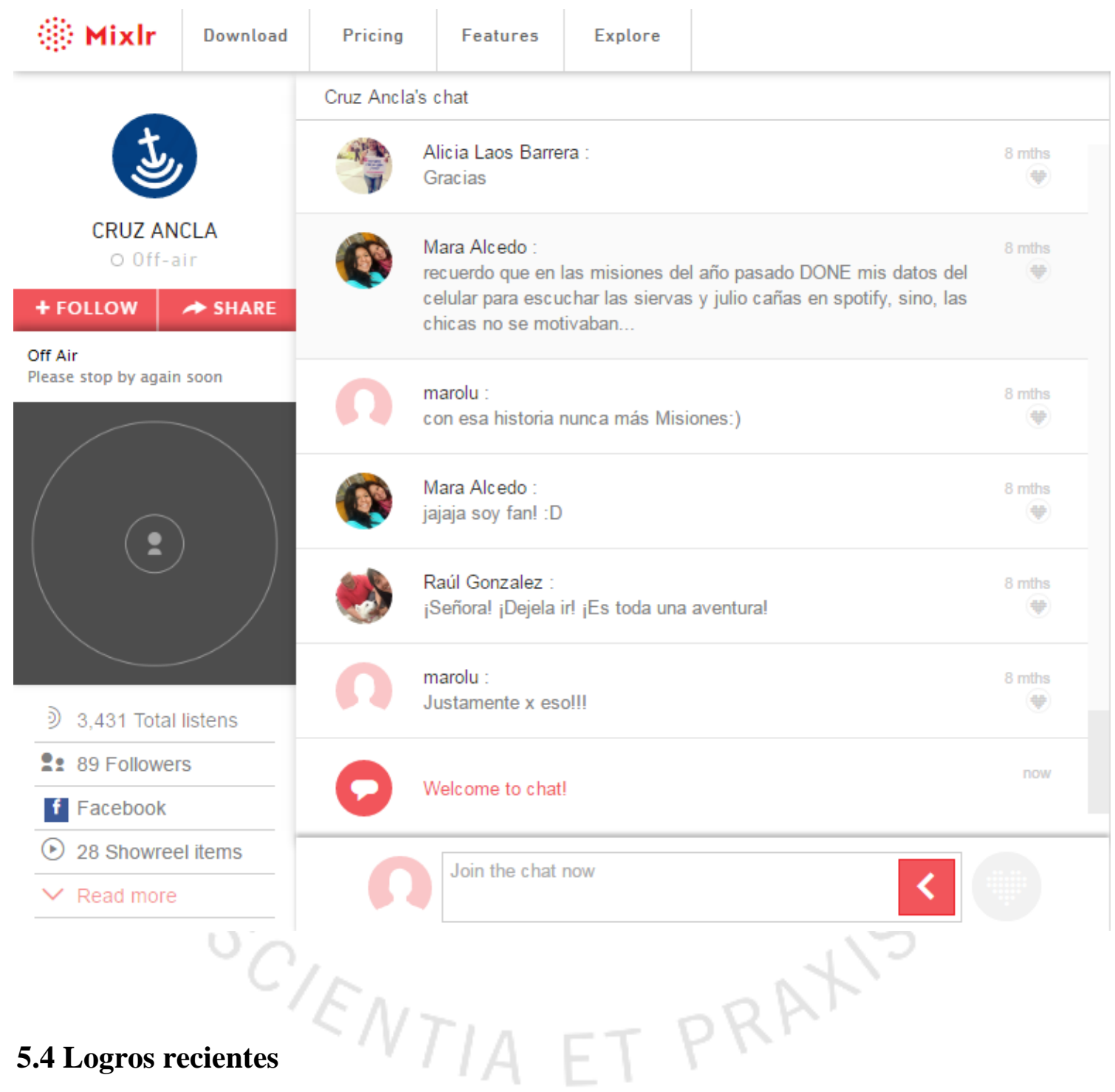

A inicios del año 2017 logramos que se incluya el programa dentro de la programación radio de FS Noticias. FS Noticias es una agencia de noticias católica que se especializa en dar información sobre las actividades y novedades de la Familia Sodálite, entre ellos el MVC, y también de la Iglesia Católica, al rededor del mundo. 
Figura 5.6

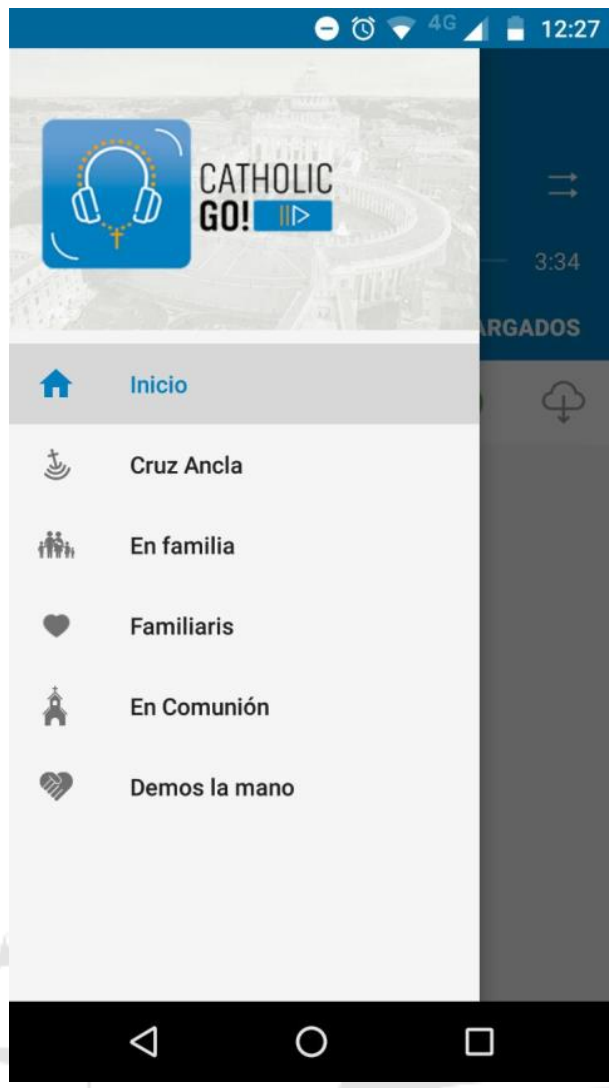

Figura 5.7

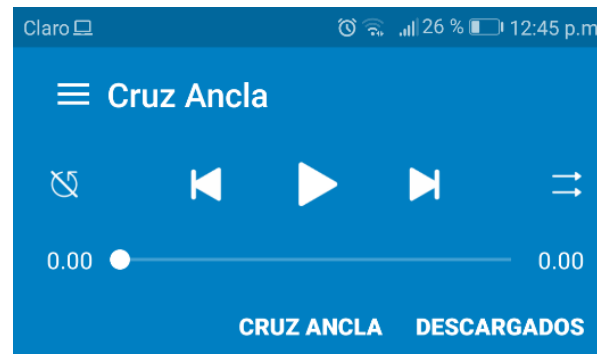

L. La modestia al vestir 00:32:10/62.0MB

Corazón de Jesús 00:32:12 / 64.0MB

Yo también quiero ser feliz 00:34:30 / 66.0MB

. Los jóvenes y la Virgen Ma... 00:26:34/ 18.0MB

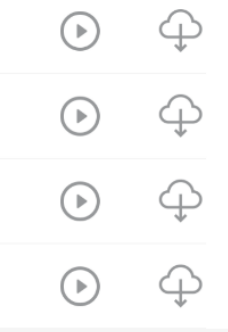

$$
\text { . }
$$

\section{$\square \quad \bigcirc \triangleleft$}

Esta App, llamada CatholicGo lanzará varios programas de contenido católico con formato de Podcast. Cruz Ancla será el programa juvenil dentro de esta nueva plataforma, se seguirá publicando un nuevo programa cada semana, pero ahora con una duración de 30 minutos y con la posibilidad de acceder a todos los programas publicados en el momento que el oyente quiera. Raúl Gonzáles sigue siendo el conductor del programa. Esta es la nueva estructura que se ha planteado para el programa en formato de Podcast:

\section{Programa juvenil: Cruz Ancla}

Tema: El Sagrado Corazón de Jesús

Duración: $30 \mathrm{~min}$.

\begin{tabular}{|c|l|c|}
\hline $\begin{array}{c}\text { SEGMENT } \\
\text { O }\end{array}$ & \multicolumn{1}{|c|}{ DESCRIPCIÓN DEL CONTENIDO } & $\begin{array}{c}\text { DURACI } \\
\text { ON }\end{array}$ \\
\hline $\begin{array}{c}\text { Bloque 1: } \\
\text { Presentació } \\
\mathbf{n}\end{array}$ & $\begin{array}{l}\text { Cuña de inicio } \\
\text { Hola! yo soy Raúl Gonzáles y les doy la bienvenida nuevamente } \\
\text { a Cruz Ancla. En esta ocasión tenemos un tema muy bonito. } \\
\text { Queremos hablar del sagrado Corazón de Jesús y por eso } \\
\text { tenemos con nosotros a dos invitados muy especiales. }\end{array}$ & 2min \\
\hline
\end{tabular}




\begin{tabular}{|c|c|c|}
\hline $\begin{array}{c}\text { Bloque } 2 \\
\text { Entrevista } \\
\text { parte } 1\end{array}$ & $\begin{array}{l}\text { Entrevistados: Yohei Icochea y Nathi Paredes } \\
\text { Para empezar, está con nosotros Yohei Icochea, él pertenece a la } \\
\text { Parroquia Sagrado Corazón de Jesús y también nos acompaña } \\
\text { Nathi, vocalista del grupo Tabor. } \\
\text { Preguntas: } \\
\text { ¿Cuál es el origen de la devoción al Sagrado Corazón de Jesús? } \\
\text { ¿Cuáles son las promesas que hace? } \\
\text { Corte canción }\end{array}$ & $30 "$ \\
\hline Canción & Corazón de Jesús & $1 '$ \\
\hline $\begin{array}{c}\text { Entrevista } \\
\text { parte } 2\end{array}$ & $\begin{array}{l}\text { Estuvimos escuchando Corazón de Jesús, y continuamos hablando con } \\
\text { Yohei } \\
\text { ¿Qué importancia tiene para ti el Sagrado Corazón de Jesús? } \\
\text { ¿Cuál ha sido tu experiencia? } \\
\text { Conclusión y canción de Nathi: "Confío en ti" } \\
\text { Preguntas para Nathi: Cuéntanos sobre Tabor } \\
\text { Agradecimiento y despedida de los invitados }\end{array}$ & $7^{\prime}$ \\
\hline $\begin{array}{c}\text { Bloque } 5 \\
\text { Despedida }\end{array}$ & $\begin{array}{l}\text { Hemos llegado al final del programa, recuerden que cada semana } \\
\text { podrán escuchar uno nuevo, así que estén atentos. } \\
\text { Y no se olviden que pueden mandarnos sus sugerencias, } \\
\text { comentarios, o si quieres hacer pedidos musicales también, } \\
\text { pueden escribirnos. Gracias por escucharnos, ¡ esto fue CRUZ } \\
\text { ANCLA! ¡Nos vemos! }\end{array}$ & $4^{\prime}$ \\
\hline
\end{tabular}

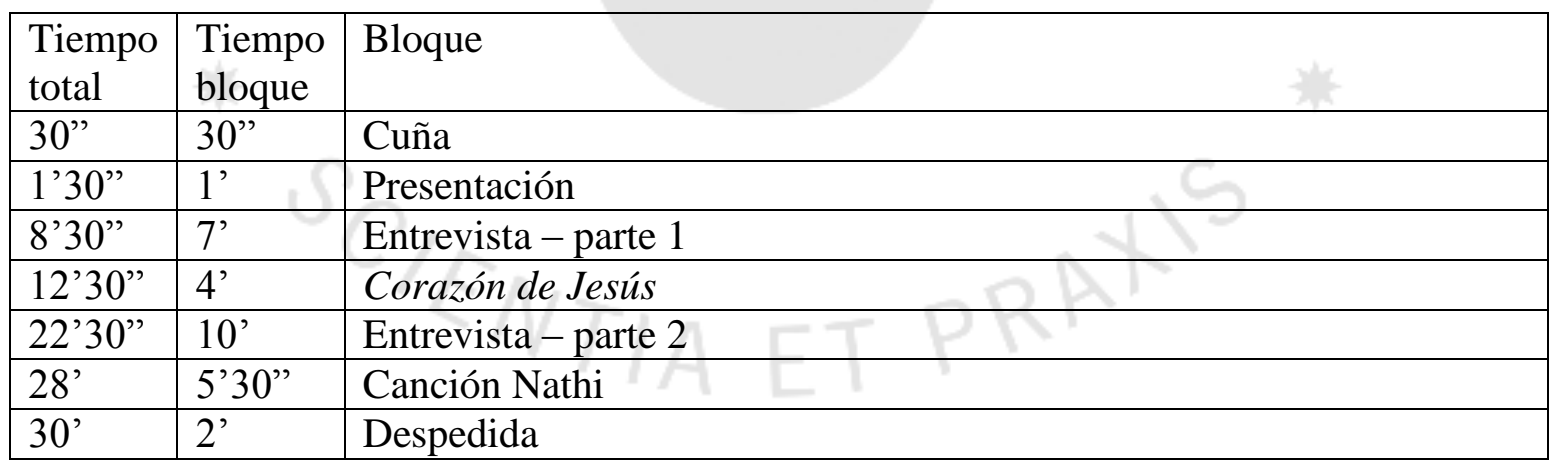

Ya se empezaron a grabar los nuevos capítulos de Cruz Ancla con este nuevo formato y algunos de ellos ya se encuentran en la aplicación, que ya está disponible y se puede descargar para Android. 


\section{LECCIONES APRENDIDAS}

\subsection{Producción}

Lo más difícil durante los primeros meses fue sacar adelante los programas en vivo. Esto requiere mucha organización y trabajo previo, pero sobre todo mucha ayuda. En este sentido, vimos que era necesario siempre tener a alguien que se encargue de recibir a los invitados antes y durante el programa y chequeando las redes sociales, en el caso de que este sea en vivo y, por otro lado, tener a alguien que se dedique solo a hacer controles y dirigir a los conductores. Mientras más personas ayudan en la producción, tanto en la organización previa y durante la transmisión, es más fácil y se puede conseguir un mejor producto.

Dado que no siempre podíamos tener a muchas personas ayudándonos, decidimos hacer los programas grabados y ya no en vivo, para asegurar la calidad de los programas. Esto definitivamente nos ayudó mucho, ya que teníamos más flexibilidad con los horarios para poder conseguir a los entrevistados y también podíamos corregir cualquier error que tuviéramos durante la grabación del programa.

\subsection{Manejo Técnico}

Durante los primeros programas tuvimos muchos errores de silencios, o canciones que no entraban a tiempo. En algunas ocasiones se colaban las voces de los conductores entre otros errores. Con la práctica fuimos mejorando en el uso de los controles. También mejoró la coordinación entre el controlador y los conductores. Aprendimos a medir bien los tiempos, para que el programa no se exceda de una hora o que no quede demasiado corto.

Ha sido motivo de un gran aprendizaje haciendo controles, de mejorar la coordinación y también del funcionamiento de la cabina y las conexiones que en algunos casos fueron problemáticas y muchas veces tuvimos que arreglarlos nosotros. Por ello, más adelante, preferimos conseguir nuestros propios equipos, que nos dieron la posibilidad de grabar en diversos lugares y de acuerdo a nuestros horarios. 


\subsection{Contenido}

Conforme fuimos produciendo los programas, nos dimos cuenta de que cierto tipo de contenido tenía mejor respuesta por parte de nuestros oyentes. Vimos que los temas que generaban más enganche y participación, por medio de comentarios, eran los relacionados a experiencias que se viven en diversas actividades o relacionadas con ciertos temas. Eso nos motivó a realizar más programas donde los oyentes pudieran comentar sus experiencias.

\section{Figura 6.1}

Cruz Ancla

10 de mayo de $2016 \cdot$ e

En este \#MesDeMaría queremos celebrar a nuestra Madre ¡Comenta!

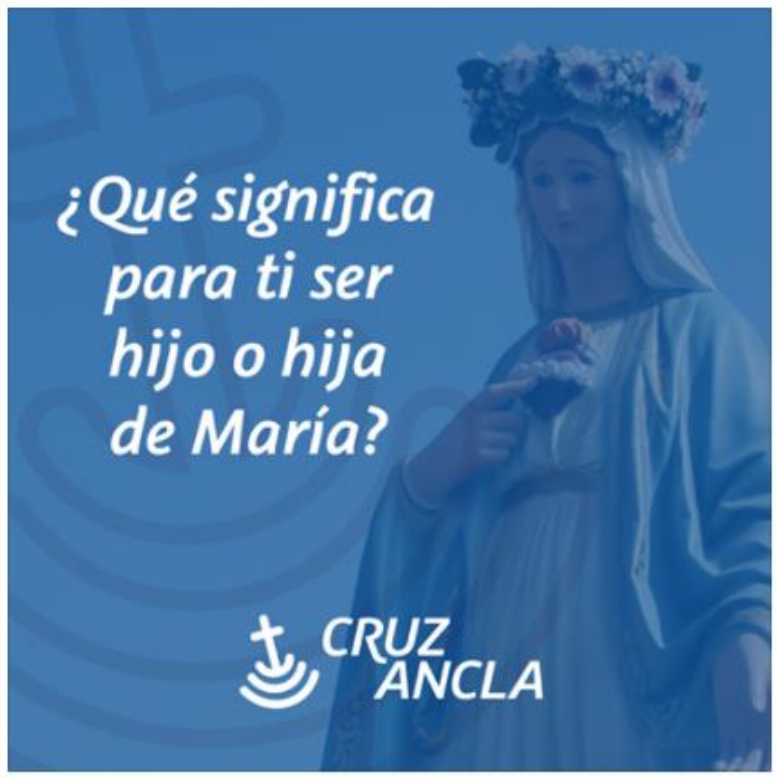

\subsection{Personas alcanzadas}

54

\begin{tabular}{l|l|l}
30 & 8 & 22 \\
Me gusta & En publicación & En
\end{tabular}

$9 \quad 0$

En contenido compartido

Me encanta En publicación En contenicho

\begin{tabular}{l|l}
9 & 2 \\
6
\end{tabular} \begin{tabular}{l|l|l} 
Comentarios & En publicación & En contenido \\
compartido
\end{tabular}

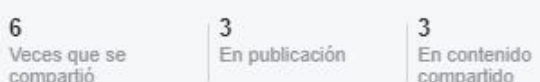

compartio compartido

61 Clics en publicaciones

\begin{tabular}{l|l|l}
31 & 0 & 30
\end{tabular} Visualizaciones de Clics en el enlace Otros clics?

COMENTARIOS NEGATIVOS

1 Ocultar publicación

0 Ocultar todas las publicaciones

0 Reportar como span 0 Ya no me gusta esta página

Otros temas que gustaban mucho eran los relacionados a la formación en la fe. Cuando teníamos invitados que hablaban de ciertos temas que permitían a los oyentes aprender más sobre la fe católica también generaron una respuesta positiva y comentarios en redes sociales con respecto a lo interesante que resultó la entrevista.

\subsection{Oferta musical}

En los primeros programas las canciones que incluíamos eran todas del MVC, pero conforme fuimos avanzando, empezamos a incluir cada vez más canciones de otros 
artistas católicos, con muy buena respuesta por parte del público. En ambos casos los oyentes nos escribían para saber el nombre de la canción y del grupo que la tocaba, lo cual fue muy bueno porque así alcanzamos nuestro objetivo de difundir la música católica y del MVC.

\subsection{Horario}

Nos dimos cuenta de que es realmente complicado que las personas puedan conectarse a una hora determinada para escuchar el programa, y nos faltó recordar a los oyentes que los programas se quedan grabados en la cuenta de Mixlr, y por lo tanto los podrían escuchar cuando quieran. De todas maneras, vimos que cuando se trata de una programación que dura todo el día, es más factible que las personas lo escuchen, porque pueden conectarse cuando es más factible para cada uno y no tiene que ser en un horario determinado.

Si bien lo que más llamó la atención fueron los temas que se trataron en la radio, quizá estos temas podrían ser mejor explotados a través de podcasts a los que las personas puedan acceder en cualquier momento, ya sea para escuchar algún audio informativo, formativo o de reflexión. Algo que nos faltó, en ese sentido, fue compartir el link donde se puede escuchar los programas que ya han sido transmitidos, de forma que las personas pudiesen escucharlos en cualquier momento. Se podría haber mencionado en los programas o en Facebook, cada cierto tiempo, que los programas quedaban grabados y podían escucharlos desde la página de Mixlr, pero como en un inicio la idea era que las personas escucharan el programa en vivo, esto no se hizo.

Al inicio el programa tuvo éxito porque, al ser novedad, muchas personas querían escucharlo, pero con el tiempo fue difícil conseguir que las personas puedan seguir escuchándolo, sobre todo porque al ser una vez a la semana, muchos tenían cosas quehacer a esa hora o se olvidaban. Algunos preferían escuchar la grabación después. 


\subsection{Formato del programa}

Si bien la propuesta del programa fue como una radio online y fue por eso que se planteó la duración de dos horas, consideramos, en base a nuestra experiencia y a lo mencionado en los puntos anteriores, que podría funcionar mucho mejor si se trabajara el programa como Podcast, sobre todo si se trata de programas de corta duración.

Si bien con un Podcast se pierde la riqueza de la interacción que se obtienen en la radio en vivo, se gana en audiencia, que, finalmente, es la clave de la participación. Dado que uno de los objetivos era crear un programa interactivo, conforme fue disminuyendo la participación del público se fue pareciendo un poco a un podcast. En ese sentido, la estructura del programa se debe adaptar al formato del podcast, que es mucho más accesible y la interacción con la audiencia debe ser diferente, lo que requiere ser muy creativos e innovar.

En este formato quizá sería mejor un audio de 20 a 30min, ya no un programa de 1 hora y con menos cortes musicales. Además, se hablaría solo de un tema concreto y se buscaría un solo invitado por programa. Podría seguir saliendo un programa nuevo cada semana, pero se tendría que buscar una plataforma, quizá una página web o una aplicación para celular, donde se pueda acceder a todos los Podcasts, de manera que estos se puedan escuchar en cualquier momento. Esto facilitaría la escucha por parte de nuestro público objetivo.

\subsection{Identidad y Compromiso}

Dentro del programa incluimos un bloque llamado "Calendario emevecista", en el cual se compartían los diversos eventos y actividades que se realizarían los días siguientes a la transmisión del programa tanto en el Perú como en otros países. Esto fue muy bueno porque los oyentes estaban al tanto de las actividades, sobre todo del MVC, que se realizaban en diversos lugares. Esto no siempre es posible pues muchas de las actividades se pierden en medio de tanta información que uno encuentra en las redes sociales como Facebook, así que logramos conectar a emevecistas de diversos lugares y contarles lo que hacía el MVC alrededor del Perú y del mundo. 


\subsection{Uso de Facebook}

Uno de los factores que ayudó mucho a mantener la audiencia fueron las publicaciones regulares en Facebook. Aprendimos que es una herramienta vital para generar enganche con el público, para interactuar con ellos y para que tengan presente el programa y lo escuchen.

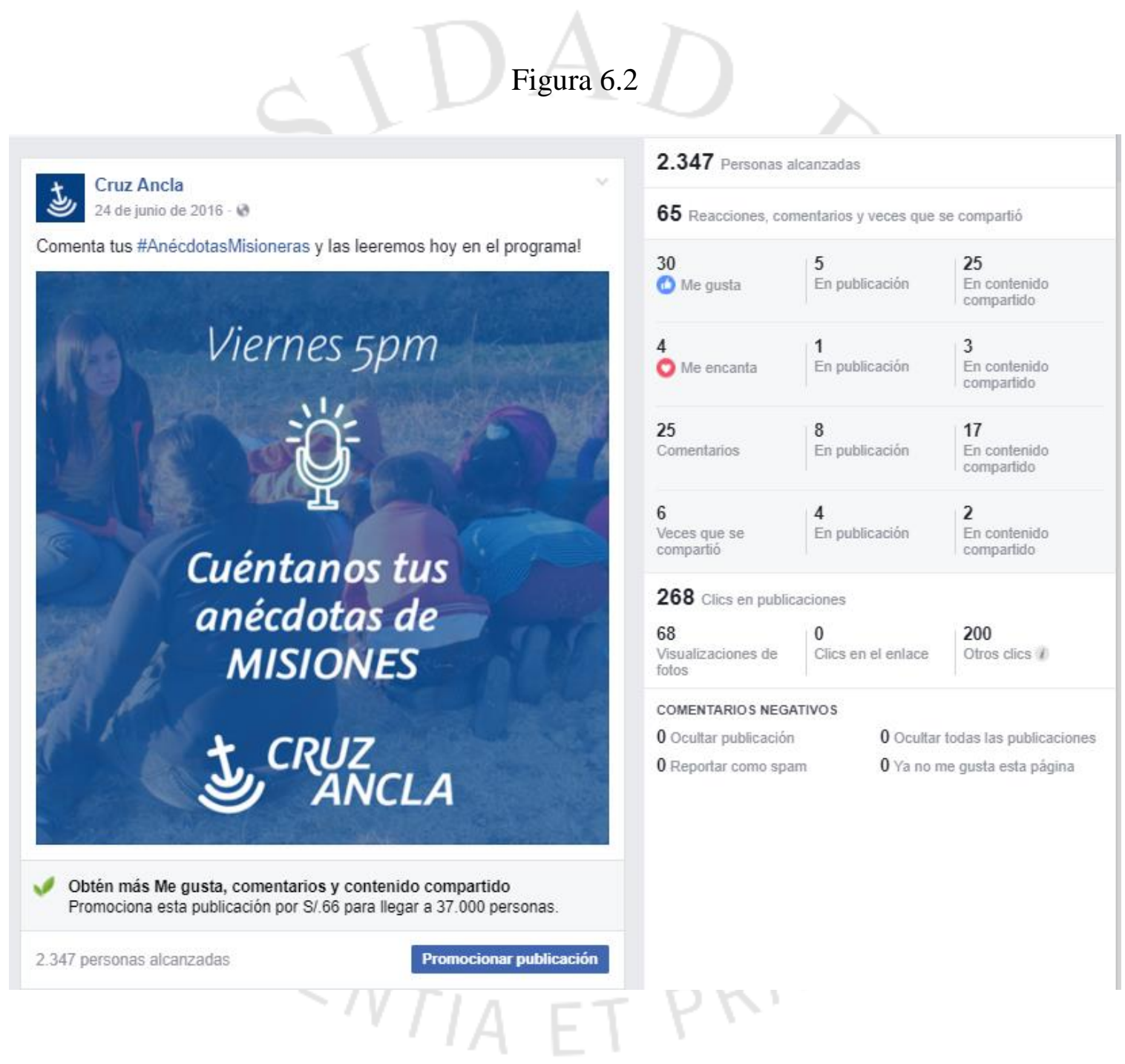

Lo que hicimos fue publicar cada semana el tema del que se iba a tratar el siguiente programa. Muchas veces también hacíamos preguntas que las personas respondían en los comentarios y luego esos comentarios los leíamos en el programa. Descubrimos que esta forma de participación es muy valorada por los oyentes y hace que sigan participando. 
En otras ocasiones también compartíamos videoclips de las canciones que pasamos en el programa, de manera que las personas podían escuchar nuevas canciones o, si no habían escuchado el programa, hacerse una idea del tipo de música que teníamos en el programa.

\section{Figura 6.3}

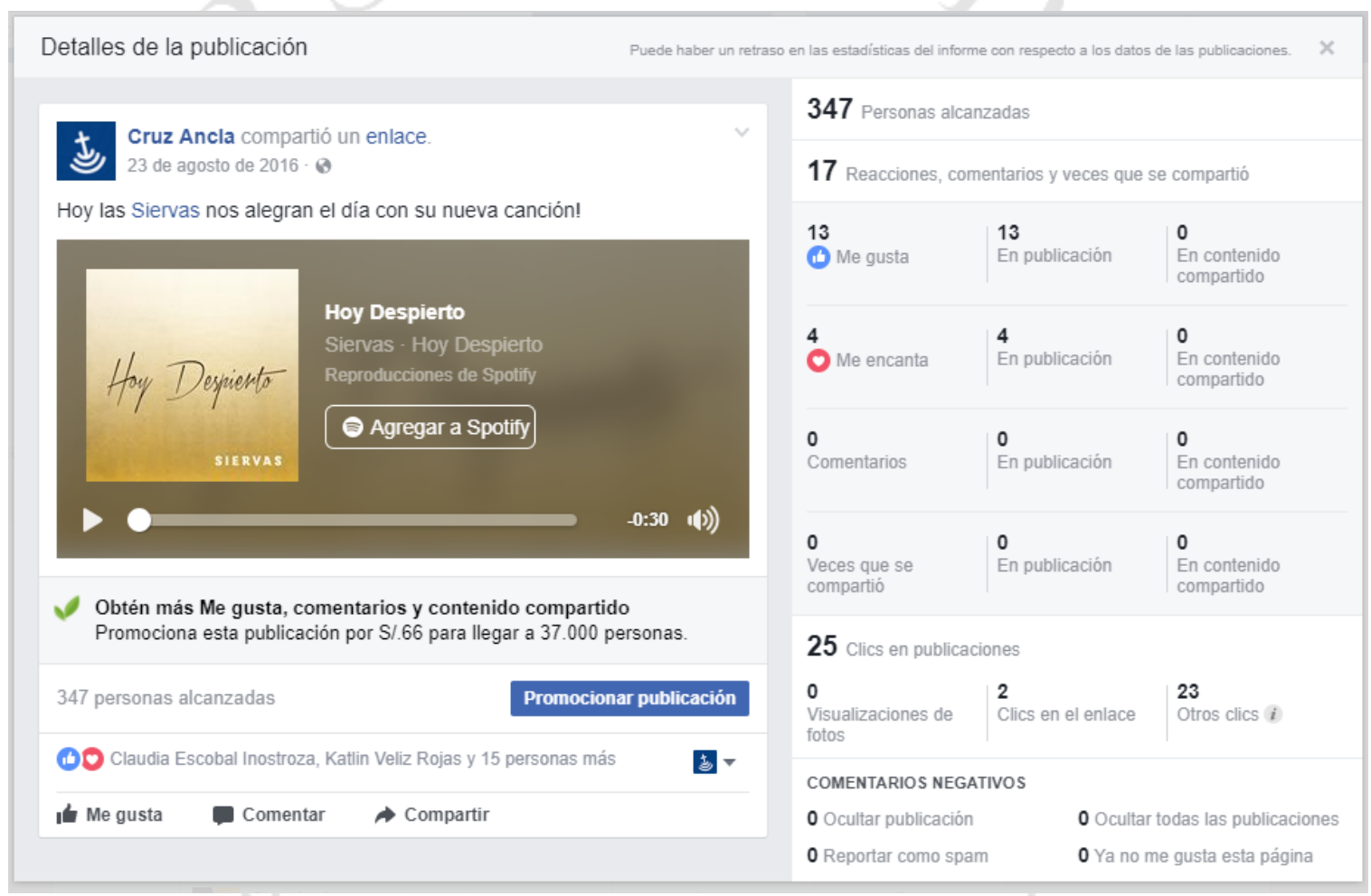

El Facebook resulta ser una gran herramienta para mantener contacto con tus oyentes, que ellos participen y para darles información sobre el programa.

En general, realizar este proyecto nos ha permitido aprender mucho sobre la producción de un programa de radio y sobre los hábitos de consumo del público al que nos dirigimos, además de cómo la radio va adaptándose a los nuevos medios y siempre se puede sacar provecho de ellos. Nos ha permitido explorar el amplio mundo de la radio y ha sido una experiencia muy grata y enriquecedora, que nos ha llenado de experiencias que nos ayudarán a seguir creciendo como profesionales. Esperamos que Cruz Ancla pueda seguir 
creciendo y aportando a la vida de los jóvenes católicos, siempre con una propuesta novedosa y de gran calidad.

\section{2 \\ REFERENCIAS}

Fajardo, R. (2015). Online radio use on the rise. CaribbeanBusiness, 22.

García González, A. (2009). Radio Digital e Interactiva. Icono $14 n^{\circ} 15,133-146$.

Glantz, M. (2016). Internet Radio Adopts a Human Touch: A. Journal of Radio \& Audio Media, 36-49.

Gonzáles, A. G. (2013). De la radio interactiva a la radio transmedia: nuevas perspectivas para los profesionales del medio. Icono 14, volumen 11, 251 - 267.

IPSOS. (2017). Hábitos, usos y actitudes hacia Internet. Perú.

Jaime Núñez, A., García López, J., \& López Martínez, Á. (2013). Eumed.net. Obtenido de http://www.eumed.net/libros-gratis/2013a/1312/radio-online.html

López Vidales, N., Gómez Rubio, L., \& Redondo García, M. (2014). La radio de las nuevas generaciones de jóvenes españoles: Hacia un consumo on line de música y entretenimiento. Zer, 45-64.

Misión. (2015). Luis Enrique Ascoy.

Montiel, E. R. (2011). Nativos digitales en la reconfiguración radiofónica. Razón y Palabra.

Osiptel. (2016). Penetración del Servicio de Internet Móvil.

Puro Marketing. (Diciembre de 2015). Recuperado el Diciembre de 2015, de http://www.puromarketing.com/46/25705/radio-cada-dia-mas-digital-vuelveesplendor-gracias-internet-moviles.html

Rivadeneyra Olcese, C. (2013). La era digital de la radio. Lima: Felafacs. www.enlaradio.pe/2014/05/Lima.html. (2017). http://www.enlaradio.pe/2014/05/Lima.html. Obtenido de En la radio.Pe. 



\section{ANEXO 1: \\ ESTADÍSTICAS DE LOS PROGRAMAS}

Estadística general:

\begin{tabular}{|c|l|c|c|c|c|c|}
\hline No. Tema & Fecha & $\begin{array}{c}\text { Audiencia } \\
\text { (Unique } \\
\text { listeners) }\end{array}$ & $\begin{array}{c}\text { Peak } \\
\text { listener } \\
\text { s }\end{array}$ & Chat & Likes \\
\hline 1 & Primer programa & $24 / 10 / 2015$ & 186 & 61 & 61 & 32 \\
\hline 2 & Mi santo amigo y Pan para mi hermano & $31 / 10 / 2015$ & 64 & 31 & 13 & 3 \\
\hline 3 & La familia y la vocación & $7 / 11 / 2015$ & 58 & 32 & 22 & 9 \\
\hline 4 & La música y el apostolado & $14 / 11 / 2015$ & 75 & 55 & 19 & 8 \\
\hline 5 & Navidad es Jesús & $28 / 11 / 2015$ & 19 & 10 & 1 & 8 \\
\hline 6 & Adviento & $5 / 12 / 2015$ & 23 & 27 & 10 & 6 \\
\hline 7 & Navidad & $19 / 12 / 2015$ & 3 & 2 & 0 & 0 \\
\hline 8 & iFelices Fiestas! & $26 / 12 / 2015$ & 21 & 12 & 2 & 1 \\
\hline 9 & El Bautismo & $8 / 01 / 2016$ & 36 & 21 & 15 & 13 \\
\hline 10 & El Apostolado en la Familia & $15 / 01 / 2016$ & 46 & 23 & 4 & 3 \\
\hline 11 & La confirma y Cruz Blanca & $22 / 01 / 2016$ & 87 & 40 & 30 & 20 \\
\hline 12 & Julio Cañas y Anécdotas de Agrupación & $29 / 01 / 2016$ & 36 & 21 & 5 & 7 \\
\hline 13 & Miércoles de Ceniza & $5 / 02 / 2016$ & 33 & 35 & 4 & 10 \\
\hline 14 & Cuaresma MVC & $12 / 02 / 2016$ & 28 & 26 & 112 & 28 \\
\hline 15 & Entrevista a Mauricio Alen & $19 / 02 / 2016$ & 30 & 16 & 25 & 6 \\
\hline 16 & Signo de Contradicción & $26 / 02 / 2016$ & 24 & 18 & 16 & 3 \\
\hline 17 & El apostolado y mi carrera & $4 / 03 / 2016$ & 12 & 7 & 7 & 3 \\
\hline 18 & La mujer en la Iglesia & $11 / 03 / 2016$ & 27 & 33 & 13 & 11 \\
\hline 19 & Semana Santa & $18 / 03 / 2016$ & 19 & 14 & 5 & 4 \\
\hline 20 & Ser Católico en la Universidad & $1 / 04 / 2016$ & 8 & 4 & 3 & 3 \\
\hline 21 & Navis en Cruz Ancla & $8 / 04 / 2016$ & 57 & 29 & 46 & 14 \\
\hline 22 & Entrevistas & $15 / 04 / 2016$ & 22 & 20 & 6 & 7 \\
\hline 23 & Aniversario del CP Jesús María & $22 / 04 / 2016$ & 60 & 32 & 60 & 7 \\
\hline 24 & Solidaridad & $29 / 04 / 2016$ & 12 & 19 & 2 & 2 \\
\hline 25 & Con María C / & $13 / 05 / 2016$ & 14 & 7 & 5 & 2 \\
\hline 26 & Arte y apostolado & $20 / 05 / 2016$ & 7 & 14 & 7 & 2 \\
\hline 27 & El Espíritu Santo & $27 / 05 / 2016$ & 11 & 11 & 1 & 1 \\
\hline 28 & El corazón de Jesús & $3 / 06 / 2016$ & 11 & 6 & 0 & 0 \\
\hline 29 & Apostolado en el trabajo & $10 / 06 / 2016$ & 4 & 5 & 0 & 6 \\
\hline 30 & San José modelo de padre & $17 / 06 / 2016$ & 5 & 4 & 3 & 5 \\
\hline 31 & Anécdotas misioneras & $24 / 06 / 2016$ & 12 & 10 & 5 & 8 \\
\hline & & & & & \\
\hline
\end{tabular}


Estadística por cada programa, brindada por Mixlr:

24/10/15

\section{Mixir}

Dear Cruz Ancla,

Congratulations! Your broadcast "Primer Programa" has been saved. You broadcast live for $1 \mathrm{~h} 0 \mathrm{~m}$.

- Listen: Listen back to your broadcast now

- Export: Export this broadcast to SoundCloud, Dropbox and more

- Delete: Delete this broadcast for ever

New feature: Change the audio quality of your broadcast on the fly. Learn more

Stats for this broadcast
186 New
Peak listeners
$677_{\text {recordl }}^{\text {New }}$
61 New
32 New
186 record!

What are these statistics? More info.

$31 / 10 / 15$

Mixlr

Dear Cruz Ancla,

Congratulations! Your broadcast "Mi Santo Amigo/Pan para mi Hermano" has been saved. You broadcas live for $0 \mathrm{~h} 59 \mathrm{~m}$.

- Listen: Listen back to your broadcast now

- Export: Export this broadcast to SoundCloud, Dropbox and more

- Delete: Delete this broadcast for ever

New feature: Change the audio quality of your broadcast on the fly. Learn more

Stats for this broadcast

Unique listeners Peak listeners

64

What are these statistics? More info.

$07 / 11 / 15$

Mixlr

Dear Cruz Ancla,

Congratulations! Your broadcast "La Familia y la vocacion" has been saved. You broadcast live for 0h $59 \mathrm{~m}$.

- Listen: Listen back to your broadcast now

- Export: Export this broadcast to SoundCloud, Dropbox and more

- Delete: Delete this broadcast for ever

New feature: Change the audio quality of your broadcast on the fly. Learn more

Stats for this broadcast
58
32
22

What are these statistics? More info. 
$14 / 11 / 15$

\section{Mixlr}

Dear Cruz Ancla,

Congratulations! Your broadcast "La Música y el apostolado" has been saved. You broadcast live for $1 \mathrm{~h}$ $0 \mathrm{~m}$.

- Listen: Listen back to your broadcast now

- Export: Export this broadcast to SoundCloud, Dropbox and more

- Delete: Delete this broadcast for ever

New feature: Change the audio quality of your broadcast on the fly. Learn more

Stats for this broadcast
75
pak listeners
19
8

$28 / 11 / 15$

Mixlr

Dear Cruz Ancla,

Congratulations! Your broadcast "Navidad es Jesús" is complete. You broadcast live for $1 \mathrm{~h} 1 \mathrm{~m}$.

New feature: Change the audio quality of your broadcast on the fly. Learn more

Stats for this broadcast
19
10
1
4
$5 / 12 / 15$
Mixlr

Dear Cruz Ancla,

Congratulations! Your broadcast "Adviento" has been saved. You broadcast live for $1 \mathrm{~h} 0 \mathrm{~m}$.

- Listen: Listen back to your broadcast now

- Export: Export this broadcast to SoundCloud, Dropbox and more

- Delete: Delete this broadcast for ever

New feature: Change the audio quality of your broadcast on the fly. Learn more

Stats for this broadcast
23 
$19 / 12 / 2015$

\section{Mixlr}

Dear Cruz Ancla,

Congratulations! Your broadcast "Navidad" is complete. You broadcast live for $0 \mathrm{~h} 57 \mathrm{~m}$.

New feature: Change the audio quality of your broadcast on the fly. Learn more

Stats for this broadcast
3
Peak listeners
0
0

$26 / 12 / 15$

Mixlr

Dear Cruz Ancla,

Congratulations! Your broadcast "iFelices Fiestas!" is complete. You broadcast live for $0 \mathrm{~h} 58 \mathrm{~m}$.

New feature: Change the audio quality of your broadcast on the fly. Learn more

Stats for this broadcast
21
12
2
1

08/01/16

IMixır

Dear Cruz Ancla,

Congratulations! Your broadcast "El Bautismo" has been saved. You broadcast live for $1 \mathrm{~h} 0 \mathrm{~m}$.

- Listen: Listen back to your broadcast now

- Export: Export this broadcast to SoundCloud, Dropbox and more

- Delete: Delete this broadcast for ever

New feature: Change the audio quality of your broadcast on the fly. Learn more

Stats for this broadcast

$\begin{array}{llll}\text { Unique listeners } & \text { Peak listeners } & \text { Chat } & \text { Hearte } \\ 36 & 21 & 15 & 13\end{array}$


$15 / 01 / 16$

\section{Mixlr}

Dear Cruz Ancla,

Congratulations! Your broadcast "El Apostolado en la Familia" is complete. You broadcast live for $1 \mathrm{~h}$ $1 \mathrm{~m}$.

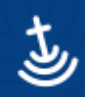

New feature: Change the audio quality of your broadcast on the fly. Learn more

Stats for this broadcast
$46 \quad 23$
Peak listeners
Chat
Hearts
4
3

$22 / 1 / 16$

Mixlr

Dear Cruz Ancla,

Congratulations! Your broadcast "La Confirma y Cruz Blanca" has been saved. You broadcast live for $1 \mathrm{~h}$ $0 \mathrm{~m}$.

- Listen: Listen back to your broadcast now

- Export: Export this broadcast to SoundCloud, Dropbox and more

- Delete: Delete this broadcast for ever

New feature: Change the audio quality of your broadcast on the fly. Learn more

Stats for this broadcast

$\begin{array}{llll}87 & \mathbf{4 0} & \mathbf{3 0} & \mathbf{2 0}\end{array}$

$29 / 1 / 16$

Mixlr

Dear Cruz Ancla,

Congratulations! Your broadcast "Programa 14" has been saved. You broadcast live for $1 \mathrm{~h} 0 \mathrm{~m}$.

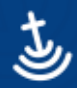

- Listen: Listen back to your broadcast now

- Export: Export this broadcast to SoundCloud, Dropbox and more

- Delete: Delete this broadcast for ever

Stats for this broadcast

$\begin{array}{llll}\text { Unique listeners } & \text { Peak listeners } & \text { Chat } & \text { Hearts } \\ \mathbf{3 6} & \mathbf{2 1} & \mathbf{5} & \mathbf{7}\end{array}$


$05 / 02 / 16$

\section{Mixlr}

Dear Cruz Ancla,

Congratulations! Your broadcast "Miércoles de Ceniza" has been saved. You broadcast live for 0h $59 \mathrm{~m}$.

- Listen: Listen back to your broadcast now

- Export: Export this broadcast to SoundCloud, Dropbox and more

- Delete: Delete this broadcast for ever

Stats for this broadcast
33
35
4
10

$12 / 02 / 16$

Mixlr

Dear Cruz Ancla,

Congratulations! Your broadcast "Cuaresma MVC" is complete. You broadcast live for $1 \mathrm{~h} 2 \mathrm{~m}$.

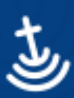

Stats for this broadcast

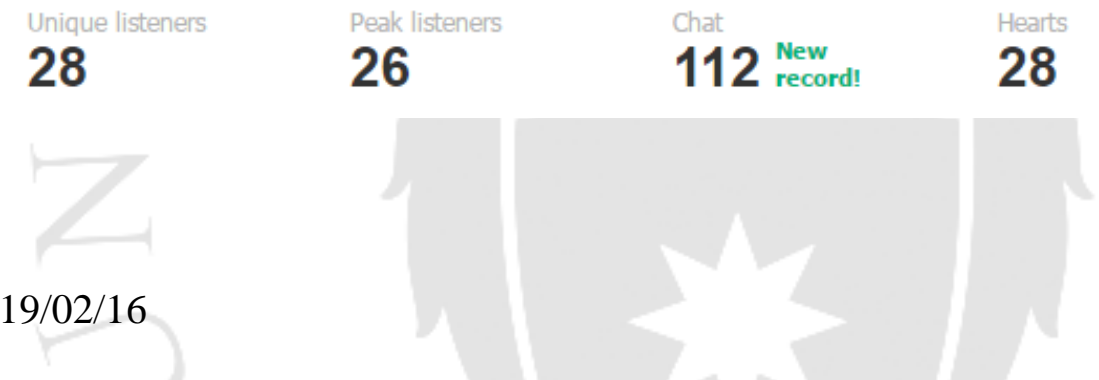

Mixlr

Dear Cruz Ancla,

Congratulations! Your broadcast "Entrevista a Mauricio Alen" has been saved. You broadcast live for 0h $59 \mathrm{~m}$.

- Listen: Listen back to your broadcast now

- Export: Export this broadcast to SoundCloud, Dropbox and more

- Delete: Delete this broadcast for ever

Stats for this broadcast
30
16
25
6 
$26 / 02 / 16$

Mixlr

Dear Cruz Ancla,

Congratulations! Your broadcast "Signo de Contradicción y Entrevista a MVC Talara" has been saved. You broadcast live for $0 \mathrm{~h} 59 \mathrm{~m}$.

- Listen: Listen back to your broadcast now

- Export: Export this broadcast to SoundCloud, Dropbox and more

- Delete: Delete this broadcast for ever

Stats for this broadcast
24
18
16
3

$04 / 03 / 16$

Mixlr

Dear Cruz Ancla,

Congratulations! Your broadcast "El apostolado y mi carrera" is complete. You broadcast live for $1 \mathrm{~h} 1 \mathrm{~m}$.

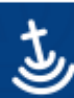

Stats for this broadcast

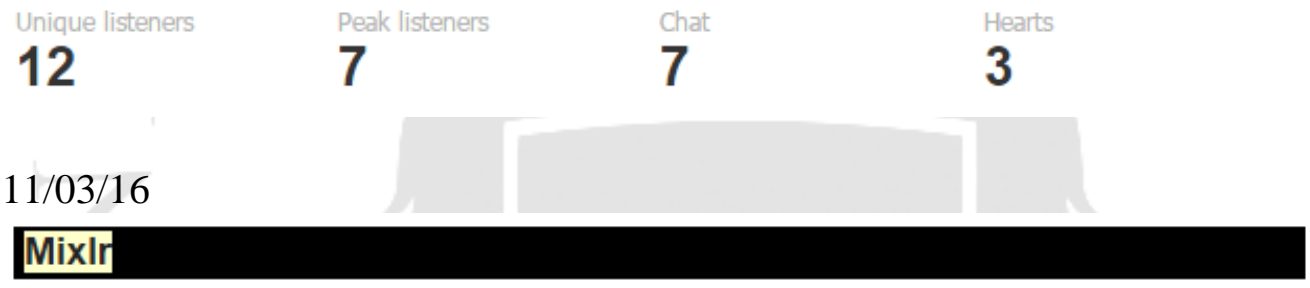

Dear Cruz Ancla,

Congratulations! Your broadcast "La mujern en la Iglesia" is complete. You broadcast live for $1 \mathrm{~h} 1 \mathrm{~m}$.

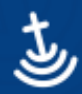

Stats for this broadcast

Unique listeners

Peak listeners

33

13

11

18/03/16

Mixlr

Dear Cruz Ancla,

Congratulations! Your broadcast "Semana Santa" has been saved. You broadcast live for 0h 58m.

- Listen: Listen back to your broadcast now

- Export: Export this broadcast to SoundCloud, Dropbox and more

- Delete: Delete this broadcast for ever

Stats for this broadcast

$\begin{array}{llll}\text { Unique listeners } & \text { Peak listeners } & \text { Chat } & \text { Hearts } \\ \mathbf{1 9} & \mathbf{1 4} & \mathbf{5} & \mathbf{4}\end{array}$


$01 / 04 / 16$

Mixlr

Dear Cruz Ancla,

Congratulations! Your broadcast "Ser católico en la Universidad" has been saved. You broadcast live for oh $55 \mathrm{~m}$.

- Listen: Listen back to your broadcast now

- Export: Export this broadcast to SoundCloud, Dropbox and more

- Delete: Delete this broadcast for ever

Stats for this broadcast
8
4
3
3

$08 / 04 / 16$

Mixlr

Dear Cruz Ancla,

Congratulations! Your broadcast "Navis en Cruz Ancla" has been saved. You broadcast live for $1 \mathrm{~h} 0 \mathrm{~m}$.

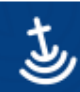

- Listen: Listen back to your broadcast now

- Export: Export this broadcast to SoundCloud, Dropbox and more

- Delete: Delete this broadcast for ever

Stats for this broadcast

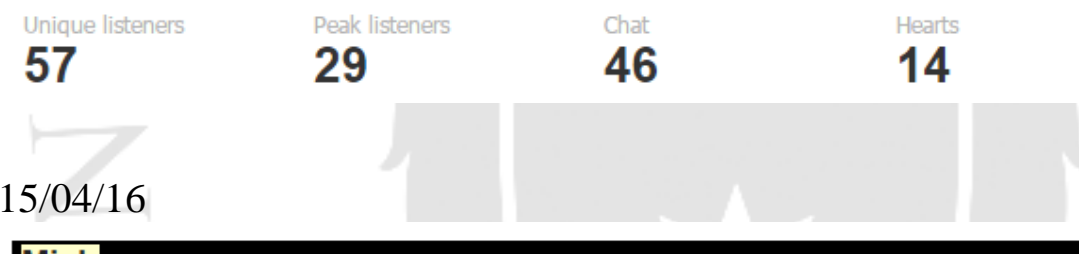

\section{Mixln}

Dear Cruz Ancla,

Congratulations! Your broadcast "Entrevistas" is complete. You broadcast live for $1 \mathrm{~h} 1 \mathrm{~m}$.

Stats for this broadcast
22
20
6
7

$22 / 04 / 16$

Mixlr

Dear Cruz Ancla,

Congratulations! Your broadcast "Aniversario del CP Jesús María" has been saved. You broadcast live for 0 h $55 \mathrm{~m}$.

- Listen: Listen back to your broadcast now

- Export: Export this broadcast to SoundCloud, Dropbox and more

- Delete: Delete this broadcast for ever

Stats for this broadcast
60
32
60
7 
29/04/16

Mixlr

Dear Cruz Ancla,

Congratulations! Your broadcast "Solidaridad " is complete. You broadcast live for $0 \mathrm{~h} 59 \mathrm{~m}$.

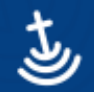

Stats for this broadcast
$\begin{array}{llll}\text { Unique listeners } & \text { Peak listeners } & \text { Chat } & \text { Heats } \\ & \mathbf{9} & \mathbf{2} & \mathbf{2}\end{array}$
$\begin{array}{llll}\text { Inique listeners } & \text { Peak listeners } & \text { Chat } & \text { Heats } \\ 2 & 9 & 2 & 2\end{array}$

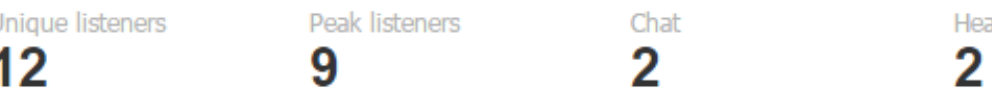
Hearts

$13 / 05 / 16$

Mixlr

Dear Cruz Ancla,

Congratulations! Your broadcast "Con María" is complete. You broadcast live for $1 \mathrm{~h} 1 \mathrm{~m}$.

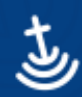

Stats for this broadcast
$\begin{array}{llll}\text { Unique listeners } & \text { Peak listeners } & \text { Chat } & \text { Heas } \\ \mathbf{1 4} & \mathbf{7} & \mathbf{5} & \mathbf{2}\end{array}$

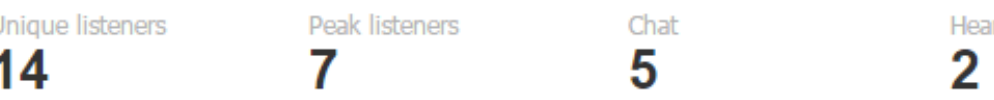
$\begin{array}{llll}\text { Unique listeners } & \text { Peak listeners } & \text { Chat } & \text { Hea }\end{array}$
$\begin{array}{llll} & & \text { Hearts } \\ & \mathbf{7} & \mathbf{5} & \mathbf{2}\end{array}$

20/05/16

Mixlr

Dear Cruz Ancla,

Congratulations! Your broadcast "Arte y Apostolado" is complete. You broadcast live for $1 \mathrm{~h} 1 \mathrm{~m}$.

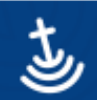

Stats for this broadcast

$\begin{array}{llll}\text { Unique listeners } & \text { Peak listeners } & \text { Chat } & \text { Hearts } \\ \mathbf{7} & \mathbf{1 4} & \mathbf{7} & \mathbf{2}\end{array}$

27/05/16

Mixlr

Dear Cruz Ancla,

Congratulations! Your broadcast "El Espíritu Santo" is complete. You broadcast live for 1h 0m.

Stats for this broadcast

$\begin{array}{llll}\text { Unique listeners } & \text { Peak listeners } & \text { Chat } & \text { Hearts } \\ 11 & 11 & 1 & 1\end{array}$

03/06/16 


\section{Mixlr}

Dear Cruz Ancla,

Congratulations! Your broadcast "El corazón de Jesús" has been saved. You broadcast live for $1 \mathrm{~h} 0 \mathrm{~m}$.

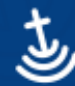

- Listen: Listen back to your broadcast now

- Export: Export this broadcast to SoundCloud, Dropbox and more

- Delete: Delete this broadcast for ever

Stats for this broadcast
11
Peak listeners
Chat
Hearts
Unique listenters
6
0
0

$10 / 06 / 16$

Mixlr

Dear Cruz Ancla,

Congratulations! Your broadcast "Apostolado en el trabajo" has been saved. You broadcast live for $1 \mathrm{~h}$ $0 \mathrm{~m}$.

- Listen: Listen back to your broadcast now

- Export: Export this broadcast to SoundCloud, Dropbox and more

- Delete: Delete this broadcast for ever

Stats for this broadcast
Unique listeners
Peak listeners
Chat
Hearts
4
5
0
6

$17 / 06 / 16$

Mixlr

Dear Cruz Ancla,

Congratulations! Your broadcast "San José, modelo de Padre" is complete. You broadcast live for $1 \mathrm{~h}$ $2 \mathrm{~m}$.

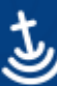

Stats for this broadcast
5
Peak listeners
3
5

$24 / 06 / 16$

Mixlr

Dear Cruz Ancla,

Congratulations! Your broadcast "Anecdotas misioneras" has been saved. You broadcast live for 0h 59m.

- Listen: Listen back to your broadcast now

- Export: Export this broadcast to SoundCloud, Dropbox and more

- Delete: Delete this broadcast for ever

Stats for this broadcast
12
5 


\section{ANEXO 2: \\ PAUTAS RADIALES DE LOS PROGRAMAS}

PAUTA RADIAL 1

Tema: Presentación primer programa

PROGRAMA RADIAL: Cruz Ancla

HORARIO: Sábados 12am

DURACIÓN: 1 hora

\begin{tabular}{|c|c|c|}
\hline SEGMENTO & TEXTO & TIEMPO \\
\hline 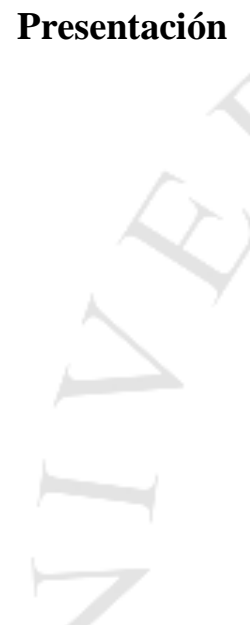 & $\begin{array}{l}\text { Presentación creativa/entretenida del programa } \\
\text { CARLOS: Bienvenidos al nuevo programa CRUZ } \\
\text { ANCLA, Del CP a la FM } \\
\text { R: Este es un espacio donde podremos compartir como } \\
\text { emevecistas diversos temas de actualidad, nuestras } \\
\text { experiencias, las distintas cosas que hacemos como } \\
\text { agrupados.... } \\
\text { C: Así es, también les compartiremos todas las actividades que } \\
\text { se vienen, comentaremos sobre los diversos proyectos que } \\
\text { hay en el MVC y siempre con la mejor música que siempre } \\
\text { quisimos escuchar en la radio. } \\
\text { R: Y hablando de música, vamos a una pausa, los dejamos con } \\
\text { una canción que habla de la amistad que compartimos todos } \\
\text { los agrupados. ¡Ya volvemos! }\end{array}$ & $\begin{array}{l}10 \min \\
11- \\
11: 10\end{array}$ \\
\hline $\begin{array}{l}\text { Bloque } \\
\text { Musical }\end{array}$ & $\begin{array}{l}\text { (1 canción) } \\
\text { No morirá }\end{array}$ & $\begin{array}{l}4 \min \\
11: 10- \\
11: 14\end{array}$ \\
\hline $\begin{array}{l}\text { Diálogo } \\
\text { Actualidad }\end{array}$ & $\begin{array}{l}\text { R: Estábamos escuchando: "No Morirá”, y ha llegado el } \\
\text { momento de que nos presentemos } \\
\text { C: Yo soy.... soy agrupado del CP } \\
\text { R: Yo soy........., agrupada de------ } \\
\text { C: Yo soy.... soy agrupado del CP } \\
\text { R: Cuéntanos VALENTINA ¿cómo te agrupaste? } \\
\text { C: Bueno yo me agrupé...... } \\
\text { R: Qué bonita....... Y ¿Qué es ser agrupado para ti? } \\
\text { CARLOS: Para mí es..... y Para ti Raúl? } \\
\text { Bueno ahora ya nos conocen un poco más. } \\
\text { Ahora queremos que ustedes participen y nos digan ¿qué es } \\
\text { ser agrupado para ti? } \\
\text { R: Comenten en Facebook o en twitter } \\
\text { Usando el hashtag \#SerAgruapadoEs, recuerden que } \\
\text { estamos como cruz ancla en Facebook y @ Cruzancla, todo } \\
\text { junto, en twitter } \\
\text { C: Ahora vamos a escuchar algo de música, pero luego } \\
\text { volveremos para seguir contándote TODO sobre este nuevo } \\
\text { programa CRUZ ANCLA }\end{array}$ & $\begin{array}{l}12 \mathrm{~min} \\
11: 14- \\
11: 26\end{array}$ \\
\hline
\end{tabular}




\begin{tabular}{|c|c|c|}
\hline & R: Los dejamos con No nos basta & \\
\hline $\begin{array}{l}\text { Bloque } \\
\text { Musical }\end{array}$ & $\begin{array}{l}\text { (2 canciones) } \\
\text { No nos basta } \\
\text { No pares }\end{array}$ & $\begin{array}{l}7 \text { min } \\
11: 26- \\
11: 33\end{array}$ \\
\hline $\begin{array}{l}\text { Proyectos o } \\
\text { temas (2) }\end{array}$ & $\begin{array}{l}\text { C: Estuvimos escuchando No pares de Julio cañas (pueden } \\
\text { comentar) } \\
\text { R: Ahí es y ahora queremos contarles Por qué la radio es } \\
\text { para agrupados } \\
\text { C: La idea de esta radio es que todos los agrupados } \\
\text { podamos tener un espacio para escuchar buena música } \\
\text { católica, pero evidentemente eso no es todo } \\
\text { R: Así es, también queremos conversar y comentar sobre } \\
\text { diversos temas que nos interesan, } \\
\text { C: tanto cosas de nuestro día a día como los proyectos y } \\
\text { actividades en las que participamos } \\
\text { R: Así podremos compartir nuestra identidad emevecista y } \\
\text { conocer más sobre el MVC } \\
\text { C: Queremos que CRUZ ANCLA sea un espacio de los } \\
\text { agrupados y por ello siempre tendremos diversos invitados } \\
\text { y les pediremos a ustedes también que comenten y nos } \\
\text { compartan sus experiencias en las redes sociales } \\
\text { R: Queremos unir a todos los agrupados, porque somos } \\
\text { jóvenes y queremos que el mundo nos escuche } \\
\text { C: Pero también queremos que, como emevecistas, } \\
\text { estemos unidos y qué mejor que la radio para que tolos los } \\
\text { agrupados de los distintos Centros pastorales puedan } \\
\text { compartir entre ellos y saber en qué andan los demás } \\
\text { R: ¡Exacto! Es un proyecto muy chévere en el que nos } \\
\text { estamos embarcando y por eso queremos que ustedes nos } \\
\text { ayuden compartiéndolo con sus amigos, sus hermanos de } \\
\text { agrupa } \\
\text { C: Con toda la gente de su cp, etc. Para que más personas } \\
\text { escuchen y participen del programa. } \\
\text { R: Así es, por eso ahora escucharemos un poco de lo que } \\
\text { nos han compartido varios agrupados. Ellos nos contaron } \\
\text { qué es para ellos ser agrupados, así que vamos a } \\
\text { escucharlos: } \\
\text { Se escuchan audios de gente contando que es ser agrupados } \\
\text { para ellos } \\
\text { C: Qué lindos testimonios, ahora vamos a ir a una pausa, pero } \\
\text { de ahí volvemos. } \\
\text { R: Así es, vamos a escuchar una canción de Las Siervas: } \\
\text { Confía en Dios! }\end{array}$ & $12 \min$ \\
\hline $\begin{array}{l}\text { Bloque } \\
\text { Musical }\end{array}$ & $\begin{array}{l}\text { (Dos canciones) } \\
\text { - Confía en Dios } \\
\text { Somos convocados }\end{array}$ & $7 \mathrm{~min}$ \\
\hline $\begin{array}{l}\text { Agenda } \\
\text { Y despedida }\end{array}$ & $\begin{array}{l}\text { C: El programa ya está llegando a su fin, pero antes queremos } \\
\text { presentarles el gran } \\
\text { (Música de suspenso) } \\
\text { RAUL: ¡Calendario emevecista! Para que estés al tanto de las } \\
\text { actividades que se vienen }\end{array}$ & $7 \min$ \\
\hline
\end{tabular}




\begin{tabular}{|c|c|c|}
\hline & $\begin{array}{l}\text { C: Así es, todos los sábados les recordaremos los eventos que } \\
\text { se vienen para que no se pierdan de nada. } \\
\text { R: Por ejemplo, Hoy se celebra el aniversario del cp cristo } \\
\text { reconciliador. ¡Los saludamos y felicitamos por su aniversario! } \\
\text { C: También se celebra CPerú en el CP de san Borja, se ve que } \\
\text { va a estar genial. } \\
\text { R: Otro gran evento que se viene es la esperada Ola de santidad } \\
\text { el domingo } 1 \text { de noviembre } \\
\text { C: y el } 14 \text { de noviembre es el concierto de las siervas } \\
\text { Así es y esto ha sido el Calendario emevecista } \\
\text { ¡Ha llegado el momento de despedirnos, ha sido genial estar } \\
\text { con ustedes en la primera edición de Cruz Ancla! } \\
\text { C: Yo soy Carlos } \\
\text { R: Y yo soy Raúl } \\
\text { C: Nos despedimos hasta el próximo sábado a las } 11 \\
\text { R: ¡No se olviden de seguir en Facebook y twitter como cruz } \\
\text { ancla! } \\
\text { C: Chau! }\end{array}$ & \\
\hline Música & $\begin{array}{l}\text { Música } \\
\text { - Quién dices que soy } \\
\text { - Manifiesto } \\
\text { - No tengo miedo } \\
\text { - Tu noticia es libertad } \\
\text { - Universal Youth }\end{array}$ & $5 \min$ \\
\hline & TIEMPO TOTAL & $60 \mathrm{~min}$ \\
\hline \multicolumn{3}{|c|}{$\begin{array}{l}\text { Tema: Santidad / Pan Para mi hermano } \\
\text { PROGRAMA RADIAL: Cruz Ancla } \\
\text { HORARIO: Sábados 11am } \\
\text { DURACIÓN: } 1 \text { hora }\end{array}$} \\
\hline SEGMENTO & 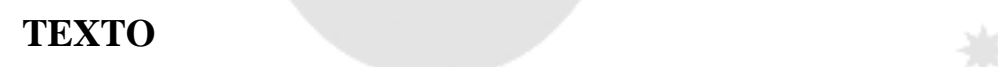 & TIEMPO \\
\hline Presentación & $\begin{array}{l}\text { Presentación creativa/entretenida del programa } \\
\text { R: ¡Bienvenidos a CRUZ ANCLA, La radio de los agrupados, } \\
\text { Yo soy Raúl y hoy nos acompaña Valentina, ella también } \\
\text { estará todos los sábados aquí en la radio, ¡Bienvenida!! } \\
\text { V: Gracias Raúl, estoy muy feliz de poder estar aquí este } \\
\text { pequeño momento de compartir entre agrupados } \\
\text { R: qué bueno. Y cuéntanos: ¿De qué hablaremos hoy? } \\
\text { V: Hoy hablaremos sobre varios temas, y para empezar sobre } \\
\text { la santidad } \\
\text { C: Así es, primero estaremos hablando sobre la santidad, ya } \\
\text { que mañana celebraremos el día de todos los Santos } \\
\text { V: Si, comentaremos sobre aquellos amigos nuestros cuyas }\end{array}$ & $\begin{array}{l}10 \mathrm{~min} \\
12- \\
12: 10\end{array}$ \\
\hline
\end{tabular}




\begin{tabular}{|c|c|c|}
\hline & $\begin{array}{l}\text { vidas son un ejemplo para nosotros } \\
\text { R: Y luego tendremos un par de invitados } \\
\text { V: ¿Quiénes van a venir? } \\
\text { C: Hoy vienen dos voluntarios de pan para mi hermano para } \\
\quad \text { contarnos su experiencia en este lindo proyecto y para } \\
\text { invitarnos también a participar } \\
\text { V: Qué bien, así que también ustedes pueden participar } \\
\text { contándonos sus experiencias a través de las redes sociales } \\
\text { R: Muy bien, antes de continuar, escuchemos un poco de } \\
\text { música, Los dejamos con una canción llamada "La } \\
\text { felicidad" }\end{array}$ & \\
\hline $\begin{array}{l}\text { Bloque } \\
\text { Musical }\end{array}$ & $\begin{array}{l}\text { (1 canción) } \\
\text { La felicidad }\end{array}$ & $\begin{array}{l}4 \mathrm{~min} \\
12: 10- \\
12: 15\end{array}$ \\
\hline $\begin{array}{l}\text { Diálogo } \\
\text { Actualidad } \\
\text { Tu Santo } \\
\text { amigo }\end{array}$ & $\begin{array}{l}\text { V: Como todos sabemos, mañana celebramos a todos los } \\
\text { santos } \\
\text { R: Si, todas aquellas personas que han ido al cielo } \\
\text { V: Y muchos de ellos ahora son ejemplo para nosotros } \\
\text { R: Así es, Todos tenemos algún santo amigo al cual le } \\
\text { tenemos particular cariño } \\
\text { V: si claro, siempre hay algún santo cuya historia nos ha } \\
\text { llamado la atención, o con quien nos hemos sentido } \\
\text { identificados } \\
\text { R: Hoy queremos que nos comenten quién es su santo } \\
\text { amigo y por qué } \\
\text { V: Pueden escribirnos en Facebook y twitter con el } \\
\text { Hashtag \#MiSantoAmigo } \\
\text { R: Valentina, ¿cuál es tu Santo amigo? } \\
\text { V: mi santo amigo es.... y el tuyo? } \\
\text { R: el mío es.... } \\
\text { V: Comenten en Facebook o en twitter } \\
\text { Usando el hashtag \#MisantoAmigo, recuerden que } \\
\text { estamos como cruz ancla en Facebook y @ Cruzancla, en } \\
\text { twitter } \\
\text { R: Ahora nos vamos a una pequeña pausa musical } \\
\text { V: Los dejamos con “A dónde iré” }\end{array}$ & $\begin{array}{l}10 \mathrm{~min} \\
12: 15- \\
12: 25\end{array}$ \\
\hline
\end{tabular}




\begin{tabular}{|c|c|c|}
\hline $\begin{array}{l}\text { Bloque } \\
\text { Musical }\end{array}$ & $\begin{array}{l}\quad \text { ( } 2 \text { canciones }) \\
\text { A dónde iré } \\
\text { el sí de María }\end{array}$ & $\begin{array}{l}7 \mathrm{~min} \\
12: 33- \\
12: 40\end{array}$ \\
\hline $\begin{array}{l}\text { Proyectos o } \\
\text { temas (2) } \\
\text { Pan para mi } \\
\text { hermano }\end{array}$ & 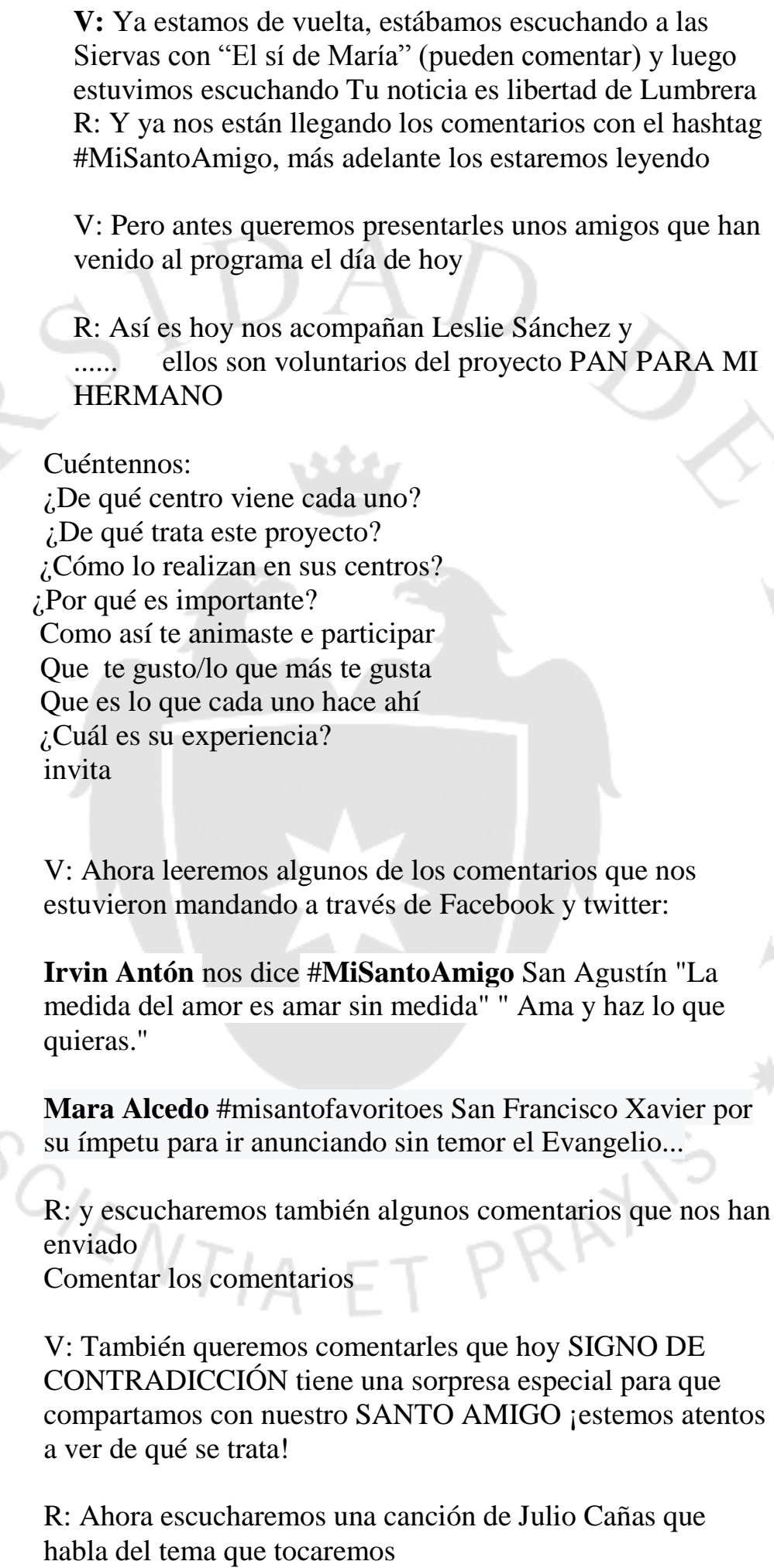 & $\begin{array}{l}12 \mathrm{~min} \\
12: 40- \\
12: 52\end{array}$ \\
\hline Bloque & (Dos canciones) & $7 \mathrm{~min}$ \\
\hline
\end{tabular}




\begin{tabular}{|c|c|c|}
\hline Musical & $\begin{array}{l}\text {-Pan para mi hermano } \\
\text {-Romper Barreras }\end{array}$ & $12: 52-$ \\
\hline $\begin{array}{l}\text { Agenda } \\
\text { Y despedida }\end{array}$ & $\begin{array}{l}\text { CUÑA: Calendario emevecista } \\
\text { R: Hoy es la noche de talentos en el cp Jesús maría: } \\
\text { Jesús María tiene Talento, a las 5:00pm } \\
\text { V: El } 7 \text { y } 8 \text { de noviembre se realizará en HUARAZ el 9no } \\
\text { Congreso Universitario: “EEres libre en la Universidad?" } \\
\text { R: sábado } 14 \text { de noviembre } \\
\text { - Ave María Gratis, Santiago, Chile. } \\
\text { - Segundo Concierto de las Siervas, Lima, Perú. } \\
\text { V: Domingo } 15 \text { de noviembre } \\
\text {-continua Ave María Gratis, Santiago, Chile. } \\
\text { - Jornada de Formación para Colecta NEJ, Piura, Perú. } \\
\text { R: Así es y esto ha sido el Calendario emevecista } \\
\text { V: Ha llegado el momento de despedirnos, pero antes } \\
\text { queremos mandarle un saludo a Carlos que no ha podido estar } \\
\text { con nosotros porque está un poco delicado de salud así que les } \\
\text { pedimos sus oraciones por él } \\
\text { R: Y yo soy Raúl } \\
\text { V: Yo soy Valentina } \\
\text { C: Esto fue CRUZ ANCLA } \\
\text { V: Nos despedimos hasta el próximo sábado a las } 12 \\
\text { R: No se olviden de seguirnos en Facebook y twitter como } \\
\text { cruz ancla y dejarnos sus comentarios sobre el programa! } \\
\text { V: Hasta el próximo sábado! }\end{array}$ & 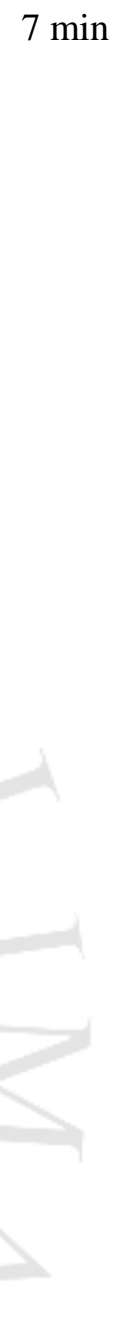 \\
\hline Música & $\begin{array}{l}\text { Música } \\
\text { - Frágil } \\
\text { - Companions of the Lamb }\end{array}$ & $5 \mathrm{~min}$ \\
\hline & TIEMPO TOTAL & $60 \mathrm{~min}$ \\
\hline
\end{tabular}

Tema: Vocación, familia, santidad

PAUTA 3

PROGRAMA RADIAL: Cruz Ancla

HORARIO: Sábados 12am

DURACIÓN: 1 hora

\begin{tabular}{|l|l|l|}
\hline SEGMENTO & TEXTO & TIEMPO \\
\hline Presentación & Presentación creativa/entretenida del programa & 5 min \\
& R: Bienvenidos a CRUZ ANCLA, & $12-$ \\
& & $12: 05$ \\
& C: ¿Qué tal la semana Raúl? & \\
\hline
\end{tabular}




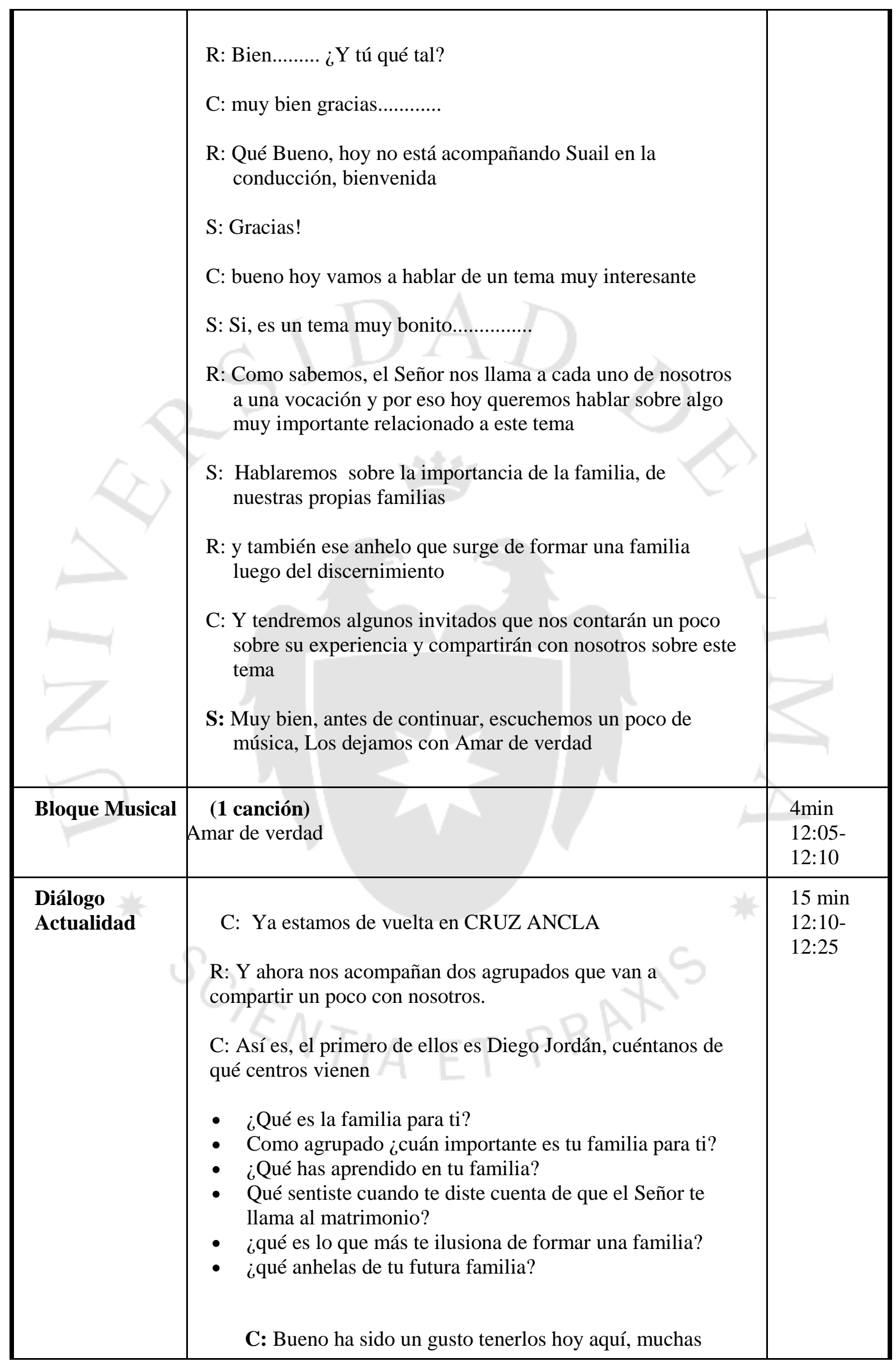




\begin{tabular}{|c|c|c|}
\hline & $\begin{array}{l}\text { gracias por compartir con nosotros. } \\
\mathbf{R} \text { : Ahora nos vamos a una pequeña pausa musical } \\
\text { C: Los dejamos con Love is blind }\end{array}$ & \\
\hline Bloque Musical & $\begin{array}{l}\text { (2 canciones) } \\
\text { Love is blind }\end{array}$ & $\begin{array}{l}7 \text { min } \\
12: 25- \\
12: 35\end{array}$ \\
\hline $\begin{array}{l}\text { Proyectos o } \\
\text { temas (2) }\end{array}$ & $\begin{array}{l}\text { V: Ya estamos de vuelta, estábamos escuchando a Love is } \\
\text { blind, de un grupo llamado estadounidense The Thirsting } \\
\text { R: Y ahora están con nosotros Fernando y Lissete } \\
\text { Magallanes, ellos son una joven pareja de esposos, que se } \\
\text { han casado hace poco verdad? (Empiezan a conversar) } \\
\text { - ¿Hace cuánto que están casados? } \\
\text { - ¿Ya tienen hijos? } \\
\text { - ¿Qué es la familia para ustedes? } \\
\text { - ¿Cómo se vive más les ilusiona de formar una familiana en la familia? } \\
\text { - ¿Qué dificultades normalmente hay en una familia? } \\
\text { - Cómo se relaciona la familia con la santidad? } \\
\text { ¿amilia? }\end{array}$ & $\begin{array}{l}15 \mathrm{~min} \\
12: 35- \\
12: 45\end{array}$ \\
\hline & $\begin{array}{l}\text { V: Bueno que lindo testimonio, ha sido genial poder } \\
\text { conversar con ustedes un rato, muchísimas gracias por venir. } \\
\text { R: Ahora escucharemos una canción del grupo ecuatoriano } \\
\text { Vox Lumini llamada Sin Fe } \\
\text { Ya volvemos! }\end{array}$ & \\
\hline Bloque Musical & $\begin{array}{l}\text { (Dos canciones) } \\
\text { Sin fe } \\
\text { No temáis }\end{array}$ & $\begin{array}{l}7 \mathrm{~min} \\
12: 45- \\
12-53\end{array}$ \\
\hline $\begin{array}{l}\text { Agenda } \\
\text { Y despedida }\end{array}$ & $\begin{array}{l}\text { CUÑA: Calendario emevecista! } \\
\text { R: Como ya muchos saben, el próximo Sábado } 14 \text { de } \\
\text { Noviembre se realizará } \\
\text { - Ave María Gratis, Santiago, Chile. } \\
\text { - Segundo Concierto de las Siervas, Lima, Perú. } \\
\text { Jueves } 19 \text { de Noviembre: } \\
\text { - Aniversario del CP Nuestra Señora de la Cruz. } \\
\text { Y nos ponemos internacionales porque el 20, } 21 \text { y } 22 \text { de } \\
\text { Noviembre: } \\
\text { - Convivio "¿Qué buscas?" } 5 \text { pm, Cali, Colombia. } \\
\text { Y como ya todos saben este } 28 \text { de noviembre es la gran }\end{array}$ & $7 \mathrm{~min}$ \\
\hline
\end{tabular}




\begin{tabular}{|c|c|c|}
\hline & $\begin{array}{l}\text { COLECTA NAVIDAD ES JESÚS } \\
\text { R: Así es y esto ha sido el Calendario emevecista } \\
\text { S: Y lamentablemente Ha llegado el momento de } \\
\text { despedirnos, } \\
\text { R: Y yo soy Raúl } \\
\text { S: Yo soy Suail } \\
\text { C y yo Carlos } \\
\text { C: Y esto fue CRUZ ANCLA } \\
\text { R: Nos despedimos hasta el próximo sábado a las } 12 \\
\text { S: No se olviden de seguirnos en Facebook y twitter como } \\
\text { cruz ancla y dejarnos sus comentarios sobre el programa! } \\
\text { C: Hasta el próximo sábado! }\end{array}$ & \\
\hline Música & $\begin{array}{l}\text { Música } \\
\text { • María en camino }\end{array}$ & $5 \mathrm{~min}$ \\
\hline & TIEMPO TOTAL & $60 \mathrm{~min}$ \\
\hline
\end{tabular}

\section{PAUTA RADIAL 4}

Tema: La música y el apostolado

PROGRAMA RADIAL: Cruz Ancla

HORARIO: Sábados 11am

DURACIÓN: 1 hora

\begin{tabular}{|l|l|c|}
\hline SEGMENTO & TEXTO & TIEMPO \\
\hline Presentación & Empiezan con impro musical & 5 min \\
& R: Qué talento tenemos ah? & $12-$ \\
& V: Jaja si, bueno esos fuimos nosotros improvisando un poco & $12: 10$ \\
C: Esto solo lo vas a escuchar en CRUZ ANCLA!! & \\
& R: Bienvenidos un sábado más al programa hecho por & \\
& agrupados & \\
& V: Hoy tenemos un programa súper musical & \\
& C: Así que ya saben, llamen a sus amigos músicos, pásenles & \\
& la voz porque no se pueden perder este programa & \\
& V: Sí, porque estaremos hablando sobre la música y su & \\
& relación con el apostolado & \\
& R: Así es, entre los emevecistas tenemos muchos talentos & \\
& musicales y artísticos en general & \\
& V: Y muchos de estos jóvenes artistas aprovechan estos & \\
& talentos que tienen para hacer apostolado & \\
& C: Si, y además tenemos ejemplos claros como el de las & \\
& Siervas por ejemplo, que hoy van a tener el último & \\
& concierto de su gira y se ve que va a ser un conciertazo! & \\
& V: Sí, lindas las Siervas & \\
& R: Así es, así que tenemos un programa recontra musical y & \\
& por eso escucharemos una canción antes de continuar & \\
& conversando & \\
\end{tabular}




\begin{tabular}{|c|c|c|}
\hline & $\begin{array}{l}\text { C: Los dejamos con una canción de las Siervas: El sí de } \\
\text { María }\end{array}$ & \\
\hline Bloque Musical & El sí de María & $\begin{array}{l}4 \mathrm{~min} \\
12: 10- \\
12: 14\end{array}$ \\
\hline $\begin{array}{l}\text { Diálogo } \\
\text { Actualidad }\end{array}$ & $\begin{array}{l}\text { ENTREVISTA } \\
\text { V: Ya estamos de vuelta } \\
\text { R: La canción que estuvimos escuchando era El sí de María } \\
\text { V: iQué buena canción! } \\
\text { C: Si, justo hoy es el concierto de las Siervas y ellas dan un } \\
\text { gran testimonio de cómo hacer apostolado a través de la } \\
\text { música } \\
\text { V: Si, ellas ya han ganado un poco de fama y llevan su } \\
\text { mensaje cada vez a más personas } \\
\text { C: Y ahora sí nos vamos de frente al tema de hoy } \\
\text { V: Pero antes no se olviden de comentar en las redes sociales } \\
\text { cuáles son sus canciones católicas favoritas } \\
\text { V: Comenten en Facebook o en twitter Usando el hashtag } \\
\text { \#MiCanciónFavorita o } \\
\text { R: Tenemos aquí en la cabina a unos invitados muy } \\
\text { especiales } \\
\text { V: Bienvenidos } \\
\text { - Cuéntennos ¿de qué centro viene cada uno? } \\
\text { • ¿Cómo descubriste que te gustaba la música? } \\
\text { • ¿Qué es la música para ti? } \\
\text { - ¿Cómo se puede hacer apostolado a través de la } \\
\text { música? } \\
\text { V: Comenten en Facebook o en twitter Usando el hashtag } \\
\text { \#MiCanciónFavorita, recuerden que estamos como CRUZ } \\
\text { ANCLA en Facebook y @ Cruzancla, en twitter } \\
\text { R: Ahora nos vamos a una pequeña pausa musical } \\
\text { V: Los dejamos con No Morirá }\end{array}$ & $\begin{array}{l}10 \mathrm{~min} \\
12: 14- \\
12: 24\end{array}$ \\
\hline Bloque Musical & $\begin{array}{l}\text { no morirá } \\
\text { no pares }\end{array}$ & $\begin{array}{l}7 \mathrm{~min} \\
12: 24- \\
12: 32\end{array}$ \\
\hline $\begin{array}{l}\text { Proyectos o } \\
\text { temas (2) }\end{array}$ & $\begin{array}{l}\text { V: Ya estamos de vuelta, estábamos escuchando a Julio } \\
\text { Cañas } \\
\text { R: Así es, él es un músico que se tomó en serio la idea de } \\
\text { hacer apostolado con la música } \\
\text { V: ¿Y ustedes han escuchado el disco que ha sacado el Papa } \\
\text { Francisco? } \\
\text { C: ¿Cuál? } \\
\text { V:Han sacado un disco de rock con fragmentos } \\
\text { musicalizados de los discursos del Papa } \\
\text { C: ¿qué en serio?? } \\
\text { V: En verdad esta increíble! Nosotros no lo podemos pasar } \\
\text { por acá todavía porque nos demandan jaja } \\
\text { R: Tenemos que pedir permiso pero pueden buscarlo en }\end{array}$ & $\begin{array}{l}10 \mathrm{~min} \\
12: 32- \\
12: 45\end{array}$ \\
\hline
\end{tabular}




\begin{tabular}{|c|c|c|}
\hline & $\begin{array}{l}\text { souncloud esta una de las canciones se llama Wake Up, } \\
\text { súper recomendada } \\
\text { C: Y ya nos están llegando los comentarios con el hashtag } \\
\text { \#MiCanciónFavorita } \\
\text { V:más adelante los estaremos leyendo } \\
\text { C: Pero antes vamos a escuchar unos audios que nos han } \\
\text { mandado nuestros amigos emevecistas alrededor del mundo } \\
\text { R: Ellos también querían participar de la radio, así que } \\
\text { vamos a escucharlos } \\
\text { Comenten los audios } \\
\text { V: Ahora leeremos algunos de los comentarios que nos } \\
\text { estuvieron mandando a través de Facebook y twitter: } \\
\text { C: } \\
\text { R: Ahora nos vamos a otra pausa musical porque y luego } \\
\text { viene el último bloque } \\
\text { V: No tan rápido?? } \\
\text { C: Así es los dejamos con QUIEN DICES QUE SOY de } \\
\text { VOX LUMINI }\end{array}$ & \\
\hline Bloque Musical & $\begin{array}{l}\text { QUIEN DICES QUE SOY } \\
\text { Avanzar }\end{array}$ & $\begin{array}{l}7 \text { min } \\
12: 42- \\
12: 48\end{array}$ \\
\hline $\begin{array}{l}\text { Agenda } \\
\text { y despedida } \\
\text { C, R y V }\end{array}$ & $\begin{array}{l}\text { CUÑA: Calendario emevecista! } \\
\text { R: Este Jueves } 19 \text { de Noviembre: } \\
\text { - Aniversario del CP Nuestra Señora de la Cruz. } \\
\text { C: Y como ya todos saben este } 28 \text { de noviembre es la gran } \\
\text { COLECTA NAVIDAD ES JESÚS } \\
\text { R: Pero en Piura se nos adelantan y van a empezar la colecta } \\
\text { antes, ellos empiezan el Viernes } 27 \text { de Noviembre y la } \\
\text { continúan el } 28 \\
\text { R: Así es y esto ha sido el Calendario emevecista } \\
\text { V: Ha llegado el momento de despedirnos, } \\
\text { C: Pero antes nuestra productora nos ha pedido que le } \\
\text { mandemos un saludo a Andrea Farro, su hermana de } \\
\text { agrupación que ha estado de cumpleaños ayer } \\
\text { R: Y yo soy Raúl } \\
\text { V: Yo soy Valentina } \\
\text { C: Yo soy Carlos } \\
\text { C: Esto fue CRUZ ANCLA } \\
\text { V: Nos despedimos hasta el próximo sábado a las } 12 \\
\text { R: Chau }\end{array}$ & $\begin{array}{l}7 \text { min } \\
12: 48- \\
12: 55\end{array}$ \\
\hline
\end{tabular}




\begin{tabular}{|l|l|c|}
\hline Música & Música & $5 \mathrm{~min}$ \\
\hline & TIEMPO TOTAL & $60 \mathrm{~min}$ \\
\hline
\end{tabular}

Tema: SOLIDARIDAD

\section{PAUTA 5}

PROGRAMA RADIAL: Cruz Ancla

HORARIO: Sábados 12am

DURACIÓN: 1 hora

\begin{tabular}{|c|c|c|}
\hline SEGMENTO & 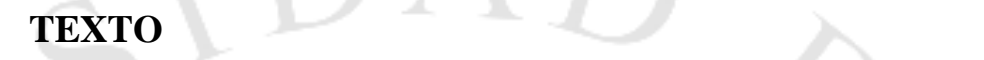 & TIEMPO \\
\hline Presentación & $\begin{array}{l}\text { Presentación creativa/entretenida del programa } \\
\text { R: Bienvenidos a un nuevo episodio de CRUZ ANCLA, } \\
\text { C: Yo soy Carlos } \\
\text { R: Yo Raúl } \\
\text { V: Y yo Valentina } \\
\text { C: Y hoy les tenemos preparado un programa muy } \\
\text { interesante } \\
\text { R: Así es, como siempre tendremos invitados súper especiales } \\
\text { V: Sí, porque hablaremos sobre la solidaridad cristiana } \\
\text { R: Así es, y en el movimiento tenemos varios proyectos } \\
\quad \text { solidarios así que también ustedes podrán compartir un } \\
\text { poco su experiencia con nosotros. } \\
\text { C: Vamos a ver de qué se trata y por qué es tan importante la } \\
\text { solidaridad cristiana } \\
\text { V: Y tendremos algunos invitados que nos contarán su } \\
\text { experiencia } \\
\text { R: }\end{array}$ & $\begin{array}{l}10 \mathrm{~min} \\
12-12: 10\end{array}$ \\
\hline Bloque Musical & (1 canción) & $\begin{array}{l}4 \min \\
12: 10- \\
12: 15\end{array}$ \\
\hline $\begin{array}{l}\text { Diálogo } \\
\text { Actualidad }\end{array}$ & $\begin{array}{l}\text { Estuvimos escuchando } \\
\text { Ahora tenemos un invitado que ha venido a hablarnos un poco } \\
\text { sobre } \\
\text { Y en el siguiente bloque tendremos una entrevista especial y } \\
\text { por eso hemos enviado a Daniela para que converse con } \\
\text { nuestra invitada } \\
\text { Ahora los dejamos con }\end{array}$ & $\begin{array}{l}10 \min \\
12: 15- \\
12: 25\end{array}$ \\
\hline Bloque Musical & -amar de verdad & $\begin{array}{l}7 \min \\
12: 33- \\
12: 40\end{array}$ \\
\hline $\begin{array}{l}\text { Proyectos o } \\
\text { temas (2) }\end{array}$ & $\begin{array}{l}\text { C: Ya estamos de vuelta en CRUZ ANCLA } \\
\text { estuvimos escuchando Amar de verdad } \\
\text { Y ahora vamos a conversar con Grazia, ella nos acompaña hoy }\end{array}$ & $\begin{array}{l}12 \mathrm{~min} \\
12: 40-\end{array}$ \\
\hline
\end{tabular}




\begin{tabular}{|c|c|c|}
\hline & $\begin{array}{l}\text { para contarnos sobre acción universitaria } \\
\text { Bienvenida } \\
\text { Bueno cuéntanos: } \\
\text { ¿Qué es Acción universitaria? } \\
\text { ¿Cuáles son sus objetivos? } \\
\text { ¿Qué proyectos tienen? } \\
\text { - ¿Por qué es importante lo que hacen? } \\
\text { - ¿Qué es lo que más te gusta? } \\
\text { - ¿De qué manera se manifiesta el Señor en este tipo de } \\
\text { proyectos? } \\
\text {-¿Tu cómo conociste el MVC? } \\
\text { Qué bonito testimonio Grazia, muchas gracias por haber } \\
\text { compartido con nosotros } \\
\text { Ahora escucharemos algunas canciones y luego se viene el } \\
\text { esperado Calendario Emevecista } \\
\text { Vamos a escuchar una canción del grupo ecuatoriano Vox } \\
\text { Lumini llamada } \\
\text { Ya volvemos! }\end{array}$ & $12: 52$ \\
\hline Bloque Musical & (Dos canciones) & $\begin{array}{l}7 \text { min } \\
12: 52-\end{array}$ \\
\hline $\begin{array}{l}\text { Agenda } \\
\text { Y despedida }\end{array}$ & $\begin{array}{l}\text { CUÑA: Calendario emevecista! } \\
\text { R: } \\
\text { C: Y como ya todos saben este } 28 \text { de noviembre es la gran } \\
\text { COLECTA NAVIDAD ES JESÚS } \\
\text { R: Pero en Piura se nos adelantan y van a empezar la colecta } \\
\text { antes, ellos empiezan el Viernes } 27 \text { de Noviembre y la } \\
\text { continúan el } 28 \\
\text { V: este domingo } 22 \text { AuPeru tienes Rus regala una sonrisa y } \\
\text { están involucradas universidades como upc up y ulima } \\
\text { R: Así es y esto ha sido el Calendario emevecista } \\
\text { V: Ha llegado el momento de despedirnos, } \\
\text { R: Y yo soy Raúl } \\
\text { V: Yo soy Valentina } \\
\text { C: Yo soy Carlos } \\
\text { C: Esto fue CRUZ ANCLA }\end{array}$ & 7 min \\
\hline \multirow[t]{2}{*}{ Música } & $\begin{array}{l}\text { Música } \\
\quad \text { María en camino }[-1 /\end{array}$ & $5 \mathrm{~min}$ \\
\hline & TIEMPO TOTAL & \\
\hline
\end{tabular}

\section{PAUTA RADIAL 6}

Tema: Colecta Navidad es Jesús / Anécdotas colecteras PROGRAMA RADIAL: Cruz Ancla HORARIO: Sábados $11 \mathrm{am}$ 


\begin{tabular}{|c|c|c|}
\hline SEGMENTO & TEXTO & TIEMPO \\
\hline $\begin{array}{l}\text { Presentación } \\
\text { R, C Y V }\end{array}$ & $\begin{array}{l}\text { R: Bienvenidos a una nueva emisión de CRUZ ANCLA! } \\
\text { V: Hoy muchos emevecistas, sobre todo en Perú, salimos a las } \\
\text { calles a participar de la Colecta NAVIDAD ES JESÚS, les } \\
\text { mandamos un saludo a todos los colecteros que están en } \\
\text { estos momentos por las calles } \\
\text { R: Y los que no han salido con sus latas no se olviden de } \\
\text { colaborar } \\
\text { V: Así es, el objetivo de Navidad es Jesús es llevar a muchos } \\
\text { niños el verdadero significado de la Navidad } \\
\text { C: Así que estaremos hablando de eso el día de hoy } \\
\text { V: Y estaremos reportando también el desarrollo de esta colecta } \\
\text { R: Si, hemos salido más temprano a algunos puntos a recoger } \\
\text { las opiniones de muchos colecteros que nos han compartido } \\
\text { su emoción por colaborar con esta campaña } \\
\text { V: Y también nos han contado por qué se han animado a } \\
\text { colaborar y unas anécdotas muy divertidas } \\
\text { C: Bueno. nos vamos a una pausa musical y al regreso } \\
\text { escucharemos lo que nos han dicho los colecteros } \\
\text { V: Los dejamos con Romper barreras }\end{array}$ & $\begin{array}{l}10 \min \\
12- \\
12: 10\end{array}$ \\
\hline $\begin{array}{l}\text { Bloque } \\
\text { Musical }\end{array}$ & $\begin{array}{l}\text { (2 canciones) } \\
\text { Romper barreras } \\
\text { pobres de espiritu }\end{array}$ & $\begin{array}{l}4 \min \\
12: 10- \\
12: 15\end{array}$ \\
\hline $\begin{array}{l}\text { Diálogo } \\
\text { Actualidad }\end{array}$ & $\begin{array}{l}\text { R: Estuvimos escuchando Pobres de espíritu de las Siervas, y } \\
\text { bueno hoy estaremos comentando sobre Anécdotas colecteras, } \\
\text { las anécdotas colecteras en realidad es un término que } \\
\text { acabamos de inventar pero son las cosas que te han pasado } \\
\text { cuando has estado colectando en la calle } \\
\text { Tipo cuando te encuentras con gente que conoces en los } \\
\text { carros, por ejemplo } \\
\text { C: Así que cuéntennos su anécdotas con el Hashtag } \\
\text { \#AnecdotasColecteras o \#ColectaNEJ } \\
\text { R: Y de paso sube tu foto con tu lata y hagamos que sea } \\
\text { tendencia en las redes sociales } \\
\text { C:Y hoy temprano estuvimos recogiendo algunas experiencias } \\
\text { de los colecteros que han salido hoy mismo, así que ahora } \\
\text { escucharemos algunas anécdotas que nos contaron esta } \\
\text { mañana } \\
\text { R: qué genial ver tanta gente entusiasmada por ayudar! Ahora } \\
\text { nos vamos a otra pausa pero no se olviden de comentar en } \\
\text { Facebook o en twitter usando el hashtag } \\
\text { \#AnécdotasColecteras, recuerden que estamos como cruz } \\
\text { ancla en Facebook y @ Cruzancla, en twitter } \\
\text { R: Ahora nos vamos a una pequeña pausa musical } \\
\text { V: Los dejamos con No pares de Julio Cañas }\end{array}$ & $\begin{array}{l}10 \min \\
12: 15- \\
12: 25\end{array}$ \\
\hline Bloque & No pares & $7 \mathrm{~min}$ \\
\hline
\end{tabular}




\begin{tabular}{|c|c|c|}
\hline Musical & Ocean of mercy & $\begin{array}{l}12: 33- \\
12: 40\end{array}$ \\
\hline $\begin{array}{l}\text { Proyectos o } \\
\text { temas (2) } \\
\text { Pan para mi } \\
\text { hermano } \\
\text { C y V }\end{array}$ & $\begin{array}{l}\text { V: Ya estamos de vuelta, estábamos escuchando a Ocean Of } \\
\text { mercy, de un grupo estadounidense llamado The Thirsting } \\
\text { Y les cuento que durante la semana estuvimos preguntando a } \\
\text { algunos agrupados qué expectativas tienen para hoy que cosa } \\
\text { esperan para hoy en la colecta así que vamos a escucharlos } \\
\text { Y bueno hay mucha expectativa, todos esperamos que sea un } \\
\text { éxito esta colecta para poder llevar a muchos niños el } \\
\text { verdadero sentido de la navidad } \\
\text { Ahora nos vamos con Viva cristo Rey y sigamos colectando!! }\end{array}$ & $\begin{array}{l}12 \mathrm{~min} \\
12: 40- \\
12: 52\end{array}$ \\
\hline $\begin{array}{l}\text { Bloque } \\
\text { Musical }\end{array}$ & $\begin{array}{l}\text { Viva cristo Rey } \\
\text { navidad }\end{array}$ & $\begin{array}{l}7 \min \\
12: 52-\end{array}$ \\
\hline $\begin{array}{l}\text { Agenda } \\
\text { y despedida } \\
\text { C, R y V }\end{array}$ & $\begin{array}{l}\text { CALENDARIO EMEVECISTA } \\
\text { El } 8 \text { de diciembre es la Misa por la Familia Sodálite } \\
\text { Me han dicho que en esos días va a haber chifa masivo también, } \\
\text { no sé pero se vienen cosas muy buenas para diciembre } \\
\text { V: Nos despedimos hasta el próximo sábado a las } 12\end{array}$ & $7 \mathrm{~min}$ \\
\hline Música & Música & $5 \mathrm{~min}$ \\
\hline & TIEMPO TOTAL & $60 \mathrm{~min}$ \\
\hline \multicolumn{3}{|c|}{$\begin{array}{l}\text { Tema: El adviento } \\
\text { PROGRAMA RADIAL: Cruz Ancla, } \\
\text { HORARIO: Sábados 12am, } \\
\text { DURACIÓN: } 1 \text { hora }\end{array}$} \\
\hline SEGMENTO & \begin{tabular}{|l|} 
TEXTO \\
\end{tabular} & TIEMPO \\
\hline Presentación & $\begin{array}{l}\text { Presentación creativa/entretenida del programa } \\
\text { r: Bienvenidos } \\
\text { C: Yo soy Raúl } \\
\text { C: Y esta es una nueva emisión de Cruz Ancla } \\
\text { R: Y empezamos con mucha alegría porque estamos en un } \\
\text { nuevo tiempo } \\
\text { C:Así es, tenemos toda la alegría del adviento, ya falta poco } \\
\text { para la llegada del Señor } \\
\text { R:Y justamente queremos hablar el día de hoy sobre este } \\
\text { tiempo litúrgico tan bonito y especial } \\
\text { C: Para seguir preparando los caminos del Señor, preparar } \\
\text { nuestros corazones y aprovechar este tiempo } \\
\text { V: Así es, seguiremos conversando sobre esto después de } \\
\text { escuchar algo de música } \\
\text { R: Los dejamos con Ven Pronto Señor }\end{array}$ & $\begin{array}{l}10 \mathrm{~min} \\
12-12: 10\end{array}$ \\
\hline
\end{tabular}




\begin{tabular}{|c|c|c|}
\hline Bloque Musical & (1 canción) & $\begin{array}{l}4 \min \\
12: 10- \\
12: 15\end{array}$ \\
\hline $\begin{array}{l}\text { Diálogo } \\
\text { Actualidad }\end{array}$ & $\begin{array}{l}\text { C: Ya estamos de vuelta en CRUZ ANCLA, estuvimos } \\
\text { escuchando a Las Siervas } \\
\text { Y estábamos conversando sobre el adviento } \\
\text { Ahora tenemos algunos audios con las impresiones de varios } \\
\text { emevecistas sobre el adviento } \\
\text { Y ahora los dejamos con Regalos a Jesús }\end{array}$ & $\begin{array}{l}10 \mathrm{~min} \\
12: 15- \\
12: 25\end{array}$ \\
\hline Bloque Musical & ( 2 canciones) & $\begin{array}{l}7 \text { min } \\
12: 33- \\
12: 40\end{array}$ \\
\hline $\begin{array}{l}\text { Proyectos o } \\
\text { temas (2) }\end{array}$ & $\begin{array}{l}\text { C: Ya estamos de vuelta y seguiremos conversando sobre } \\
\text { el adviento } \\
\text { Ahora nos acompaña Ricardo Salas para comentarnos un } \\
\text { poco más sobre este tiempo } \\
\text { Hola Ricardo, Cuéntanos } \\
\text { ¿Por qué es importante aprovechar este tiempo? } \\
\text { ¿Qué cosas ha dicho el Papa últimamente que nos puedan } \\
\text { guiarnos o ayudarnos a vivir el adviento? } \\
\text { ¿Cuál es el papel de la Virgen María en este tiempo? } \\
\text { ¿Qué de especial tiene este adviento iniciando el año de la } \\
\text { misericordia? }\end{array}$ & $\begin{array}{l}12 \mathrm{~min} \\
12: 40- \\
12: 52\end{array}$ \\
\hline Bloque Musical & (Dos canciones) & $\begin{array}{l}7 \text { min } \\
12: 52-\end{array}$ \\
\hline $\begin{array}{l}\text { Agenda } \\
\text { Y despedida }\end{array}$ & $\begin{array}{l}\text { CUÑA: Calendario emevecista! } \\
\text { R: Y bueno hoy es el rosario por el año de la Misericordia en } \\
\text { todos los centros pastorales } \\
\text { en el Centro Apostólico NSR después del rosario habrá una } \\
\text { jornada de Adviento } \\
\text { En Jesús María tienen Star entre Hermanos que se ve que va a } \\
\text { estar genial } \\
\text { Y el Martes } 8 \text { es la Misa de Aniversario del Sodalicio de Vida } \\
\text { Cristiana a las } 12 \text { y luego tendremos el almuerzo pro fondos de } \\
\text { Jesús María, vamos a comer un rico pollo a la brasa } \\
\text { Y eso es todo por ahora, esto ha sido el Calendario emevecista } \\
\text { Ha llegado el momento de despedirnos } \\
\text { C: Esto fue CRUZ ANCLA }\end{array}$ & $7 \mathrm{~min}$ \\
\hline \multirow[t]{2}{*}{ Música } & $\begin{array}{c}\text { Música } \\
\bullet\end{array}$ & $5 \mathrm{~min}$ \\
\hline & TIEMPO TOTAL & $60 \mathrm{~min}$ \\
\hline
\end{tabular}

\section{PAUTA RADIAL 8}


Tema: Signo de contradicción y conoce a los emevecistas

PROGRAMA RADIAL: Cruz Ancla

HORARIO: Sábados 11am

DURACIÓN: 1 hora

\begin{tabular}{|c|c|c|}
\hline SEGMENTO & TEXTO & TIEMPO \\
\hline 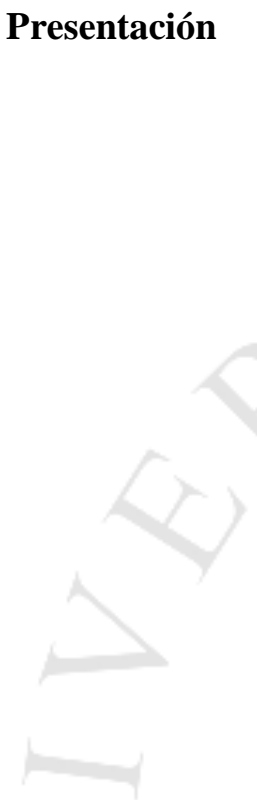 & $\begin{array}{l}\text { R: Bienvenidos a CRUZ ANCLA!! } \\
\text { D: Bienvenidos hoy a una nueva emisión del programa } \\
\text { R: Gracias por acompañarnos } \\
\text { D: Yo soy Daniela } \\
\text { R: Yo soy Raúl } \\
\text { D: y les tenemos un programa muy chévere } \\
\text { R: Primero tendremos al gran Roberto Chumbimuni, que } \\
\text { nos contará sobre uno de sus proyectos más conocidos: } \\
\text { signo de contradicción } \\
\text { D: Y luego continuaremos con una entrevista que hicimos } \\
\text { a nuestros amigos agrupados de Talara que estuvieron } \\
\text { aquí en Lima durante la Semana Emevecista } \\
\text { R: Por qué es bueno que podamos conocer a los } \\
\text { agrupados de distintos lugares } \\
\text { D: así es } \\
\text { R: Entonces vamos a escuchar algo de música antes de } \\
\text { continuar } \\
\text { Los dejamos con No pares de Julio Cañas }\end{array}$ & 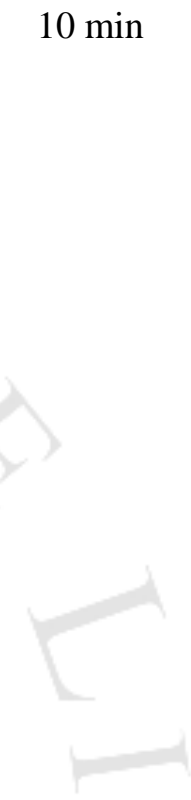 \\
\hline Musica & Julio cañas no pares & $4 \mathrm{~min}$ \\
\hline $\begin{array}{l}\text { Diálogo } \\
\text { Actualidad }\end{array}$ & $\begin{array}{l}\text { Ya estamos de vuelta } \\
\text { Y queremos hablar de una iniciativa que creo que ya } \\
\text { todos conocemos } \\
\text { Se trata de Signo de contradicción } \\
\text { R: Muy bien ya estamos con Roberto } \\
\text { - Para los que todavía no saben muy bien cuéntanos un } \\
\text { poco de qué se trata? } \\
\text { - Quienes conforman el equipo? } \\
\text { - ? } \\
\text { - Qué planes o proyectos tienen para este año? } \\
\text { R: muy bien ahora vamos a escuchar el nuevo hit del } \\
\text { verano, no mentira, pero es una gran canción:"Who says } \\
\text { you can't be a saint" de los BOSCO BOYS }\end{array}$ & $10 \mathrm{~min}$ \\
\hline \multirow[t]{2}{*}{$\begin{array}{l}\text { Bloque } \\
\text { Musical }\end{array}$} & $\begin{array}{l}\text { Bosco boys } \\
\text { Siervas }\end{array}$ & $7 \mathrm{~min}$ \\
\hline & $\begin{array}{l}\text { C: Hemos vuelto y queremos seguir conociendo a los } \\
\text { agrupados } \\
\text { R: Así es qué les compartimos una entrevista qué } \\
\text { hicimos durante la semana emevecista a nuestros } \\
\text { hermanos agrupados de talara } \\
\text { R: comentario sobre la entrevista }\end{array}$ & $12 \mathrm{~min}$ \\
\hline
\end{tabular}




\begin{tabular}{|c|c|c|}
\hline & $\begin{array}{l}\text { Qué bien qué bonito, ojala podamos seguir conociendo } \\
\text { a los emevecistas de todas partes del mundo } \\
\text { no se olviden de comentar, pueden hacer sus pedidos } \\
\text { también y chequear nuestro Facebook porque ahí } \\
\text { estaremos publicando información sobre las nuevas } \\
\text { canciones y las nuevas bandas } \\
\text { Ahora vamos con un grupo nuevo en la radio, vamos a } \\
\text { escuchar a estación cero con "te doy mi corazón" }\end{array}$ & \\
\hline $\begin{array}{l}\text { Bloque } \\
\text { Musical }\end{array}$ & te doy mi corazón" & $7 \mathrm{~min}$ \\
\hline $\begin{array}{l}\text { Agenda } \\
\text { Y despedida }\end{array}$ & $\begin{array}{l}\text { CUÑA: Calendario emevecista! } \\
\text { R: } \\
\text { D: Encuentro de voluntarios MPLV este sábado } \\
\text { R-: el } 4 \text { de marzo hay una charla en Jesús María sobre la } \\
\text { misericordia busquen info en su fanpage } \\
\text { Antes de irnos quisiera mandar saludos a Jessica } \\
\text { Chirinos y a Rafael Ismodes qué cumplen años hoy día. } \\
\text { Y saludos también a Antonio González de Chile, Valeria } \\
\text { Radio y Katy Dávila de Perú qué cumplen años este fin } \\
\text { de semana. } \\
\text { R: Bueno, esto ha sido CRUZ ANCLA } \\
\text { D: } \\
\text { R: Hasta el próximo VIERNES!! }\end{array}$ & + \\
\hline Música & Música $•$ Mauricio & $5 \mathrm{~min}$ \\
\hline & TIEMPO TOTAL & $60 \mathrm{~min}$ \\
\hline
\end{tabular}

\section{PAUTA RADIAL 9}

Tema: Cómo evangelizar a través de tu carrera

PROGRAMA RADIAL: Cruz Ancla

HORARIO: Sábados $11 \mathrm{am}$

DURACIÓN: 1 hora

\begin{tabular}{|c|l|c|}
\hline SEGMENTO & TEXTO & TIEMPO \\
\hline Presentación & R: Bienvenidos a CRUZ ANCLA!! & 5 min \\
& V: Bienvenidos hoy a una nueva emisión del programa & \\
& R: y miren a quién tenemos de vuelta & \\
& V: Hola qué tal..... & \\
& R: nos alegra que estés de nuevo con nosotros & \\
& R: Bueno hoy tenemos un gran programa para ustedes & \\
\hline
\end{tabular}




\begin{tabular}{|c|c|c|}
\hline & $\begin{array}{l}\text { V: tenemos dos invitados especiales qué nos van a hablar } \\
\text { sobre cómo hacer apostolado a través de nuestra carrera } \\
\text { R: y en general a través de los conocimientos qué } \\
\text { tenemos, porque a veces puede ser difícil para algunos } \\
\text { encontrar una forma en qué nuestras carreras nos ayuden } \\
\text { a hacer apostolado } \\
\text { V: Y luego continuaremos con una entrevista que hicimos } \\
\text { a nuestros amigos agrupados de Talara que estuvieron } \\
\text { aquí en Lima durante la Semana Emevecista } \\
\text { R: Así qué nuestros invitados van a contarnos un poco } \\
\text { sobre su experiencia } \\
\text { V: pronto les diremos quiénes son, pero primero } \\
\text { escuchemos a Julio cañas con su canción SIGUEME }\end{array}$ & \\
\hline Musica & Julio cañas sígueme & $4 \mathrm{~min}$ \\
\hline $\begin{array}{l}\text { Diálogo } \\
\text { Actualidad }\end{array}$ & $\begin{array}{l}\text { V:Ya estamos de vuelta } \\
\text { R: la canción qué estuvimos escuchando se llama Quiero } \\
\text { adorarte del grupo peruano TABOR } \\
\text { V: Y ahora queremos presentar a nuestro primer invitado } \\
\text { R: Se trata de.... } \\
\text { Hola cómo estás } \\
\text { - ¿A qué te dedicas? ¿Dónde trabajas? } \\
\text { - Cuál es tu experiencia como católico en ese lugar } \\
\text { - ¿Cómo haces apostolado a través de tu carrera? } \\
\text { - } \\
\text { R: Muchas gracias por haber venido } \\
\text { V: Ahora los dejamos con A dónde iré pero no se vayan } \\
\text { porque llega el siguiente invitado }\end{array}$ & $10 \min$ \\
\hline $\begin{array}{l}\text { Bloque } \\
\text { Musical }\end{array}$ & A dónde iré & $7 \mathrm{~min}$ \\
\hline 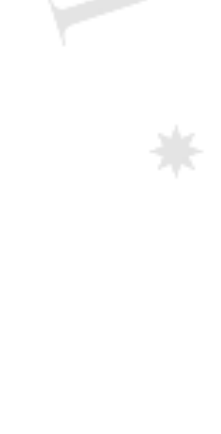 & $\begin{array}{l}\text { C: Hemos vuelto para seguir conversando } \\
\text { V: Y ahora nos acompaña..... } \\
\text { Hola cómo estás } \\
\text { • ¿A qué te dedicas? ¿Dónde trabajas? } \\
\text { • Cuál es tu experiencia como católico en ese lugar } \\
\text { • ¿Cómo haces apostolado a través de tu carrera? } \\
\text { R: Muchas gracias por haber venido } \\
\text { V: Ahora los dejamos con "espíritu de Dios" del grupo } \\
\text { Estación cero }\end{array}$ & $12 \mathrm{~min}$ \\
\hline $\begin{array}{l}\text { Bloque } \\
\text { Musical }\end{array}$ & "espíritu de Dios" del Grupo Estación cero & $7 \mathrm{~min}$ \\
\hline $\begin{array}{l}\text { Agenda } \\
\text { Y despedida }\end{array}$ & $\begin{array}{l}\text { CUÑA: Calendario emevecista! } \\
\text { R: Ya estamos con el esperado calendario } \\
\text { V: Y les comentamos qué mañana a las } 6 \text { de la tarde se } \\
\text { realizará una charla sobre La participación de los } \\
\text { cristianos en la política, será en el cp Jesús María a las }\end{array}$ & $7 \mathrm{~min}$ \\
\hline
\end{tabular}




\begin{tabular}{|l|l|l|} 
& 6pm no se olviden porque se ve súper interesante & \\
& R: Por otro lado no se olviden qué el 12 de marzo es la \\
gran MARCHA POR LA VIDA, vayamos todos a & \\
marchar por el primer derecho & \\
& $\begin{array}{l}\text { V: Bueno, esto ha sido CRUZ ANCLA } \\
\text { R: Yo soy Raúl } \\
\text { V: y yo Valentina } \\
\text { R: Hasta el próximo VIERNES!! }\end{array}$ & \\
\hline Música & $\begin{array}{l}\text { Música } \\
\bullet \quad \text { Mauricio }\end{array}$ & \\
\hline & TIEMPO TOTAL & 5 min \\
\hline
\end{tabular}

\section{PAUTA RADIAL 10}

Tema: La importancia de la mujer en la iglesia PROGRAMA RADIAL: Cruz Ancla HORARIO: Viernes 4pm DURACIÓN: 1 hora

\begin{tabular}{|c|c|c|}
\hline SEGMENTO & TEXTO & TIEMPO \\
\hline Presentación & $\begin{array}{l}\text { C: Bienvenidos a CRUZ ANCLA!! } \\
\text { V: Bienvenidos hoy a una nueva emisión del programa } \\
\text { C: y miren a quién tenemos de vuelta } \\
\text { V: Hola qué tal..... } \\
\text { C: nos alegra que estés de nuevo con nosotros } \\
\text {...COMENTAN } \\
\text { R: Bueno hoy tenemos un gran programa para ustedes } \\
\text { V: Así es, hoy hablaremos sobre las mujeres y cuál es su } \\
\text { papel dentro de la Iglesia } \\
\text { C: Para hablar de esto tenemos algunas invitadas qué } \\
\text { vamos a presentar más adelante } \\
\text { V: Y luego comentaremos también algunas cosas sobre la } \\
\text { Marcha Por la Vida } \\
\text { R: Así es, ya está quedando todo para el día de mañana } \\
\text { C: Si, hemos estado trabajando toda la semana ahí pero } \\
\text { eso les contaré más adelante } \\
\text { V: Sí, ahora Vamos a escuchar algo de música y luego } \\
\text { seguimos con el programa, los dejamos con Madre de la } \\
\text { ternura }\end{array}$ & \\
\hline Musica & Madre de la ternura & $5 \mathrm{~min}$ \\
\hline $\begin{array}{l}\text { Diálogo } \\
\text { Actualidad }\end{array}$ & $\begin{array}{l}\text { V: Ya estamos de vuelta con CRUZ ANCLA y para } \\
\text { poder conocer un poco más de nuestro tema de hoy, } \\
\text { tenemos a unas invitadas } \\
\text { R: Y ahora queremos presentar a nuestras invitadas: por } \\
\text { un lado tenemos a Melissa Vásquez, ella es agrupada del }\end{array}$ & $20 \mathrm{~min}$ \\
\hline
\end{tabular}




\begin{tabular}{|c|c|c|}
\hline & $\begin{array}{l}\text { centro apostólico Nuestra señora de la Reconciliación. } \\
\text { Hola Melissa cómo estas........ } \\
\text { V. y también nos acompaña } \\
\text { R: } \\
\text { • ¿Cómo ves qué participan las mujeres dentro de } \\
\quad \text { la iglesia? } \\
\text { - ¿Cuál es su papel concreto? } \\
\text { ¿por qué no puede hacer cosas cómo ser } \\
\text { R: Muchas gracias por haber venido } \\
\text { C: Ahora los dejamos con Septiembre, una canción qué } \\
\text { habla sobre la dulce espera de una madre ¡no se } \\
\text { desconecten! }\end{array}$ & \\
\hline $\begin{array}{l}\text { Bloque } \\
\text { Musical }\end{array}$ & $\begin{array}{l}\text { Septiembre } \\
\text { Nuestro primer derecho }\end{array}$ & $7 \mathrm{~min}$ \\
\hline Presen & $\begin{array}{l}\text { R: Ya estamos de vuelta } \\
\text { C: para Conversar sobre la Marcha Por La Vida qué se } \\
\text { va a realizar mañana } \\
\text { R: Justo estuvimos escuchando la canción oficial de } \\
\text { este año } \\
\text { C: Así es y este año tenemos que ser muchos los que } \\
\text { vayamos para levantar la voz por los más pequeños } \\
\text { R: Y como les comentamos al inicio del programa, } \\
\text { Carlos nos quiere contar como van los preparativos } \\
\text { R: Sí, así es, ya va quedando todo, esperamos que } \\
\text { vayan setecientos mil personas así que ojalá vayan } \\
\text { muchos más. } \\
\text { R: así es, y muchos estaremos ahí también como } \\
\text { voluntarios ayudando desde temprano } \\
\text { R: Ya son las } 4: 48 \text { pm, Ahora los dejamos con “Vine a } \\
\text { conquistarte” qué fue la canción de la Marcha Por la Vida } \\
\text { del año pasado, ya volvemos }\end{array}$ & $15 \mathrm{~min}$ \\
\hline $\begin{array}{l}\text { Bloque } \\
\text { Musical }\end{array}$ & $\begin{array}{l}\text { Vine a conquistarte } \\
\text { Esperanza }\end{array}$ & $7 \mathrm{~min}$ \\
\hline $\begin{array}{l}\text { Agenda } \\
\text { Y despedida }\end{array}$ & $\begin{array}{l}\text { CUÑA: Calendario emevecista! } \\
\text { R: Ya estamos con el esperado calendario } \\
\text { C: En primer lugar tenemos a la marcha por la vida este } \\
\text { domingo } \\
\text { R: El próximo jueves } 17 \text { de marzo s las } 8 \mathrm{pm} \text { en Jesús } \\
\text { María se dará la charla "Los Salmos de la Misericordia". } \\
\text { C: También Se viene semana santa y Además se viene } \\
\text { un súper concierto con Tony Meléndez, qué lo estuvimos } \\
\text { escuchando hace un rato, Estación cero y Daniel Armas. }\end{array}$ & $7 \mathrm{~min}$ \\
\hline
\end{tabular}


Será el 30de abril en la explanada del monumental, ya pronto salen a la venta las entradas

va a estar genial

$\mathrm{R}$ : Eso es todo y antes de irnos queremos mandar algunos saludos:

- Alexa correa

- Wendy

- Mariali Ismodes

- Franco Mori

C: Y además queremos enviarle un Saludo a Andrea Farro, ella fue la que nos dio la idea de hablar de la importancia de la mujer en la Iglesia, gracias Andrea!

R: esto ha sido CRUZ ANCLA. Yo soy Raúl

C: y yo Valentina

R: Hasta el próximo VIERNES!!

\begin{tabular}{l|l|l}
\hline Música & $\begin{array}{c}\text { Música } \\
\bullet \quad \text { Mauricio }\end{array}$ & $5 \mathrm{~min}$ \\
\hline & TIEMPO TOTAL & $60 \mathrm{~min}$ \\
\hline
\end{tabular}

PAUTA RADIAL 11

Tema: Semana Santa: ¿Cómo vivirla si viajo? /Mensaje del Papa

PROGRAMA RADIAL: Cruz Ancla

HORARIO: Viernes 4pm

DURACIÓN: 1 hora

\begin{tabular}{|c|c|c|}
\hline SEGMENTO & TEXTO & TIEMPO \\
\hline Presentación & $\begin{array}{l}\text { R: Bienvenidos a CRUZ ANCLA!! } \\
\text { D: Bienvenidos hoy viernes a una nueva emisión del programa } \\
\text { R: Yo soy } \\
\text { D: Y yo soy } \\
\text { R: Y hoy tenemos un gran programa especial para ustedes } \\
\text { pensando en la siguiente semana } \\
\text { D: Así es, ya llega Semana Santa y de hecho todos queremos } \\
\text { aprovechar este tiempo al máximo } \\
\text { R: por eso primero tendremos una pequeña reflexión sobre este } \\
\text { tiempo } \\
\text { D: Así es, y luego hablaremos una situación que de hecho a } \\
\text { muchos les ha pasado o quizá van a vivir en estos días: Viajar en } \\
\text { Semana Santa. } \\
\text { R Muchas veces nosotros queremos pasar Semana Santa en } \\
\text { nuestras parroquias, en nuestros centros o con nuestras } \\
\text { agrupaciones, pero a veces la familia o también los amigos } \\
\text { quieren aprovechar este tiempo para viajar juntos. }\end{array}$ & $3 \min$ \\
\hline
\end{tabular}




\begin{tabular}{|c|c|c|}
\hline & $\begin{array}{l}\text { D Hemos recogido algunos consejos que pueden ser muy útiles } \\
\text { para ustedes y también podrán comentar si ya han tenido esta } \\
\text { experiencia, escríbannos en Facebook o twitter y nosotros } \\
\text { leeremos al aire sus comentarios } \\
\text { R Recuerden que nos encuentran como CRUZ ANCLA en twitter } \\
\text { y Facebook } \\
\text { D Ahora vamos a escuchar un par de canciones y luego } \\
\text { regresamos } \\
\text { R Los dejamos con "Porque estoy vivo" de Tony Meléndez" }\end{array}$ & \\
\hline Música & $\begin{array}{l}\text { Porque estoy vivo } \\
\text { Mat Maher }\end{array}$ & $5 \mathrm{~min}$ \\
\hline $\begin{array}{l}\text { Diálogo } \\
\text { Actualidad }\end{array}$ & $\begin{array}{l}\text { D: Ya estamos de vuelta con CRUZ ANCLA } \\
\text { Y como les comentaba hemos recogido } \\
\text { y queremos aprovechar de compartirles un extracto de la charla } \\
\text { qué se realizó ayer en el Centro Apostólico NSR (Camacho) a } \\
\text { cargo de Ricardo Braz } \\
\text { D: La charla estuvo titulada ¿Cómo vivir la Semana santa? y les } \\
\text { vamos a compartir una parte que nos gustó mucho. } \\
\text { AUDIO } \\
\text { R Muy bien se ve qué estuvo muy buena, qué interesante e } \\
\text { importante meditar en torno a lo qué significa la Semana Santa y } \\
\text { todo lo que se vive en este tiempo } \\
\text { D Si, recordemos qué hay que vivirla como si estuviéramos en } \\
\text { Jerusalén y otra cosa qué mencionó Ricardo fue qué lo más } \\
\text { importante es la disposición con qué participemos en Semana } \\
\text { santa, la actitud con qué vamos a las actividades } \\
\text { R : bueno, vamos a seguir comentando sobre semana santa más } \\
\text { adelante pero Ahora los dejamos con "Mi dulce amor" de } \\
\text { estación cero }\end{array}$ & $8 \mathrm{~min}$ \\
\hline \multirow[t]{2}{*}{$\begin{array}{l}\text { Bloque } \\
\text { Musical }\end{array}$} & $\begin{array}{l}\text { Mi dulce amor } \\
\text { quien dices qué soy }\end{array}$ & $7 \mathrm{~min}$ \\
\hline & $\begin{array}{l}\text { R: Ya estamos de vuelta } \\
\text { D Y ahora vamos a hablar del tema qué han estado esperando } \\
\text { R ¿Cómo hago para vivir la Semana santa si voy a estar de viaje? } \\
\text { R Definitivamente esto depende mucho del lugar al qué nos } \\
\text { vamos. Si se trata del Perú es más fácil qué encontremos } \\
\text { parroquias a dónde ir a Misa en incluso procesiones y otras } \\
\text { celebraciones por todos lados. } \\
\text { D Pero también puede ser qué nos toque irnos a otros países } \\
\text { donde la cultura es diferente } \\
\text { R Así es, pero de todas maneras es básico primero buscar en } \\
\text { internet al respecto } \\
\text { D Podemos buscar parroquias cercanas al lugar donde nos vamos } \\
\text { a hospedar y ver qué actividades tendrán y los horarios de las } \\
\text { Misas } \\
\text { R Si, y de esta manera se pueden organizar e incluirlo si es qué } \\
\text { tienen ya un itinerario para visitar distintos lugares } \\
\text { Y, ahora queremos escuchar algunos audios qué nos han enviado } \\
\text { contándonos sus experiencias pasando Semana Santa en otros } \\
\text { lugares. } \\
\text { AUDIO }\end{array}$ & $15 \mathrm{~min}$ \\
\hline
\end{tabular}




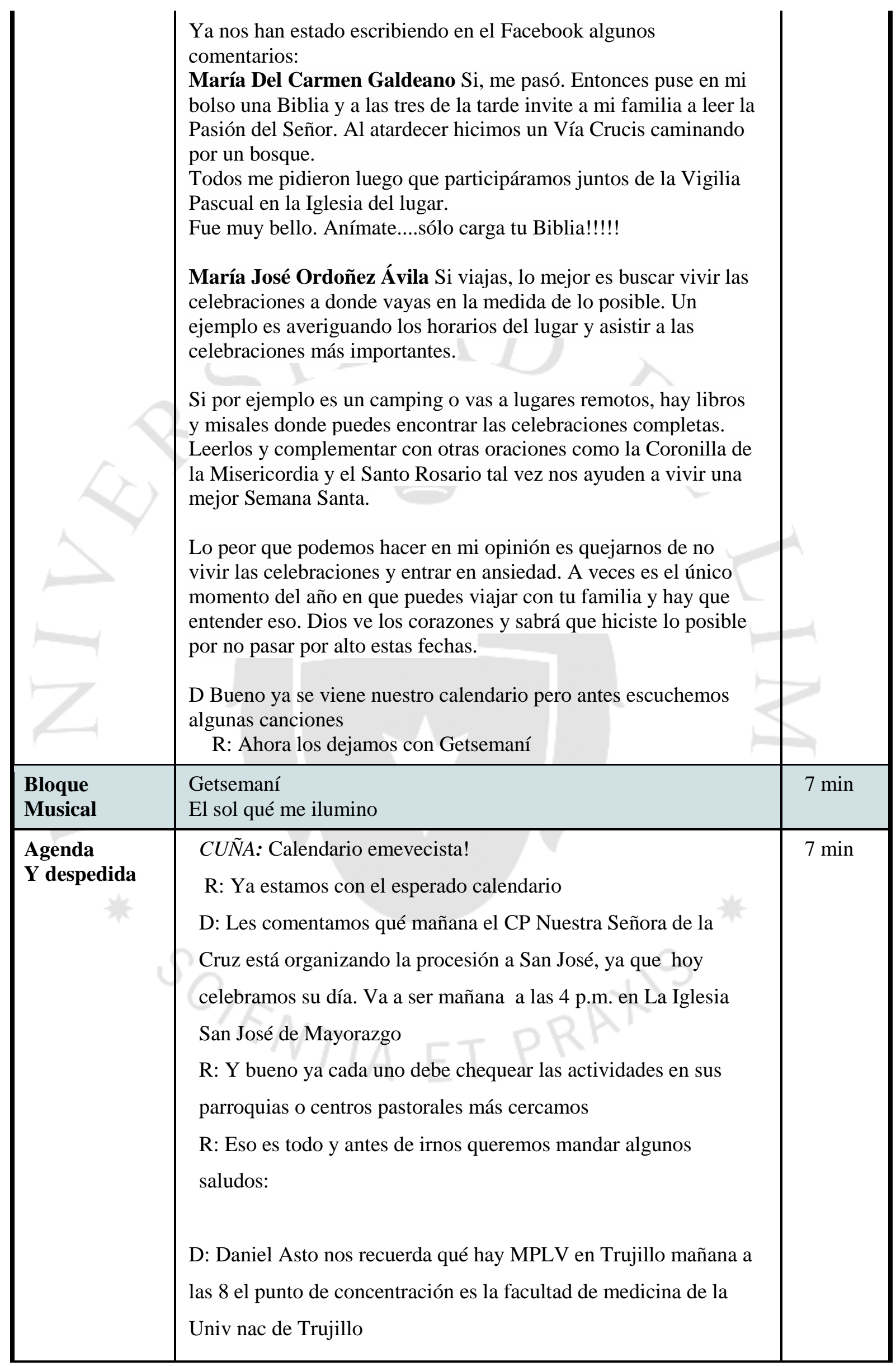




\begin{tabular}{|l|l|l|} 
& & \\
& R: eso fue todo por hoy & \\
& D: Ya saben aprovechen al máximo su Semana Santa & \\
& La otra semana les tendremos varias sorpresas & \\
& R: Hasta el próximo VIERNES!! & \\
\hline Música & Música & 5 min \\
\hline & TIEMPO TOTAL & $60 \mathrm{~min}$ \\
\hline
\end{tabular}

\section{PAUTA RADIAL 12}

Tema: Ser católico en la universidad PROGRAMA RADIAL: Cruz Ancla HORARIO: Viernes 4pm DURACIÓN: 1 hora

\begin{tabular}{|c|c|c|}
\hline SEGMENTO & TEXTO & TIEMPO \\
\hline Presentación & $\begin{array}{l}\text { A: Bienvenidos a una nueva emisión del programa } \\
\text { B: y Feliz Pascua para todos!! } \\
\text { A: Empezamos con toda la alegría que caracteriza este tiempo y } \\
\text { esperamos que hayan aprovechado su semana santa al máximo } \\
\text { B: No nos olvidemos de poner medios concretos qué nos permitan } \\
\text { seguir viviendo todo lo que el Espíritu haya podido suscitar en } \\
\text { nosotros } \\
\text { A: Y Bueno, hoy tenemos un programa especial para los universitarios } \\
\text { B: Aunque de hecho les puede servir a todos } \\
\text { A: porque Sabemos qué es difícil a veces mostrarnos como Católicos } \\
\text { y además lidiar con todo lo que podemos encontrarnos en el mundo } \\
\text { qué muchas veces puede ir en contra de nuestra fe } \\
\text { B: o a veces simplemente es difícil saber cómo hacer apostolado en } \\
\text { lugares como el colegio, la universidad o el trabajo. } \\
\text { A: Por eso hemos reunido algunos tips qué esperamos puedan } \\
\text { ayudarlos. } \\
\text { B: Pero antes de eso vamos a escuchar a Takillakta! }\end{array}$ & 3 min \\
\hline Musica & takillakkta & $5 \mathrm{~min}$ \\
\hline $\begin{array}{l}\text { Diálogo } \\
\text { Actualidad }\end{array}$ & $\begin{array}{l}\text { V: Ya estamos de vuelta con CRUZ ANCLA } \\
\text { Lo que uno normalmente aprende es que nació en Grecia, cosa que es } \\
\text { real, pero las universidades en que Newton, Rousseau, Napoleón, } \\
\text { Roosevelt o Lenin estudiaron no son como aquellas del Imperio } \\
\text { Griego. Los centros de estudios donde estuvieron Alejandro Magno, } \\
\text { Cesar Augusto o Poncio Pilatos no tenía facultades específicas, no } \\
\text { tenían una serie de libros pertenecientes a un curso determinado, no }\end{array}$ & $20 \mathrm{~min}$ \\
\hline
\end{tabular}




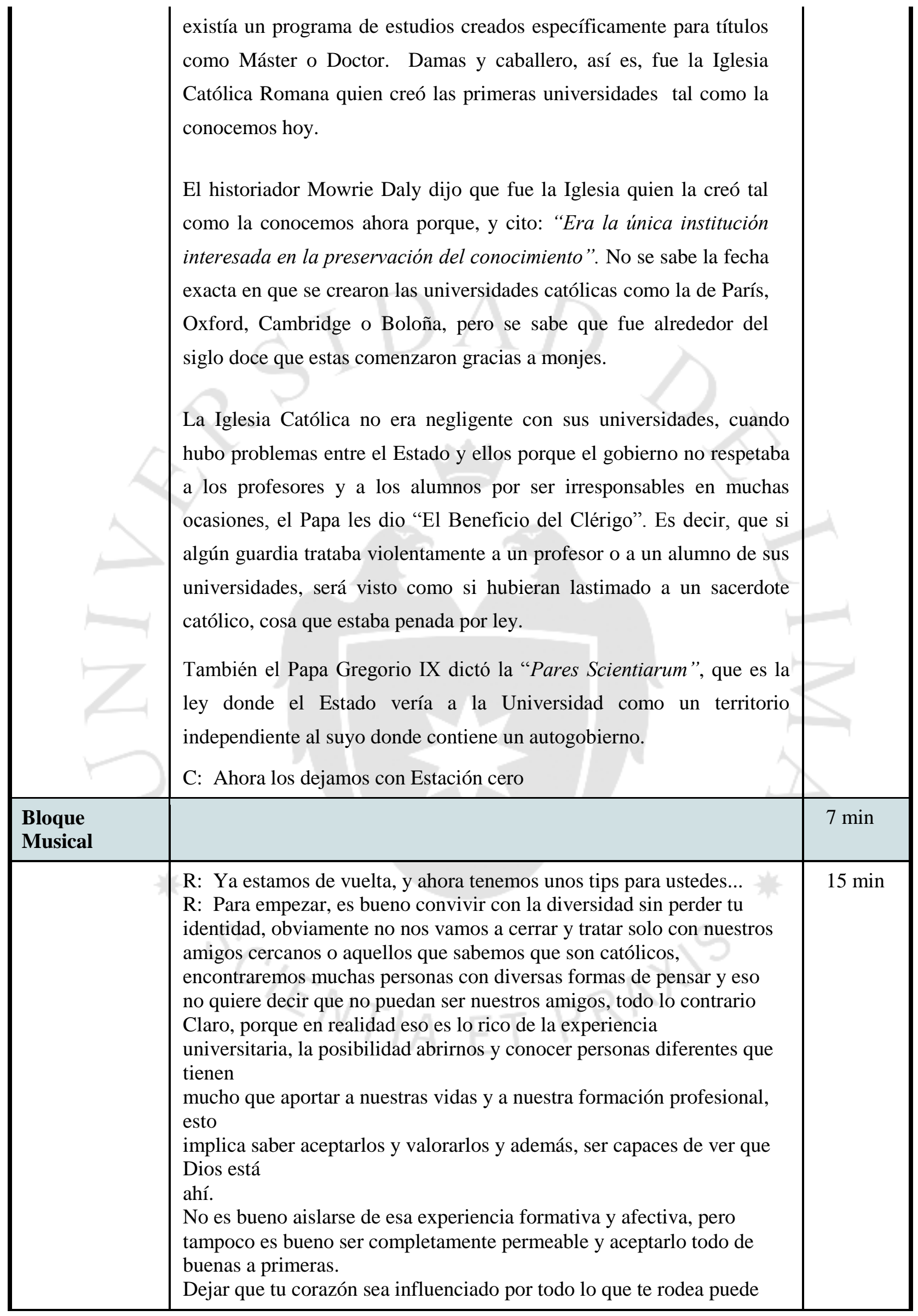


ser riesgoso, sobre todo para tu fe, hay que ir siempre alertas y pedirle al Señor que seamos capaces de discernir lo que es bueno para nosotros.

Así que disfruta de la diversidad, aprende de ella y desde tu realidad sé un aporte a los demás y no solo una esponja.

Otra cosa que ayuda mucho es mantenerse en oración a pesar de las muchas y distracciones que tenemos en la universidad. Que todas las responsabilidades y quehaceres no sean justificación para dejar tu tiempo con el Señor de lado.

Para esto es bueno recordar que nuestra vida cristiana se basa en una relación con Jesús y como toda relación, requiere de tiempo para irla cultivando.

Por eso es importantísimo que sepamos organizarnos y separar un tiempo fijo para el Señor en nuestra agenda.

Abrirse a la experiencia del encuentro con Jesús en la realidad Jesús está presente en todo lo que nos rodea, se hizo hombre y toda la experiencia humana se llenó de Dios. Es por eso que debemos ser humildes con nuestra fe y reconocer que Él está presente en personas y lugares incluso cuando no esperamos que sea así.

Si mantienes un corazón dócil, seguro te vas a llevar más de una sorpresa.

La fe es algo para compartirlo y vivirlo en público. No es algo íntimo que debes llevar bien escondida y que pocas personas conocen. No te avergüences de ella, pues tu testimonio de cristiano es tu mayor recurso de evangelización en medio del mundo.

Que el conocimiento y la ciencia no derrumben tus cimientos. Estudiar nos abre el entendimiento a nuevas formas de comprender el universo, la sociedad y las personas. Ese conocimiento, cuando es mal utilizado o cuando nuestros cimientos son frágiles puede hacer un gran daño en nuestra fe. Abraza el conocimiento y la ciencia, pero cuida tu fe al mismo tiempo.

Otro aspecto importante es mantener la fidelidad a la Eucaristía. Los que hemos estudiado en colegios católicos la teníamos fácil, nos organizaban Misas de forma periódica y nos llevaban obligados. Ahora nadie organiza Misas para ti ni te obliga, todo queda en tus manos.

Hay cosas que son fundamentales y participar en la Misa es una de ellas. No hay nada que sea más importante que eso y no puedes permitirte dejar de comulgar. Sé fiel, cuida tu tiempo para poder participar al menos los domingos en la Eucaristía.

Recuerda que puedes recurrir siempre a tu agrupación o consejero, hay que recordar que no estamos solos y no podemos solos, es bueno saber que somos parte de una iglesia y de un movimiento en donde podemos encontrar amigos en quienes sostenernos.

No te alejes de las periferias existenciales Querer cuidar la fe en medio del mundo universitario es algo noble y muy necesario, pero no tienes que marginarte, sobre todo no te alejes de las personas que creen que no necesitan a Dios en sus vidas. Debes ser luz, ahí donde hay oscuridad, luchar contra tus vergüenzas y temores y acercarte a la periferia, que quizás está en el pupitre de al lado o parado en el pasillo al salir del salón.

y hora escucharemos un audio qué nos han mandado

R: esto ha sido CRUZ ANCLA. Yo soy Raúl

C: y yo Valentina 


\begin{tabular}{|l|l|c|} 
& R: Hasta el próximo VIERNES!! & \\
\hline $\begin{array}{l}\text { Bloque } \\
\text { Musical }\end{array}$ & Esperanza de Toni Meléndez & $7 \mathrm{~min}$ \\
\hline $\begin{array}{l}\text { Agenda } \\
\text { Y despedida }\end{array}$ & & $7 \mathrm{~min}$ \\
\hline Música & & $5 \mathrm{~min}$ \\
\hline & TIEMPO TOTAL & $60 \mathrm{~min}$ \\
\hline
\end{tabular}

\section{PAUTA RADIAL 13}

Tema: Entrevista a NAVIS

PROGRAMA RADIAL: Cruz Ancla

HORARIO: Viernes 4pm

DURACIÓN: 1 hora

\begin{tabular}{|c|c|c|}
\hline SEGMENTO & TEXTO & $\begin{array}{l}\text { TIEM } \\
\text { PO }\end{array}$ \\
\hline Presentación & $\begin{array}{l}\text { R: Bienvenidos a CRUZ ANCLA! Yo soy Raúl } \\
\text { C:y yo soy Carlos y El día de hoy tenemos un gran programa } \\
\text { R: Se trata de un programa súper musical para que continuemos } \\
\text { conociendo los nuevos talentos que tenemos en nuestra iglesia } \\
\text { C: En la semana emevecista tuvieron su gran debut en los escenarios } \\
\text { y nos sorprendieron con grandes canciones } \\
\text { R: Ellos son Navis y están hoy con nosotros para contarnos un poco } \\
\text { sobre ellos y todas las novedades que han estado preparando para } \\
\text { nosotros } \\
\text { C: Bienvenidos } \\
\text { R. Gracias por acompañarnos } \\
\text { C: Bueno tenemos muchas preguntas para ustedes ya qué no todos } \\
\text { los emevecistas los conocen, no todos pudieron estar en el concierto } \\
\text { de la semana emevecista } \\
\text { R: Si quieren mandarles saludos o hacerles preguntas, escríbannos al } \\
\text { Facebook, comenten ahí y nosotros se las leeremos en el siguiente } \\
\text { bloque } \\
\text { R: Pero antes queremos empezar escuchando algunas de sus } \\
\text { canciones para ponernos en ambiente. Esto es: Contracorriente }\end{array}$ & $\begin{array}{l}4 \\
\min \end{array}$ \\
\hline \multirow[t]{2}{*}{$\begin{array}{l}\text { Bloque } \\
\text { Musical }\end{array}$} & & $\begin{array}{l}7 \\
\min \end{array}$ \\
\hline & $\begin{array}{l}\text { C: Ya estamos de vuelta, la canción qué estuvimos escuchando } \\
\text { fue multicolor } \\
\text { R: Estuvimos escuchando en exclusiva algunas de las canciones } \\
\text { de NAVIS } \\
\text { C: Están muy buenas!! y bueno ahora queremos conocer un poco } \\
\text { más de ustedes } \\
\text { Preséntense cada uno } \\
\text { • ¿Quiénes más conforman Navis? } \\
\text { • ¿de qué manera participan dentro del MVC o de la familia }\end{array}$ & $\begin{array}{l}10 \\
\min \end{array}$ \\
\hline
\end{tabular}




\begin{tabular}{|c|c|c|}
\hline & $\begin{array}{l}\text { espiritual? } \\
\text { ¿Cómo conocieron al mvc? (breve) } \\
\text { ¿Cómo surgió este grupo? } \\
\text { ¿quiénes componen las canciones? } \\
\text { ¿qué expectativas tienen? } \\
\text { C:bueno y ahora nos van a tocar algo } \\
\text { R: Recuerden qué pueden escribirles, mandarles saludos o } \\
\text { hacerles preguntas y en el siguiente bloque las leeremos. } \\
\text { C: mientras se preparan para tocar, escuchemos algunas } \\
\text { canciones, esto es porque estoy vivo de Tony Meléndez }\end{array}$ & \\
\hline $\begin{array}{l}\text { Bloque } \\
\text { Musical }\end{array}$ & & $\begin{array}{l}7 \\
\min \end{array}$ \\
\hline & $\begin{array}{l}\text { Muy bien, ahora sí ¿qué nos van a tocar? } \\
\text { Leen comentarios } \\
\text { Gabriela Domínguez nos dice: Creo que deberían salir de gira, } \\
\text { propongo a Ecuador como primer destino después de Lima! } \\
\text { Mara Alcedo dice: Un saludo a toda la banda de Navis! Tuve la } \\
\text { oportunidad de escucharlas en la Semana Emevecista, y me } \\
\text { encanto la propuesta... Definitivamente así lo quiso Dios... No } \\
\text { paren jejeje } \\
\text { Y Sesar del águila también les manda saludos } \\
\text { R: Les agradecemos un montón el que hayan venido } \\
\text { les deseamos muchos éxitos } \\
\text { Ahora los dejamos con una última canción suya que es Hacia El } \\
\text { Sol }\end{array}$ & \\
\hline $\begin{array}{l}\text { Bloque } \\
\text { Musical }\end{array}$ & & $\begin{array}{l}7 \\
\min \end{array}$ \\
\hline $\begin{array}{l}\text { Agenda } \\
\text { Y despedida }\end{array}$ & $\begin{array}{l}\text { CUÑA: Calendario emevecista! } \\
\text { R:En el callao visita al albergue de ancianos San Lucas los viernes } \\
\text { a las 10:30am. El albergue queda en el Callao, el punto de } \\
\text { encuentro es a las 10am en el cp Santa María de la Reconciliación } \\
\text { en Bellavista. Hay cupos limitados, tienen que coordinar con Carlos } \\
\text { Sánchez. } \\
\text { Y bueno como siempre rosarios los sábados a las } 6 \mathrm{pm} \text { (en ambos } \\
\text { centros), y misa en bocanegra a las } 8 \text { am y en bellavista a las 10am, } \\
\text { estamos invitados } \\
\text { C: Además, este Sábado tenemos la celebración de Pascua en el CP } \\
\text { San Borja a las } 4 \text { pm } \\
\text { R: y en Camacho es el gran lanzamiento apostólico por si quieren } \\
\text { estar al tanto de sus actividades } \\
\text { C: Además el } 23 \text { de abril se celebran los } 25 \text { años del CP de Jesús } \\
\text { María } \\
\text { R:Y este } 30 \text { de abril hay un conciertazo con Tony Meléndez y } \\
\text { Estación cero, va a estar increíble, ya pueden conseguir sus } \\
\text { entradas en teleticket } \\
\text { R: Bueno y como todos saben, hoy hay Pan para mi hermano a las } \\
7 \text { pm en Camacho y a las } 6: 30 \text { en mayorazgo }\end{array}$ & $\begin{array}{l}7 \\
\min \end{array}$ \\
\hline
\end{tabular}




\begin{tabular}{|l|l|l|} 
& C: y todos los jueves Panpa barranco a las 7:30 & \\
& $\begin{array}{l}\text { C: Y bueno se nos ha terminado el tiempo :( esto fue CRUZ } \\
\text { ANCLA } \\
\text { R: no se olviden de completar la encuesta que hemos publicado } \\
\text { para ver si cambiamos de horario } \\
\text { C: eso ha sido todo, Hasta el próximo VIERNES!! }\end{array}$ & \\
\hline Música & Música & \begin{tabular}{l} 
min \\
\hline
\end{tabular} \\
& TIEMPO TOTAL & $\begin{array}{l}60 \mathrm{~m} \\
\text { in }\end{array}$ \\
\hline
\end{tabular}

Tema:

PAUTA RADIAL 14

PROGRAMA RADIAL: Cruz Ancla

HORARIO: Viernes 4pm

DURACIÓN: 1 hora

\begin{tabular}{|c|c|c|}
\hline SEGMENTO & TEXTO & $\begin{array}{l}\text { TIEM } \\
\text { PO }\end{array}$ \\
\hline Presentación & $\begin{array}{l}\text { R: Bienvenidos a CRUZ ANCLA! Yo soy Raúl } \\
\text { R: Y para este programa les tenemos dos entrevistas qué hemos } \\
\text { hecho especialmente para ustedes y para seguir conociendo más } \\
\text { sobre lo que hay en el MVC } \\
\text { hace poco estuvimos con Alexa Correa, una agrupada de Piura y } \\
\text { estuvimos conversando con ella, así qué después de algunas } \\
\text { canciones, escucharemos la entrevista qué le hizo Raúl para saber } \\
\text { qué están haciendo nuestros hermanos emevecistas allá en Piura } \\
\text { y además más adelante en el programa les vamos a hacer una } \\
\text { invitación muy especial sobre todo a los universitarios de lima. Ya } \\
\text { volvemos, los dejamos con una canción de estación cero llamada } \\
\text { DONDE ESTES }\end{array}$ & min \\
\hline \multirow[t]{2}{*}{$\begin{array}{l}\text { Bloque } \\
\text { Musical }\end{array}$} & $\begin{array}{l}\text { Estación cero DONDE ESTES } \\
\text { A donde iré }\end{array}$ & $\begin{array}{l}7 \\
\min \end{array}$ \\
\hline & Entrevista pre grabada & $\begin{array}{l}10 \\
\min \end{array}$ \\
\hline \multirow[t]{2}{*}{$\begin{array}{l}\text { Bloque } \\
\text { Musical }\end{array}$} & $\begin{array}{l}\text { amistad } \\
\text { quien dices qué soy } \\
\text { no pares }\end{array}$ & $\begin{array}{l}7 \\
\min \end{array}$ \\
\hline & $\begin{array}{l}\text { C: Ya estamos de vuelta, la canción qué estuvimos escuchando } \\
\text { fue No pares de Julio cañas } \\
\text { y ahora tenemos unos audios qué nos han enviado invitándonos a } \\
\text { participar de una iniciativa especial para los universitarios, en este } \\
\text { caso de la universidad de lima } \\
\text { En los próximos programas seguiremos invitando a las }\end{array}$ & \\
\hline
\end{tabular}




\begin{tabular}{|c|c|c|}
\hline & $\begin{array}{l}\text { actividades de au de otras universidades } \\
\text { no se vayan porque viene el calendario emevecista } \\
\text { Los dejamos con Who says you can't be a Saint }\end{array}$ & \\
\hline $\begin{array}{l}\text { Bloque } \\
\text { Musical }\end{array}$ & $\begin{array}{l}\text { Who says you can't } \\
\text { Tony Melendez }\end{array}$ & $\begin{array}{l}7 \\
\min \end{array}$ \\
\hline $\begin{array}{l}\text { Agenda } \\
\text { Y despedida }\end{array}$ & $\begin{array}{l}\text { CUÑA: Calendario emevecista! } \\
\text {-Para empezar, en Camacho mañana Habrá noche deportiva } \\
\text { después del rosario de 5:30 } \\
\text {-En Cristo reconciliador habrá una tarde de Juegos después del } \\
\text { rosario, el rosario es a las } 5 \text { pm están invitados } \\
\text {-Además, como ya les hemos comentado, el } 23 \text { de abril se celebran } \\
\text { los } 25 \text { años del CP de Jesús María, habrá una gran celebración en la } \\
\text { Parroquia San Felipe Apóstol, a las 5pm. Vayamos todos en } \\
\text { mancha para celebrar con ellos } \\
\text { Y en Medellín Colombia } \\
\text {-Y este } 30 \text { de abril en lima hay un conciertazo con Tony Meléndez } \\
\text { y Estación cero, va a estar increíble, ya pueden conseguir sus } \\
\text { entradas en teleticket y quizá tengamos aquí en la radio alguna } \\
\text { sorpresa con respecto a este gran evento } \\
\text {-: Bueno y como todos saben, hoy hay Pan para mi hermano a las } \\
7 \text { pm en Camacho y a las } 6: 30 \text { en mayorazgo } \\
\text { C: y todos los jueves Panpa barranco a las 7:30 } \\
\text { Antes de irnos queremos pedirles a todos qué recen por Toti } \\
\text { Rodríguez ella es una agrupada qué va a ser operada este fin de } \\
\text { semana así qué cuenta con nuestras oraciones Toti!! } \\
\text { C: Y bueno se nos ha terminado el tiempo esto fue CRUZ } \\
\text { ANCLA } \\
\text { R: no se olviden de completar la encuesta que hemos publicado } \\
\text { para ver si cambiamos de horario } \\
\text { C: eso ha sido todo, Hasta el próximo VIERNES!! }\end{array}$ & $\begin{array}{l}7 \\
\min \end{array}$ \\
\hline \multirow[t]{2}{*}{ Música } & Música & $\begin{array}{l}5 \\
\min \end{array}$ \\
\hline & TIEMPO TOTAL & $\begin{array}{l}60 \mathrm{~m} \\
\text { in }\end{array}$ \\
\hline
\end{tabular}

\section{PAUTA RADIAL 15}

Tema: 25 aniversario del Centro Apostólico Jesús María

PROGRAMA RADIAL: Cruz Ancla

HORARIO: Sábados 11am

DURACIÓN: 1 hora

\begin{tabular}{|c|l|c|}
\hline SEGMENTO & TEXTO & TIEMPO \\
\hline Presentación & $\begin{array}{l}\text { R: Bienvenidos a CRUZ ANCLA!! } \\
\text { Hoy les tenemos preparado un programa especial por el } \\
\text { aniversario del Centro pastoral Jesús maría, así qué } \\
\text { estaremos con vario de los miembros de este centro } \\
\text { conversando y conociéndolos }\end{array}$ & 5 min \\
\hline
\end{tabular}




\begin{tabular}{|c|c|c|}
\hline & $\begin{array}{l}\text { y además tendremos como siempre su música católica } \\
\text { favorita } \\
\text { Así qué los dejamos con SIGUEME de Julio cañas }\end{array}$ & \\
\hline Musica & Julio cañas sígueme & $4 \mathrm{~min}$ \\
\hline $\begin{array}{l}\text { Diálogo } \\
\text { Actualidad }\end{array}$ & entrevista a los mayores & $10 \mathrm{~min}$ \\
\hline \multirow{2}{*}{$\begin{array}{l}\text { Bloque } \\
\text { Musical }\end{array}$} & A dónde iré & $7 \mathrm{~min}$ \\
\hline & entrevista a los jóvenes & $12 \mathrm{~min}$ \\
\hline $\begin{array}{l}\text { Bloque } \\
\text { Musical }\end{array}$ & "espíritu de Dios" del Grupo Estación cero & $7 \mathrm{~min}$ \\
\hline $\begin{array}{l}\text { Agenda } \\
\text { Y despedida }\end{array}$ & $\begin{array}{l}\text { CUÑA: Calendario emevecista! } \\
\text { Raúl: Bueno hemos regresado con el calendario } \\
\text { emevecista. Y si piensa que en el cp solo hay una } \\
\text { agrupada, iNO ES CIERTO! Con nosotros leyendo el } \\
\text { calendario tenemos a María Fernanda Vásquez. Hola } \\
\text { Mafer, bienvenida a la Radio. } \\
\text { María Fernanda: Hola... } \\
\text { Raúl: Gracias por venir de verdad. Más bien les tenemos } \\
\text { una sorpresa a los radioyentes y a los miembros del cp. } \\
\text { Han mandado audios importantes. ¿Vamos a } \\
\text { escucharlos? } \\
\text { María Fernanda: ¡Vamos! } \\
\text { ESCUHA DE AUDIOS. } \\
\text { María Fernanda Vásquez: ... } \\
\text { Raúl: Que bonito la verdad, han hablado el encargado del } \\
\text { MVC, el encargado del MVC Perú y Fabiola Trelles quien } \\
\text { estuvo apoyando al MVC Perú en estos tiempos. Desde la } \\
\text { radio y el cp, un saludo. Y bien vamos a comenzar con las } \\
\text { actividades. } \\
\text { María Fernanda: Sí! Quería invitarles a nuestra misa de } \\
\text { aniversario que se dará mañana a las 5pm en la Parroquia } \\
\text { San Felipe Apóstol. Queda en calle Marconi, 160 San } \\
\text { Isidro. } \\
\text { Raúl: En Camacho el lunes empieza un nuevo curso. "El } \\
\text { poder de la oración”. Es a las 7:30pm y si no llegas el } \\
\text { jueves a las 9:30pm. } 60 \text { soles en total. } \\
\text { María Fernanda: En María Guía, el } 30 \text { de abril hay un } \\
\text { festival de postres en María Guía. Es a las 6pm. } \\
\text { Raúl: Existe una colecta mundial de oraciones por el } \\
\text { último terremoto en Ecuador. La iniciativa se llama Pray } \\
\text { for Ecuador. Puede saber más en } \\
\text { www.prayforecuador.com. Fuerza para nuestros hermanos } \\
\text { agrupados de Guayaquil y Quito. Y para todos los } \\
\text { ecuatorianos. } \\
\text { Mafer: Ahora Raúl déjame saludar a los que cumplen } \\
\text { años. Es una fecha especial como CP y desde el CP les } \\
\text { mandamos saludos a: Andy Zevallos, que cumple años }\end{array}$ & 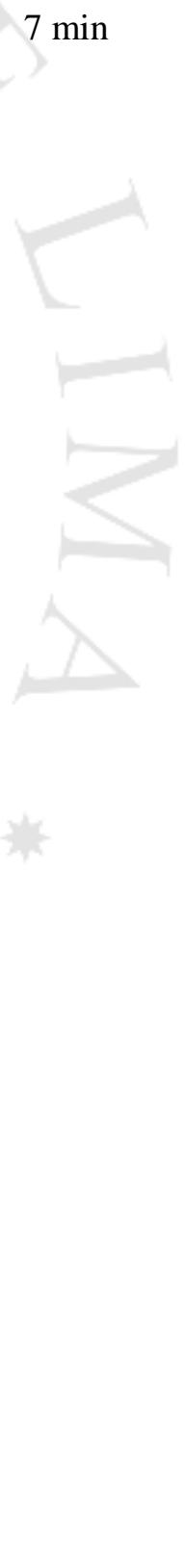 \\
\hline
\end{tabular}




\begin{tabular}{|l|l|l|} 
& $\begin{array}{l}\text { hoy. Al Padre Christian Yamanija que cumple años } \\
\text { mañana. Y a Jean Piere Ortiz, quien cumple años el } \\
\text { domingo. Y por supuesto, UN FELIZ CUMPLEAÑOS A } \\
\text { MI CP. FELIZ 25 AÑOS! } \\
\text { Raúl: Muy bien, esto fue Cruz Ancla, yo soy Raúl } \\
\text { González. } \\
\begin{array}{l}\text { Mafer: Y yo Maria Fernanda Vasquez. } \\
\text { Raúl: Y esto fue Radio Cruz Ancla. Nos vemos! } \\
\text { R:: Hasta el próximo VIERNES!! }\end{array}\end{array}$ & \\
\hline Música & $\begin{array}{l}\text { Música } \\
\bullet \quad \text { Mauricio }\end{array}$ & 5 min \\
\hline & TIEMPO TOTAL & $60 \mathrm{~min}$ \\
\hline
\end{tabular}

\section{PAUTA RADIAL 16}

Tema: Anécdotas solidarias

PROGRAMA RADIAL: Cruz Ancla

HORARIO: Sábados 11am

DURACIÓN: 1 hora

\begin{tabular}{|l|l|l|}
\hline $\begin{array}{l}\text { SEGME } \\
\text { NTO }\end{array}$ & TEXTO & $\begin{array}{l}\text { TIEM } \\
\text { PO }\end{array}$ \\
\hline $\begin{array}{l}\text { Presentac } \\
\text { ión }\end{array}$ & $\begin{array}{l}\text { R: Bienvenidos a CRUZ ANCLA!! } \\
\text { Yo Soy Raúl y quiero darle la Bienvenida a un nuevo miembro de la } \\
\text { radio, se trata de Alexandra del Castillo qué nos estará acompañando el } \\
\text { día de hoy, Bienvenida! } \\
\text { A: Hola Raúl muchas gracias.....estoy muy feliz de estar aquí en CRUZ } \\
\text { ANCLA... }\end{array}$ & $\begin{array}{l}\text { min } \\
\text { R: Bueno y hoy tenemos un tema muy interesante y qué espero que sea } \\
\text { entretenido también } \\
\text { A: Así es, hoy queremos hablar sobre nuestras experiencias en } \\
\text { actividades solidarias. } \\
\text { R: si, muchas veces ya en el programa hemos hablado de las distintas } \\
\text { iniciativas qué hay en el movimiento y qué están enfocadas en el servicio } \\
\text { solidario } \\
\text { A: pero ahora queremos qué ustedes nos cuenten sus experiencias y } \\
\text { también por qué creen que es importante participar siempre de este tipo } \\
\text { de actividades } \\
\text { R: por eso les pedimos qué participen y comenten en Facebook cuáles } \\
\text { han sido las anécdotas qué más recuerdan de todas las veces qué han ido } \\
\text { a pan para mi hermano, o a misiones } \\
\text { A: O a Navidad es Jesús, al cerro San Cristóbal, etc. } \\
\text { R: y si se trata de actividades o proyectos de otros países u otras partes } \\
\text { del Perú también nos pueden contar de qué se trata para así conocerlos. } \\
\text { A: Ahora escucharemos una canción de Matt Maher y luego volveremos } \\
\text { con nuestros invitados }\end{array}$ \\
$\begin{array}{l}\text { matt maher } \\
\text { Musica }\end{array}$ & \\
\hline
\end{tabular}




\begin{tabular}{|c|c|c|}
\hline $\begin{array}{l}\text { Diálogo } \\
\text { Actualida } \\
\text { d }\end{array}$ & $\begin{array}{l}\text { Ahora estamos con Gianfranco } \\
\text { Y queremos qué nos digas por qué es importante para ti participar de } \\
\text { proyectos solidarios } \\
\text { qué bien, ahora vamos a escuchar una canción y después contaremos } \\
\text { nuestras experiencias y anécdotas en actividades solidarias, recuerden que } \\
\text { nos pueden escribir y leeremos sus anécdotas al aire } \\
\text { Vamos a escuchar a julio cañas }\end{array}$ & $\begin{array}{l}10 \\
\min \end{array}$ \\
\hline $\begin{array}{l}\text { Bloque } \\
\text { Musical }\end{array}$ & & $\begin{array}{l}7 \\
\min \end{array}$ \\
\hline risenger & $\begin{array}{l}\text { R:Ya estamos de vuelta y ahora queremos compartir anécdotas y leer } \\
\text { algunas de las qué nos han compartido } \\
\text { Dani: recuerdas cuando nos canceló el bus? } \\
\text { Toti Rodríguez Robles Hace } 3 \text { años, en unas misiones en Huaraz, me } \\
\text { mandaron el primer día junto a una agrupada a reconocer el pueblo } \\
\text { (dormíamos en otro pueblo y al día siguiente teníamos que guiar a las } \\
\text { demás), en el camino dejé cáscaras de mandarina para que nos orienten, } \\
\text { al día siguiente no estaban las cáscaras, los burros se las comieron, } \\
\text { demoramos un montón en llegar } \\
\text { RAUL VEGA: Causa hablando de proyectos solidarios...Cuenta que este } \\
\text { domingo haremos una chambatón en Dos Cruces (limpiaremos y } \\
\text { pintaremos el local donde hacemos catequesis para sacramentos)... } \\
\text { Partimos a las 10:30am de Virgen de Fátima en Miraflores (hay Misa de } \\
\text { 9:30) y estamos de vuelta a las 2pm } \\
\text { Ahora nos vamos con música y después tendremos el calendario } \\
\text { emevecista, esto es Estación cero }\end{array}$ & $\begin{array}{l}12 \\
\min \end{array}$ \\
\hline $\begin{array}{l}\text { Bloque } \\
\text { Musical }\end{array}$ & & $\begin{array}{l}7 \\
\min \end{array}$ \\
\hline $\begin{array}{l}\text { Agenda } \\
\text { Y } \\
\text { despedida }\end{array}$ & $\begin{array}{l}\text { CUÑA: Calendario emevecista! } \\
\text { Raúl: y estamos con todas las actividades del calendario emevecista } \\
\text { Ale: Mañana finalmente es el gran concierto de Tony Meléndez con } \\
\text { Estación cero y Miguel Quiñones. Ya les estaremos compartiendo todos } \\
\text { los pormenores del concierto qué estará increíble } \\
\text { Raúl: Así es, y bueno, En Camacho mañana habrá una charla sobre El } \\
\text { amor filial a María. Será luego del rosario del 5:30 así qué todos estamos } \\
\text { invitados } \\
\text { Ale: Este } 21 \text { de mayo se realizará Ave Marías Gratis, si ya han ido saben } \\
\text { qué es una experiencia única. Es muy bonito poder rezar con la gente en } \\
\text { las calles así qué este año tenemos qué ser muchos los qué vayamos. } \\
\text { Además habrá concierto y todo así qué no se lo pueden perder. } \\
\text { Mara nos comenta qué el sábado } 7 \text { de mayo pan para mi hermano en el } \\
\text { callao, y el domingo } 15 \text { tendrán la visita al albergue San Lucas } \\
\text { Gianfranco: } \\
\text { Ale: y esos son todas las actividades qué se vienen al menos por ahora } \\
\text { R: esto ha sido todo por hoy en CRUZ ANCLA, Hasta el próximo } \\
\text { VIERNES!! }\end{array}$ & $\begin{array}{l}7 \\
\min \end{array}$ \\
\hline \multirow[t]{2}{*}{ Música } & $\begin{array}{c}\text { Música } \\
\bullet\end{array}$ & $\begin{array}{l}5 \\
\min \end{array}$ \\
\hline & TIEMPO TOTAL & 60 \\
\hline
\end{tabular}




\section{PAUTA RADIAL 17}

Tema: Novedades e iniciativas

PROGRAMA RADIAL: Cruz Ancla

HORARIO: Viernes 5pm

DURACIÓN: 1 hora

\begin{tabular}{|c|c|c|}
\hline $\begin{array}{l}\text { SEGME } \\
\text { NTO }\end{array}$ & TEXTO & $\begin{array}{l}\text { TIEM } \\
\text { PO }\end{array}$ \\
\hline $\begin{array}{l}\text { Presentac } \\
\text { ión }\end{array}$ & $\begin{array}{l}\text { R: Bienvenidos a CRUZ ANCLA!! } \\
\text { D: Hoy somos las mujeres al poder, me está acompañando en la cabina } \\
\text { Alexandra del Castillo, bienvenida Ale } \\
\text { A: Gracias Dani } \\
\text { D: Bueno pues ya tocaba tener más voces femeninas en la radio } \\
\text { y cuéntanos Ale un poco de ti para qué te conozcan todos los qué nos } \\
\text { están escuchando } \\
\ldots \ldots \\
\text { A: si pues Dani y cuéntanos, de qué vamos a hablar hoy? } \\
\text { D: Hoy queremos comentarles sobre algunas iniciativas nuevas qué han } \\
\text { surgido en los distintos centros pastorales } \\
\text { A: claro porque siempre hay ideas muy chéveres y creativas qué se } \\
\text { pueden hacer } \\
\text { Ahora Ale ¿qué canción te gustaría escuchar? }\end{array}$ & $\begin{array}{l}5 \\
\min \end{array}$ \\
\hline Musica & Who says you cant & $\begin{array}{l}4 \mathrm{mi} \\
\mathrm{n}\end{array}$ \\
\hline $\begin{array}{l}\text { Diálogo } \\
\text { Actualida } \\
\text { d }\end{array}$ & $\begin{array}{l}\text { Muy bien ya estamos de vuelta y ahora queremos comentarles de un par } \\
\text { de actividades nuevas qué hay en el MVC o mejor dicho en algunos } \\
\text { centros pastorales. } \\
\text { Primero tenemos Dos cruces y tenemos un audio de Raúl Vega donde nos } \\
\text { cuenta un poco de qué se trata, vamos a escucharlo } \\
\text { Muy bien, Raúl suele ir a este nuevo proyecto así qué ya sabemos un } \\
\text { poco más sobre qué se trata, también pueden ir si se animan todos los } \\
\text { domingos } \\
\text { Por otro lado, en Camacho hay una nueva iniciativa qué es LA HORA } \\
\text { DEL LONCHECITO, qué es un espacio que se ha creado para poder } \\
\text { hablar a micrófono abierto sobre temas variados, el primero se llamó } \\
\text { ¿nuestras palabras matan? y dialogamos sobre el impacto que tiene lo que } \\
\text { decimos, cómo lo decimos y eso nos fue llevando a tocar diversos puntos } \\
\text { relacionados en base a nuestra opinión y nuestras experiencias qué fuimos } \\
\text { compartiendo } \\
\text { Ahora que estamos en El mes de maría escuchemos una canción para ella }\end{array}$ & $\begin{array}{l}10 \\
\min \end{array}$ \\
\hline $\begin{array}{l}\text { Bloque } \\
\text { Musical }\end{array}$ & jon carlo & $\begin{array}{l}7 \\
\min \end{array}$ \\
\hline
\end{tabular}




\begin{tabular}{|c|c|c|}
\hline & & $\begin{array}{l}12 \\
\min \end{array}$ \\
\hline $\begin{array}{l}\text { Bloque } \\
\text { Musical }\end{array}$ & no nos basta & $\begin{array}{l}7 \\
\min \end{array}$ \\
\hline $\begin{array}{l}\text { Agenda } \\
\text { Y } \\
\text { despedida }\end{array}$ & $\begin{array}{l}\text { CUÑA: Calendario emevecista! } \\
\text { Raúl: y estamos con todas las actividades del calendario emevecista } \\
\text { Ale: Este } 21 \text { de mayo se realizará Ave Marías Gratis, vamos a rezar con } \\
\text { la gente en las calles así qué este año tenemos qué ser muchos los que } \\
\text { vayamos. Además habrá concierto y todo así qué no se lo pueden perder. } \\
\text { este año va a ser en el parque castilla en lince el } 21 \text { de mayo a las } 2: 30 \\
\text { Dani: Mañana varios centros celebran el día de la madre, inviten a sus } \\
\text { mamás al rosario, sé que enel cp Cristo reconciliador y nsc van a celebrar } \\
\text { el día de la madre, en Camacho también van a hacer un rosario especial } \\
\text { por ellas y el domingo de todas maneras a misa } \\
\text { Ale; Ya se inauguró la Exposición PECES de Javier Rodríguez, mejor } \\
\text { conocido como Papo, en la galería del barrio así que vayamos todos en } \\
\text { mancha para ver su arte qué se caracteriza por ser súper profundo, la } \\
\text { exposición se conforma de pinturas, dibujos y esculturas, ....... } \\
\text { así qué no se lo pueden perder } \\
\text { R: esto ha sido todo por hoy en CRUZ ANCLA, Hasta el próximo } \\
\text { VIERNES!! }\end{array}$ & $\begin{array}{l}7 \\
\min \end{array}$ \\
\hline \multirow[t]{2}{*}{ Música } & Música & $\begin{array}{l}5 \\
\min \end{array}$ \\
\hline & TIEMPO TOTAL & $\begin{array}{l}60 \\
\min \end{array}$ \\
\hline
\end{tabular}

PAUTA RADIAL 18

Tema: anécdotas marianas

PROGRAMA RADIAL: Cruz Ancla

HORARIO: Viernes 5pm

DURACIÓN: 1 hora

\begin{tabular}{|c|c|c|}
\hline $\begin{array}{l}\text { SEGME } \\
\text { NTO }\end{array}$ & TEXTO & $\begin{array}{l}\text { TIEM } \\
\text { PO }\end{array}$ \\
\hline $\begin{array}{l}\text { Presentac } \\
\text { ión }\end{array}$ & $\begin{array}{l}\text { R: Bienvenidos a CRUZ ANCLA!! } \\
\text { A: Hoy tenemos un programa súper mariano } \\
\text { R: Hoy es } 13 \text { de mayo y estamos en un mes en qué celebramos a nuestra } \\
\text { Madre del cielo } \\
\text { D: por eso tendremos algunos invitados para comentar sus anécdotas } \\
\text { pero queremos qué ustedes también nos cuenten anécdotas y } \\
\text { experiencias qué hayan tenido durante las caminatas marianas } \\
\text { Así qué mientras nos escriben vamos a escuchar un poco de música, los } \\
\text { dejamos con las Siervas }\end{array}$ & $\begin{array}{l}5 \\
\min \end{array}$ \\
\hline Musica & María en camino & $\begin{array}{l}4 \mathrm{mi} \\
\mathrm{n}\end{array}$ \\
\hline
\end{tabular}




\begin{tabular}{|c|c|c|}
\hline $\begin{array}{l}\text { Diálogo } \\
\text { Actualida } \\
\text { d }\end{array}$ & $\begin{array}{l}\text { R: Y estamos de vuelta en CRUZ ANCLA y nos acompañan Fiorella } \\
\text { Valenzuela y Carolina Bravo } \\
\text { D: bienvenidas chicas, gracias por venir, primero quisiéramos qué nos } \\
\text { comenten lo qué significa ser hijos de maría para ustedes } \\
\text { algunos nos han escrito } \\
\text { Alexandra del castillo: significa tener siempre presente a la Madre, hacer } \\
\text { todo por, para y con ella } \\
\text { muy bien, luego comentaremos algunas anécdotas en torno a una } \\
\text { actividad clasica del MVC qué es la caminata mariana } \\
\text { Así es, no se olviden también de comentar en redes sociales sus anécdotas } \\
\text { para leerlas aquí en vivo } \\
\text { Vamos a escuchar a Apumarka con Madre Santa María }\end{array}$ & $\begin{array}{l}10 \\
\min \end{array}$ \\
\hline $\begin{array}{l}\text { Bloque } \\
\text { Musical }\end{array}$ & $\begin{array}{l}\text { Mi dulce amor } \\
\text { dijo qué sí }\end{array}$ & $\begin{array}{l}7 \\
\min \end{array}$ \\
\hline Pens & $\begin{array}{l}\text { R: Ya volvimos y queremos seguir conversando con nuestros invitados } \\
\text { D: ahora sí queremos qué nos cuenten sus anécdotas, cuéntanos tu Raúl } \\
\text { Mara alcedo nos ha escrito: } \\
\text { Me acuerdo que en la caminata mariana del año pasado, los chalacos ya } \\
\text { estábamos regresandonos, y estando todos en el bus a punto de arrancar, } \\
\text { uno de nosotros dice "alguien ha visto el megáfono?" felizmente apareció } \\
\text { luego de una semana, creo que lo tenia un agrupado de mayorazgo. } \\
\text { Muchas gracias a todos por venir y a los qué nos escuchan por mandarnos } \\
\text { sus anécdotas, ahora nos vamos a escuchar el calendario emevecista }\end{array}$ & $\begin{array}{l}12 \\
\min \end{array}$ \\
\hline $\begin{array}{l}\text { Bloque } \\
\text { Musical }\end{array}$ & & $\begin{array}{l}7 \\
\min \end{array}$ \\
\hline $\begin{array}{l}\text { Agenda } \\
\text { Y } \\
\text { despedida }\end{array}$ & $\begin{array}{l}\text { CUÑA: Calendario emevecista! } \\
\text { Fio: Sabemos qué esperaban que Raúl y Daniela lean el calendario pero } \\
\text { nos hemos apoderado de la radio } \\
\text { Caro: Sí, hoy nos toca a nosotras: } \\
\text { Fio: Mañana en el CP Jesús maría habrá cine con María después del } \\
\text { rosario } \\
\text { Caro: Y Mañana en la mañana Habrá una visita al asilo Canevaro } \\
\text { organizada por Acción Universitaria ulima } \\
\text { Fio: Y Este } 21 \text { de mayo se realizará Ave Marías Gratis, vamos a rezar } \\
\text { con la gente en las calles así qué este año tenemos qué ser muchos los } \\
\text { que vayamos. Además habrá concierto y todo así qué no se lo pueden } \\
\text { perder. este año va a ser en el parque castilla en lince el } 21 \text { de mayo a las } \\
2: 30 \\
\text { Caro: Ya se inauguró la Exposición PECES de Javier Rodríguez, mejor } \\
\text { conocido como Papo, en la galería del barrio } \\
\text { Fio: También este sábado } 28 \text { de mayo a las } 5: 30 \\
\quad \text { Se realizará el concurso artístico mariano en Camacho ya están abier } \\
\quad \text { inscripciones, habrá canto, teatro, dibujo, pintura, fotografía, y tamb } \\
\quad \text { una categoría para niños así qué no se lo pierdan. } \\
\text { R: esto ha sido todo por hoy en CRUZ ANCLA, Hasta el próximo } \\
\text { VIERNES!! }\end{array}$ & $\begin{array}{l}7 \\
\min \end{array}$ \\
\hline
\end{tabular}




\begin{tabular}{|l|l|l|} 
Música & $\begin{array}{l}\text { Música } \\
\bullet\end{array}$ & $\begin{array}{l}5 \\
\min \end{array}$ \\
\hline & TIEMPO TOTAL & $\begin{array}{l}60 \\
\min \end{array}$ \\
\hline
\end{tabular}

PAUTA RADIAL 19

Tema: Evangelización en la cultura

PROGRAMA RADIAL: Cruz Ancla HORARIO: Viernes 5pm DURACIÓN: 1 hora

\begin{tabular}{|c|c|c|}
\hline $\begin{array}{l}\text { SEGME } \\
\text { NTO }\end{array}$ & TEXTO & TIEMPO \\
\hline $\begin{array}{l}\text { Presentaci } \\
\text { ón }\end{array}$ & $\begin{array}{l}\text { R: Bienvenidos a una nueva emisión de CRUZ ANCLA!! } \\
\text { C: Bienvenidos, gracias por estar conectados, } \\
\text { R: De hecho hoy es un día especial!!! porque después de mucho tiempo } \\
\text { nos acompaña Carlos. } \\
\text { C: ..... } \\
\text { R: hoy vamos a hablar sobre cómo las actividades artísticas y culturales } \\
\text { pueden ser medios para evangelizar } \\
\text { C: De hecho las actividades artísticas llegan muy fácilmente a la gente, } \\
\text { llaman mucho la atención, } \\
\text { R: Además, por otro lado, hay que tener en cuenta que a veces es más fácil } \\
\text { ver de qué manera algunas cosas como la música, el canto, pueden } \\
\text { ayudarnos a hacer apostolado y a evangelizar, pero con otras actividades } \\
\text { artísticas puede ser un poco complicado ver este horizonte } \\
\text { C: Sí, es cierto, por eso hoy vamos a ver un poco la opinión y la } \\
\text { experiencia de algunos invitados } \\
\text { R: También queremos invitarlos a ustedes, a enviarnos sus comentarios o } \\
\text { experiencias sobre las actividades artísticas que realizan y cómo creen qué } \\
\text { estas pueden ayudar en el apostolado } \\
\text { C: Si, comenten en Facebook o en el chat y mientras lo hacen nosotros } \\
\text { iremos a escuchar una canción. esto es: La cima de Julio cañas. }\end{array}$ & $5 \mathrm{~min}$ \\
\hline Musica & $\begin{array}{l}\text { La cima de Julio cañas. } \\
\text { The Thirsting con Stepping into the Day }\end{array}$ & $4 \mathrm{~min}$ \\
\hline $\begin{array}{l}\text { Diálogo } \\
\text { Actualidad }\end{array}$ & $\begin{array}{l}\text { C: ya estamos de nuevo en cruz ancla } \\
\text { R: Estamos felices de tener hoy a Pía Galiano, Bienvenida } \\
\text { C: Ahora queremos leer contigo algunos de los comentarios que nos han } \\
\text { escrito, tenemos varios comentarios hoy!: } \\
\text { Mara Alcedo Claro que si! la cultura esta muy enlazada con el arte, y el } \\
\text { arte, en todas sus expresiones, comunica y transmite un mensaje, y que } \\
\text { mejor si ese mensaje es Jesus mismo. Para mi hacer apostolado a traves de } \\
\text { la cultura, en mi caso a traves de la musica, es expresar lo que creo, en } \\
\text { quien creo, y llevar a otros a Dios. } \\
\text { Alexa Correa Cruz Claroooo que sí! Una cultura de reconciliación como } \\
\text { pedía el Papa Juan Pablo II! En los distintos ámbitos : literatura, arte, }\end{array}$ & $10 \mathrm{~min}$ \\
\hline
\end{tabular}




\begin{tabular}{|c|c|c|}
\hline & $\begin{array}{l}\text { música, historia, tradiciones, etc etc } \\
\text { Carolina Bravo Rojas La música a través del coro de las parroquias o } \\
\text { bandas católicas como Las Siervas } \\
\text { Valentina Cáceres Oré A través de la fotografía! Cuando se plasma la } \\
\text { relación que hay entre el ser humano y la creación de Dios } \\
\text { Bueno muchísimas gracias por venir } \\
\text { Muy bien, ahora nos vamos a escuchar a la Siervas cn Confía en Dios }\end{array}$ & \\
\hline \multirow[t]{2}{*}{$\begin{array}{l}\text { Bloque } \\
\text { Musical }\end{array}$} & Confia en Dios Siervas & $7 \mathrm{~min}$ \\
\hline & $\begin{array}{l}\text { C:Y estamos de vuelta en CRUZ ANCLA, estábamos escuchando a The } \\
\text { Thirsting con Universal Youth } \\
\text { R: y estamos con Marcelo Rodriguez } \\
\text { C:bienvenido, muchas gracias por venir } \\
\text { Bueno muchísimas gracias por venir } \\
\text { Ahora los dejamos con tu noticia es libertad de Vox lumini }\end{array}$ & $12 \mathrm{~min}$ \\
\hline $\begin{array}{l}\text { Bloque } \\
\text { Musical }\end{array}$ & & $7 \mathrm{~min}$ \\
\hline $\begin{array}{l}\text { Agenda } \\
\text { Y } \\
\text { despedida }\end{array}$ & $\begin{array}{l}\text { CUÑA: Calendario emevecista! } \\
\text { C: mañana es Ave Marías Gratis, el punto de encuentro es el Parque castilla } \\
\text { en lince e a las 2:30 de la tarde y si se les hace muy lejos, en la Avenida La } \\
\text { Molina también van a salir a rezar ave marías gratis, el punto de encuentro } \\
\text { es el Centro Pastoral Cristo Reconciliador a las 3:30 } \\
\text { R: En el Centro apostólico Nuestra Sra de la Reconciliación también } \\
\text { mañana habrá una charla sobre La Misericordia de María en la Sagrada } \\
\text { familia } \\
\text { C:También este sábado } 28 \text { de mayo a las 5:30 se realizará el concurso } \\
\text { artístico mariano en Camacho ya están abiertas las inscripciones, habrá } \\
\text { canto, teatro, dibujo, pintura, fotografía, y también hay una categoría para } \\
\text { niños así que no se lo pierdan. } \\
\text { R: y ya para terminar, hoy se van de retiro varias emevecistas agrupadas y } \\
\text { nazareth así qué estaremos rezando por ellas, tenganlas en sus oraciones. } \\
\text { R: esto ha sido todo por hoy en CRUZ ANCLA, Hasta el próximo } \\
\text { VIERNES!! }\end{array}$ & $7 \mathrm{~min}$ \\
\hline \multirow[t]{2}{*}{ Música } & Música & $5 \mathrm{~min}$ \\
\hline & TIEMPO TOTAL & $60 \mathrm{~min}$ \\
\hline
\end{tabular}




\section{PAUTA RADIAL 20}

Tema: El Espíritu Santo

PROGRAMA RADIAL: Cruz Ancla

HORARIO: Viernes 5pm

DURACIÓN: 1 hora

\begin{tabular}{|c|c|c|}
\hline SEGMENTO & TEXTO & $\begin{array}{l}\text { TIEMP } \\
\text { O }\end{array}$ \\
\hline Presentación & $\begin{array}{l}\text { R: Bienvenidos a una nueva emisión de CRUZ ANCLA!! } \\
\text { C: Bienvenidos, gracias por estar conectados, este ya es nuestro } \\
\text { programa número } 30 \\
\text { R:Wow qué rápido se ha pasado } \\
\text { C:y bueno, de qué tema vamos a hablar hoy? } \\
\text { R: bueno, hace poco hemos celebrado pentecostés y la venida del } \\
\text { Espíritu Santo, así qué hoy vamos a hablar sobre el Espíritu Santo y } \\
\text { cómo actúa en nuestras vidas } \\
\text { C: sabemos qué es una persona muy importante y por eso queremos } \\
\text { reflexionar un poco más en torno a quién es y cuál es su papel } \\
\text { Ahora vamos con estación cero y su canción Espíritu de Dios }\end{array}$ & $5 \min$ \\
\hline Musica & & $4 \min$ \\
\hline $\begin{array}{l}\text { Diálogo } \\
\text { Actualidad }\end{array}$ & $\begin{array}{l}\text { C: ya estamos de nuevo en cruz ancla } \\
\text { R: } \\
\text { ¿Quién es el Espíritu Santo? } \\
\text { ¿Cuál es su papel? } \\
\text { ¿Por qué es importante su presencia en la vida cristiana } \\
\text { Bueno muchísimas gracias por venir } \\
\text { Muy bien, ahora nos vamos a escuchar a la Siervas cn espiritu santo }\end{array}$ & $\begin{array}{l}10 \\
\min \end{array}$ \\
\hline \multirow[t]{2}{*}{ Bloque Musical } & Confia en Dios Siervas & $7 \mathrm{~min}$ \\
\hline & $\begin{array}{l}\text { C:Y estamos de vuelta en CRUZ ANCLA, estábamos escuchando a } \\
\text { TheBosco boys con Who says you cant be a saint } \\
\text { R: y tenemos varios audios de agrupados qué nos han contado cómo } \\
\text { actúa el espíritu santo concretamente en sus vidas, así qué vamos a } \\
\text { escuchar sus experiencias } \\
\text { Ahora escucharemos espiritu inmortal de Voz Lumini }\end{array}$ & $\begin{array}{l}12 \\
\min \end{array}$ \\
\hline Bloque Musical & & $7 \mathrm{~min}$ \\
\hline $\begin{array}{l}\text { Agenda } \\
\text { Y despedida }\end{array}$ & $\begin{array}{l}\text { CUÑA: Calendario emevecista! } \\
\text { Mañana sábado el cp Jesús María está organizando una procesión } \\
\text { acompañando a nuestra Madre al rededor del Centro Pastoral para } \\
\text { terminar con un homenaje y compartir con música, comida, amistad y } \\
\text { oración. Empezará a las 5:30 } \\
\text { Este domingo se celebra Corpus Christi y habrá una procesión y Misa en } \\
\text { la Plaza de armas, van a salir buses de la parroquia de Camacho así qué }\end{array}$ & $7 \mathrm{~min}$ \\
\hline
\end{tabular}




\begin{tabular}{|l|l|l|} 
& $\begin{array}{l}\text { están todos invitados } \\
\text { En el CP de San Borja este sábado a las habrá pan para mi hermano y el } \\
\text { otro sábado 4 de junio tendrán rosario en el parque + mafia con pizza a } \\
\text { las 5:30pm } \\
\text { Y en el cp SMR hay una jornada mariana este sábado a las 5:45 } \\
\text { R: esto ha sido todo por hoy en CRUZ ANCLA, Hasta el próximo } \\
\text { VIERNES!! }\end{array}$ & \\
\hline Música & $\begin{array}{l}\text { Música } \\
\bullet\end{array}$ & 5 min \\
\hline & TIEMPO TOTAL & $\begin{array}{l}60 \mathrm{mi} \\
\mathrm{n}\end{array}$ \\
\hline
\end{tabular}

\section{PAUTA RADIAL 21}

Tema: Corazón de Jesús

PROGRAMA RADIAL: Cruz Ancla

HORARIO: Viernes 5pm

DURACIÓN: 1 hora

\begin{tabular}{|l|l|c|}
\hline $\begin{array}{l}\text { SEGM } \\
\text { ENTO }\end{array}$ & TEXTO & $\begin{array}{l}\text { TIEMP } \\
\text { O }\end{array}$ \\
\hline $\begin{array}{l}\text { Present } \\
\text { ación }\end{array}$ & $\begin{array}{l}\text { R: Bienvenidos a una nueva emisión de CRUZ ANCLA!! gracias por estar con } \\
\text { nosotros } \\
\text { Hoy tenemos varios temas qué les queremos comentar y varias cosas qué se } \\
\text { vienen } \\
\text { hoy hablaremos sobre el Sagrado Corazón de Jesús qué estamos celebrando este } \\
\text { mes }\end{array}$ & 5 min \\
Ahora para entrar un poco en el tema vamos a escuchar Corazón de Jesús & minin \\
\hline $\begin{array}{l}\text { Diálogo } \\
\text { actualid }\end{array}$ & $\begin{array}{l}\text { iYa estamos de nuevo en cruz ancla y antes de hablar del tema de hoy queremos } \\
\text { comentarles sobre un evento qué se viene sobre todo para los universitarios y los } \\
\text { jóvenes qué están empezando a trabajar } \\
\text { R: y hoy nos acompaña Valeria Rado para comentarnos sobre algo muy bueno } \\
\text { qué se viene } \\
\text { Bueno Vale primero quisiera qué te presentes para qué nuestros oyentes te } \\
\text { conozcan } \\
\text { Bueno muchísimas gracias por venir } \\
\text { Muy bien, ahora nos vamos a escuchar con A donde iré }\end{array}$ & $\begin{array}{l}10 \\
\text { min }\end{array}$ \\
\hline $\begin{array}{l}\text { Bloque } \\
\text { Music }\end{array}$ & $\begin{array}{l}\text { R:Y estamos de vuelta en CRUZ ANCLA } \\
\text { devoción al Sagrado corazón de Jesús concretamente en sus vidas, así qué vamos } \\
\text { a escuchar sus experiencias }\end{array}$ & $\begin{array}{l}12 \\
\text { min }\end{array}$ \\
\hline
\end{tabular}




\begin{tabular}{|c|c|c|}
\hline & $\begin{array}{l}\text { REFLEXIÓN } \\
\text { Ahora escucharemos No nos basta }\end{array}$ & \\
\hline $\begin{array}{l}\text { Bloque } \\
\text { Musical }\end{array}$ & & $7 \mathrm{~min}$ \\
\hline $\begin{array}{l}\text { Agenda } \\
\text { Y } \\
\text { despedi } \\
\text { da }\end{array}$ & $\begin{array}{l}\text { CUÑA: Calendario emevecista! } \\
\text { para empezar hoy son las promesas perpetuas de dos fraternas en la parroquia } \\
\text { san José de mayorazgo, ellas son Karina y Rosana, así qué les mandamos } \\
\text { saludos y oraciones } \\
\text { Ya se acercan las misiones, justo mañana será el lanzamiento de misiones en el } \\
\text { cp Jesús maría, es después del rosario y en todos los centros ya nos estamos } \\
\text { preparando } \\
\text { Mañana en el CP de san Borja tendrán rosario en el parque + mafia con pizza a } \\
\text { las 5:30pm } \\
\text { Y además no se olviden de separar el jueves } 16 \text { para el Debate ¿Trabajar para } \\
\text { vivir o vivir para los demás? organizado por acción universitaria. Sera a las 7:30 } \\
\text { en la universidad de Lima } \\
\text { R: esto ha sido todo por hoy en CRUZ ANCLA, Hasta el próximo VIERNES!! }\end{array}$ & $7 \mathrm{~min}$ \\
\hline Música & Música & $5 \mathrm{~min}$ \\
\hline & TIEMPO TOTAL & $\begin{array}{l}60 \mathrm{mi} \\
\mathrm{n}\end{array}$ \\
\hline
\end{tabular}

\section{PAUTA RADIAL 22}

Tema: Apostolado en el trabajo PROGRAMA RADIAL: Cruz Ancla HORARIO: Viernes $5 \mathrm{pm}$ DURACIÓN: 1 hora

\begin{tabular}{|l|l|c|}
\hline $\begin{array}{l}\text { SEGME } \\
\text { NTO }\end{array}$ & TEXTO & $\begin{array}{l}\text { TIEMP } \\
\text { O }\end{array}$ \\
\hline $\begin{array}{l}\text { Presentac } \\
\text { ión }\end{array}$ & $\begin{array}{l}\text { R: Bienvenidos a una nueva emisión de CRUZ ANCLA!! gracias por estar } \\
\text { con nosotros el dia de hoy } \\
\text { como estas Daniela } \\
\text { como estas raul } \\
\text { muy bien hoy queremos hablar sobre una incógnita que surge en la vida } \\
\text { cuando uno empieza a trabajar } \\
\text { hoy hablaremos sobre icómo hacer apostolado en el trabajo? } \\
\text { creo qué es algo qué muchos nos hemos preguntado } \\
\text { Así qué esperamos poder dar algunos consejos y ayudarlos un poco en este } \\
\text { programa para qué podamos ser grandes apostoles en todo momento } \\
\text { Ahora vamos a escuchar un clasica del mvc, no tengo miedo }\end{array}$ & 5 min \\
\hline Musica & & $4 \mathrm{~min}$ \\
\hline $\begin{array}{l}\text { Diálogo } \\
\text { d }\end{array}$ & $\begin{array}{l}\text { Ya estualida } \\
\text { relacionadas al trabajo }\end{array}$ & 10 \\
\hline
\end{tabular}




\begin{tabular}{|c|c|c|}
\hline & $\begin{array}{l}\text { Reza como si todo dependiera de Dios. Trabaja como si todo dependiera de ti. } \\
\text { San Agustín } \\
\text { No puedo parar de trabajar. Tendré toda la eternidad para descansar. Madre } \\
\text { Teresa de Calcuta. } \\
\text { Trabaja en algo, para que el diablo te encuentre siempre ocupado. San Jerónimo } \\
\text { Y ahora escucharemos algunos audios que nos han mandado } \\
\text { y ahora queremos }\end{array}$ & \\
\hline \multirow[t]{2}{*}{$\begin{array}{l}\text { Bloque } \\
\text { Music }\end{array}$} & & $7 \mathrm{~min}$ \\
\hline & $\begin{array}{l}\text { C:ya estamos nuevamente conversando sobre como hacer apostolado en el } \\
\text { trabajo }\end{array}$ & $\begin{array}{l}12 \\
\min \end{array}$ \\
\hline $\begin{array}{l}\text { Bloque } \\
\text { Musical }\end{array}$ & & $7 \mathrm{~min}$ \\
\hline $\begin{array}{l}\text { Agenda } \\
\text { Y } \\
\text { despedid } \\
\text { a }\end{array}$ & $\begin{array}{l}\text { CUÑA: Calendario emevecista! } \\
\text {-Retiro para hombres organizado por el MVC } 24,25 \text { y } 26 \text { de junio, en la casa de } \\
\text { retiro las mercedarias, para más inflo chequeen el fb de MVC Perú } \\
\text {-Mañana sábado hay tarde deportiva en el centro apostólico NSR después del } \\
\text { rosario de 5:30 } \\
\text {-Y NO SE OLVIDEN ESTE JUEVES se realizara el debate ¿Trabajar para vivir } \\
\text { o vivir para los demás? organizado por acción universitaria, se realizará este } \\
\text { jueves } 16 \text { a las 7:30om en el aula magna B de la ULIma } \\
\text { R: esto ha sido todo por hoy en CRUZ ANCLA, Hasta el próximo } \\
\text { VIERNES!! }\end{array}$ & $7 \mathrm{~min}$ \\
\hline \multirow[t]{2}{*}{ Música } & Música & $5 \mathrm{~min}$ \\
\hline & TIEMPO TOTAL & $\begin{array}{l}60 \mathrm{mi} \\
\mathrm{n}\end{array}$ \\
\hline
\end{tabular}

\section{PAUTA RADIAL 23}

Tema: San José como modelo de Padre PROGRAMA RADIAL: Cruz Ancla

HORARIO: Viernes $5 \mathrm{pm}$

DURACIÓN: 1 hora

\begin{tabular}{|l|l|l|}
\hline $\begin{array}{l}\text { SEGM } \\
\text { ENTO }\end{array}$ & TEXTO & $\begin{array}{l}\text { TIEMP } \\
\text { O }\end{array}$ \\
\hline $\begin{array}{l}\text { Present } \\
\text { ación }\end{array}$ & $\begin{array}{l}\text { D: Bienvenidos a una nueva emisión de CRUZ ANCLA!! } \\
\text { A: Bienvenidos, gracias todos por estar conectados } \\
\text { D: Hoy nos acompaña Alexandra del castillo ¿Cómo estás ale? }\end{array}$ & 5 min \\
\end{tabular}




\begin{tabular}{|c|c|c|}
\hline & $\begin{array}{l}\text { A: .... } \\
\text { D: Y bueno hoy queremos hablar un poco en torno a la celebración del día del } \\
\text { padre } \\
\text { A: Pero sobre todo queremos hablar sobre un personaje qué resalta como } \\
\text { miembro de la Sagrada Familia } \\
\text { D: Así es, San José fue un hombre qué supo asumir su paternidad como padre } \\
\text { de Jesús, de Cristo, y ahora es un gran ejemplo para muchos, sobre todo para los } \\
\text { hombres } \\
\text { A: Es un gran Santo qué nos puede enseñar mucho, pero antes de seguir } \\
\text { hablando sobre él, escuchemos a la banda peruana TABOR con Quiero Adorarte }\end{array}$ & \\
\hline Musica & & $4 \mathrm{~min}$ \\
\hline $\begin{array}{l}\text { Diálogo } \\
\text { Actualid } \\
\text { ad }\end{array}$ & $\begin{array}{l}\text { D: ya estamos de nuevo en cruz ancla } \\
\text { A: Y ahora leeremos los comentarios qué nos han dejado en Facebook } \\
\text { Diana J. Rodriguez Un santazo y mi mejor amigo!.....amo tanto a María que } \\
\text { prefirió negarla en secreto para salvarla de una muerte segura, creyó a Dios } \\
\text { inmediatamente por el amor que le tenía a la Madre, no dudo en acogerla, y } \\
\text { cuidar a Jesús, en dar su vida por ellos, siempre siguiendo lo que Dios le pedía. } \\
\text { Quien en este mundo va a aceptar lo que José acepto y amo tanto...una mujer } \\
\text { "embarazada por el E.S.", respetar la virginidad de su esposa hasta el final, } \\
\text { cuidar al Hijo de Dios...en cualquier mente humana quizás eso no entre, en mi } \\
\text { San José si, en su gran corazón si, en su amor eterno----Y por San José también } \\
\text { se va a María, él te señala a su esposa, te lleva a ella y a su Hijo, es el santo que } \\
\text { no quiere ser reconocido, porque sabe cuál es su lugar, y eso lo hace grande y } \\
\text { admirable. Enamoradísima de mi santo! } \\
\text { D: Qué bonito, de hecho San José también nos muestra con su ejemplo cómo ser } \\
\text { dócil al Plan de Dios } \\
\text { Así es, además aquí les tenemos algunos datos qué queremos resaltar sobre este } \\
\text { Santo: San José es llamado el "Santo del silencio" No conocemos palabras } \\
\text { expresadas por él, tan solo conocemos sus obras, sus actos de fe, amor y de } \\
\text { protección como padre responsable del bienestar de su amadísima esposa y de } \\
\text { su excepcional Hijo. José fue "santo" desde antes de los desposorios. Un } \\
\text { "escogido" de Dios. Desde el principio recibió la gracia de discernir los } \\
\text { mandatos del Señor. } \\
\text { El Papa Juan Pablo II se refirió a San José con la siguientes palabras: "La } \\
\text { extremada discreción con que José desempeñó el papel confiado por Dios } \\
\text { subraya aún más su fe, que consistió en ponerse siempre a la escucha del Señor, } \\
\text { tratando de comprender su voluntad, para obedecerla con todo el corazón y con } \\
\text { todas sus fuerzas. Por este motivo, el Evangelio lo define como hombre «justo» } \\
\text { (Mateo 1, 19). El justo, de hecho, es una persona que reza, vive de fe, y trata de } \\
\text { hacer el bien en toda circunstancia concreta de la vida." }\end{array}$ & $\begin{array}{l}10 \\
\min \end{array}$ \\
\hline \multirow[t]{2}{*}{$\begin{array}{l}\text { Bloque } \\
\text { Musical }\end{array}$} & Confia en Dios Siervas & $7 \mathrm{~min}$ \\
\hline & $\begin{array}{l}\text { C:Y estamos de vuelta en CRUZ ANCLA, } \\
\text { y tenemos un audio especial qué nos ha enviado Carlos Aguilar, él es un padre } \\
\text { de familia muy conocido en nuestra familia y con mucho cariño nos ha } \\
\text { preparado una reflexión en torno a san José, vamos a escucharlo }\end{array}$ & $\begin{array}{l}12 \\
\min \end{array}$ \\
\hline
\end{tabular}




\begin{tabular}{|l|l|c|}
$\begin{array}{l}\text { Bloque } \\
\text { Musical }\end{array}$ & & 7 min \\
\hline $\begin{array}{l}\text { Agenda } \\
\text { Yespedi } \\
\text { da }\end{array}$ & $\begin{array}{l}\text { CUÑA: Calendario emevecista! } \\
\text { Para empezar este sábado los CPs de San Borja y Camacho se han unido para } \\
\text { realizar una gran celebración para los papás de ambos centros, empieza a las } \\
\text { 5:30 y van a tener rosario, van a a ver el partido y además parrillada así qué no se } \\
\text { lo pueden perder } \\
\text { y qué bonito qué se unan los centros para hacer cosas como esta } \\
\text { También recordarles qué se acercan las misiones así qué pregunten en sus centros } \\
\text { para qué puedan ir, en varios se está haciendo el lanzamiento de misiones por } \\
\text { estos dias así qué estén atentos } \\
\text { El proximo fin de semana hay un retiro para hombres mayores de 21 años, están } \\
\text { todos invitados, pueden encontrar más info en el fb de mvc Perú. } \\
\text { R: esto ha sido todo por hoy en CRUZ ANCLA, Hasta el próximo VIERNES!! }\end{array}$ & 7 min \\
\hline Música & $\begin{array}{l}\text { Música } \\
\bullet\end{array}$ & 5 min \\
\hline TIEMPO TOTAL & $\begin{array}{l}60 \mathrm{mi} \\
\mathrm{n}\end{array}$ \\
\hline
\end{tabular}

\section{PAUTA RADIAL 24}

Tema: Misioneros

PROGRAMA RADIAL: Cruz Ancla

HORARIO: Viernes $5 \mathrm{pm}$

DURACIÓN: 1 hora

\begin{tabular}{|c|c|c|}
\hline $\begin{array}{l}\text { SEGME } \\
\text { NTO }\end{array}$ & TEXTO & $\begin{array}{l}\text { TIEMP } \\
\text { O }\end{array}$ \\
\hline $\begin{array}{l}\text { Presentac } \\
\text { ión }\end{array}$ & $\begin{array}{l}\text { D: Bienvenidos a una nueva emisión de CRUZ ANCLA!! } \\
\text { A: Bienvenidos, gracias todos por estar conectados, hoy tenemos un } \\
\text { programa especial para todos los misioneros } \\
\text { vamos a conversar sobre las misiones qué ya se acercan } \\
\text { y sobre nuestras anécdotas, de hecho a todos nos han pasado cosas } \\
\text { memorables, bonitas divertidas } \\
\text { Antes de escuchar las anécdotas vamos a escuchar: Quién dices qué soy } \\
\text { de vox }\end{array}$ & $\begin{array}{l}5 \\
\min \end{array}$ \\
\hline Musica & & $4 \mathrm{~min}$ \\
\hline $\begin{array}{l}\text { Diálogo } \\
\text { Actualida } \\
\text { d }\end{array}$ & $\begin{array}{l}\text { D: ya estamos de nuevo en cruz ancla } \\
\text { y antes de escuchar las anécdotas queremos comentarles un poco sobre } \\
\text { misiones universitarias qué son básica mente las mismas misiones del } \\
\text { MVC pero para universitarios de diversos lugares } \\
\text { para comentarnos sobre esto, Tavo tin nos ha mandado un audio, vamos a } \\
\text { escucharlo } \\
\text { Ahora queremos comentar un poco nuestras anécdotas, para eso nos } \\
\text { acompaña Fiorella Valenzuela } \\
\text { Ahora vamos a escuchar Romper barreras }\end{array}$ & $\begin{array}{l}10 \\
\min \end{array}$ \\
\hline
\end{tabular}




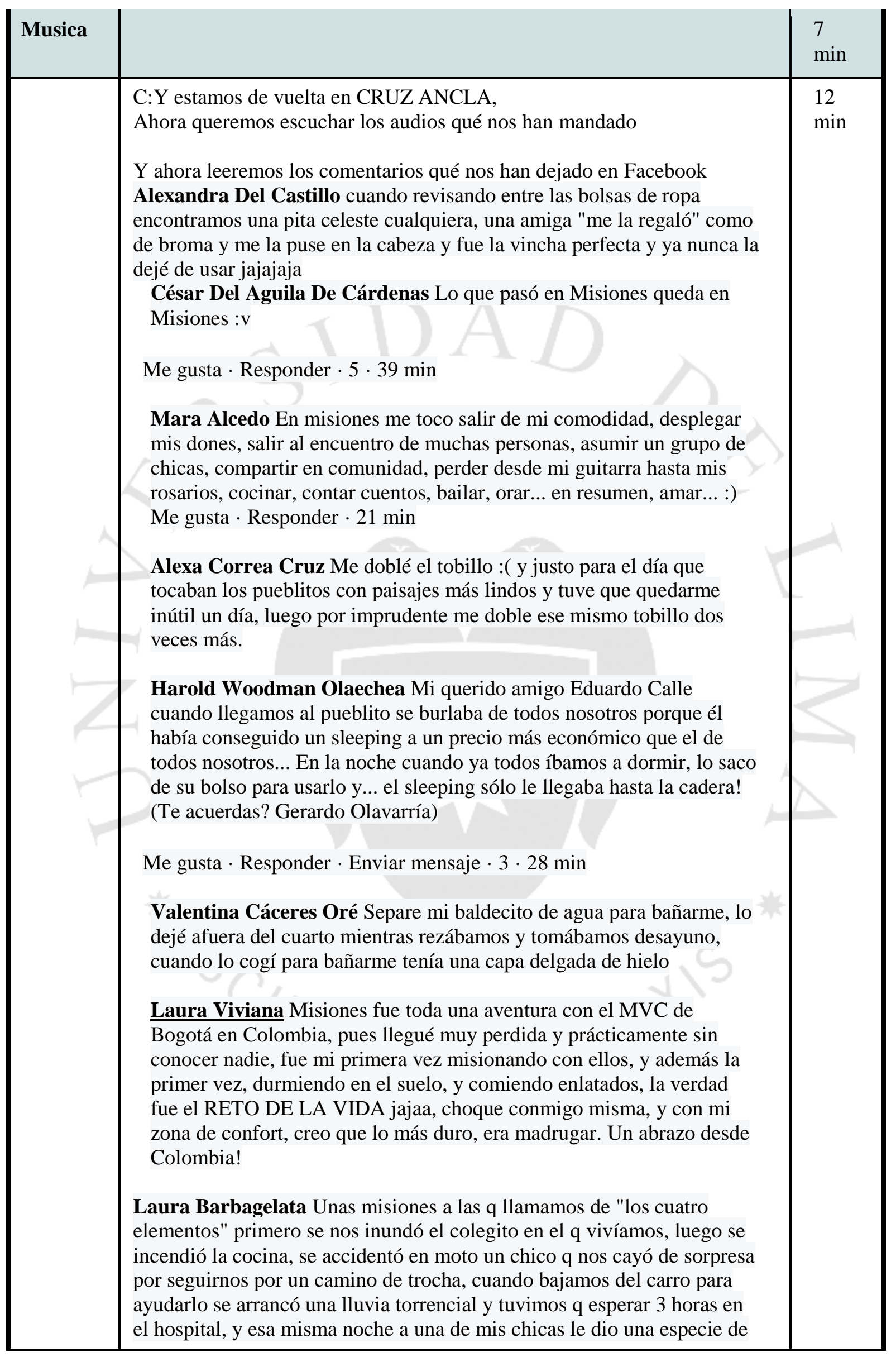




\begin{tabular}{|c|c|c|}
\hline & $\begin{array}{l}\text { ataque de nervios acompañados de hipotermia... Eso solo en dos días... } \\
\text { Pasaron más cosas pero eso fue lo q más recordamos!! Jaja nuestra } \\
\text { supervivencia! } \\
\text { Muy bien, ahora vamos a escuchar siempre alegre de athenas }\end{array}$ & \\
\hline $\begin{array}{l}\text { Bloque } \\
\text { Musical }\end{array}$ & & $\begin{array}{l}7 \\
\min \end{array}$ \\
\hline $\begin{array}{l}\text { Agenda } \\
\text { Y } \\
\text { despedid } \\
\text { a }\end{array}$ & $\begin{array}{l}\text { CUÑ } A \text { : Calendario emevecista! } \\
\text { D:mañana hay visita de comparte de au ulima, iremos a huaycan, la } \\
\text { reunión es en la ulima a las 7:30am } \\
\text { R:Misiones universitarias del } 27 \text { de julio al } 4 \text { de agosto } \\
\text { D: En Jesús María este sábado } 2 \text { de julio tendrán un festival de postres } \\
\text { pro fondos las misiones de este año después del Rosario } \\
\text { Mañana es el club de lectura de Camacho, es su } 2 \text { da reunión sobre el } \\
\text { principito } \\
\text { Hoy comienza el retiro para hombres de agrupados mayores y Nazaret. } \\
\text { En la casa de Retiro las Mercedarias. Una oración para todos ustedes. } \\
\text { R: esto ha sido todo por hoy en CRUZ ANCLA, Hasta el próximo } \\
\text { VIERNES!! }\end{array}$ & $\begin{array}{l}7 \\
\min \end{array}$ \\
\hline \multirow[t]{2}{*}{ Música } & Música & $\begin{array}{l}5 \\
\min \end{array}$ \\
\hline & TIEMPO TOTAL & $\begin{array}{l}60 \mathrm{mi} \\
\mathrm{n}\end{array}$ \\
\hline
\end{tabular}

ANEXO 3:

RESULTADOS DE LA ENCUESTA DE VALIDACIÓN SOBRE EL PROYECTO

Universo: 60 personas

Fecha: Mayo 2015

1. Distrito:

Se encuestó a personas residentes en los distritos de:

- Ate

- Barranco

- Bellavista

- Breña

- Chorrillos

- Jesús María

- La Molina 
- La Victoria

- Lima

- Lince

- Los Olivos

- Miraflores

- Pueblo Libre

- San Borja

- San Isidro

- San Luis

- San Miguel

- Santa Anita

- Surco

2. Sexo:

Mujeres $36 \quad 60 \%$

Hombres $\quad \mathbf{2 4} 40 \%$

3. Edad:

\section{Edad de los encuestados}

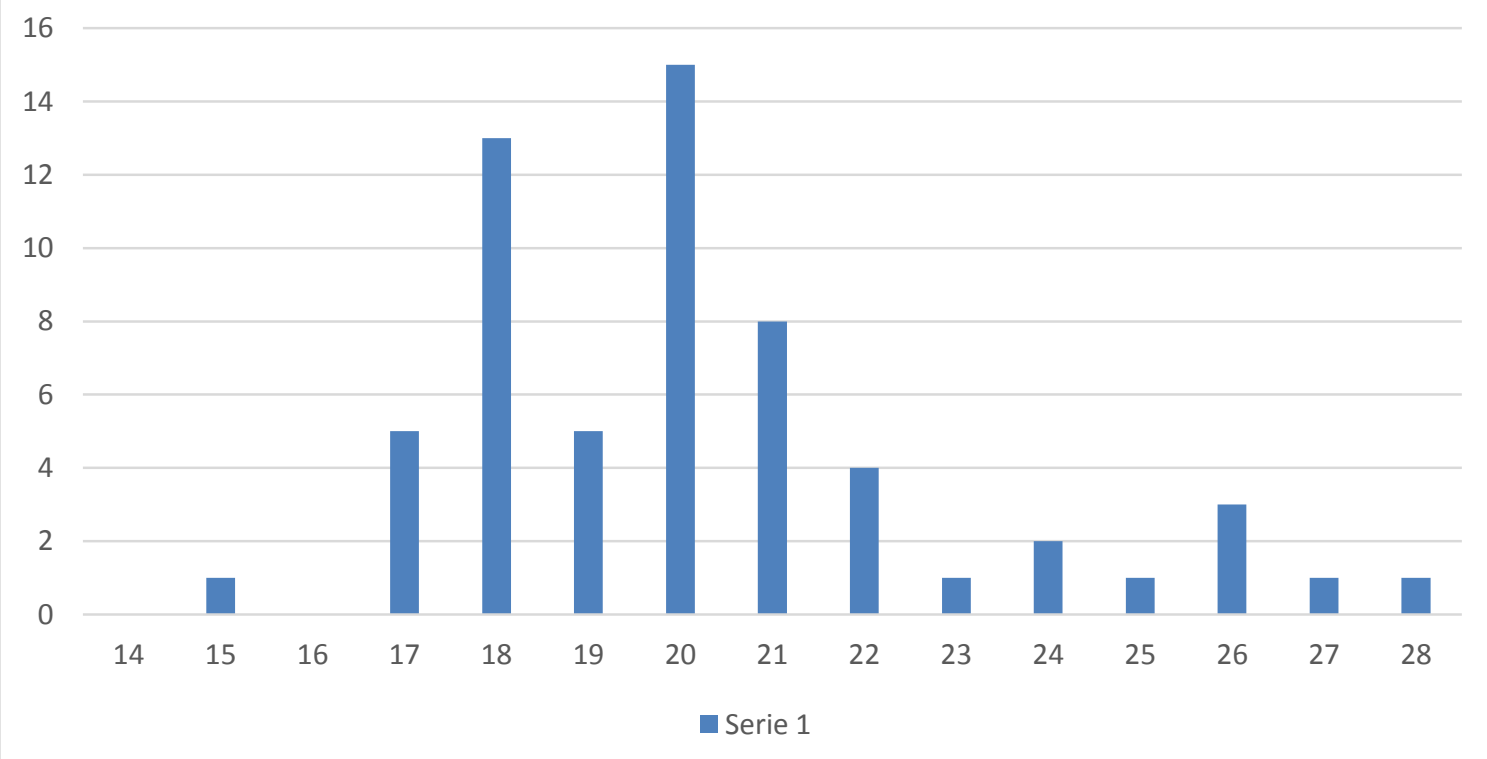

4. Ocupación: 


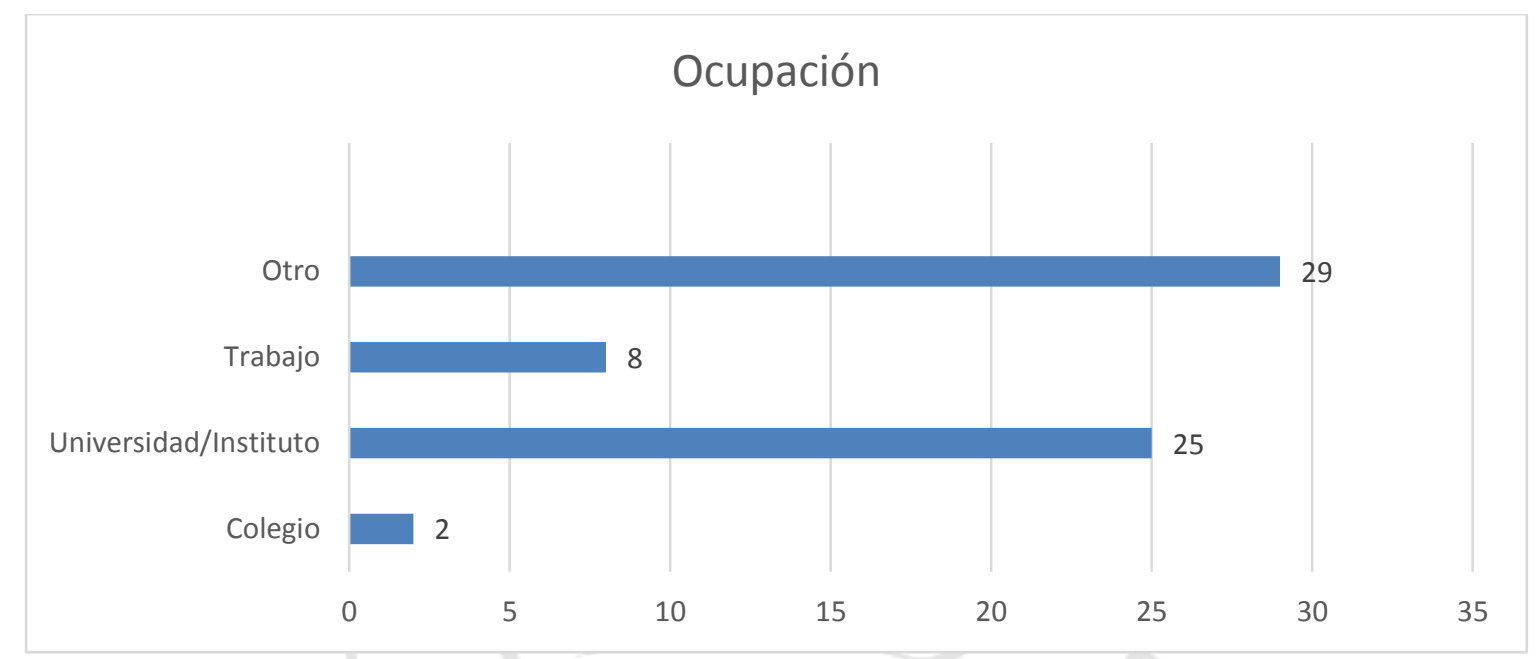

$\begin{array}{lll}\text { Estudio en el colegio } \quad \mathbf{2} & 3.3 \%\end{array}$

Estudio en la universidad/instituto $\quad \mathbf{2 5} \quad 41.7 \%$

Trabajo $8 \quad 13.3 \%$

Otro $29 \quad 48.3 \%$

\section{Carrera:}

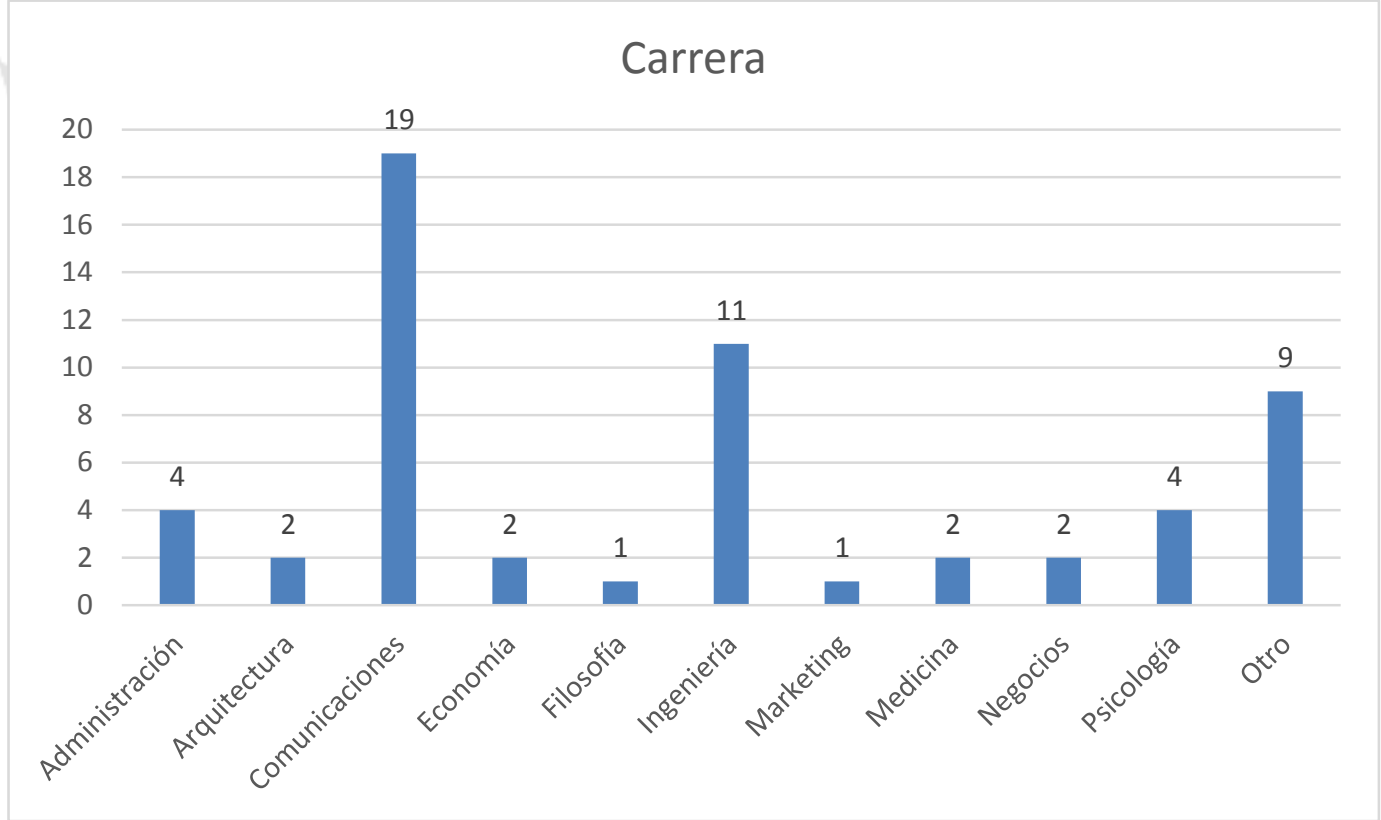

6. ¿Escuchas radio? 


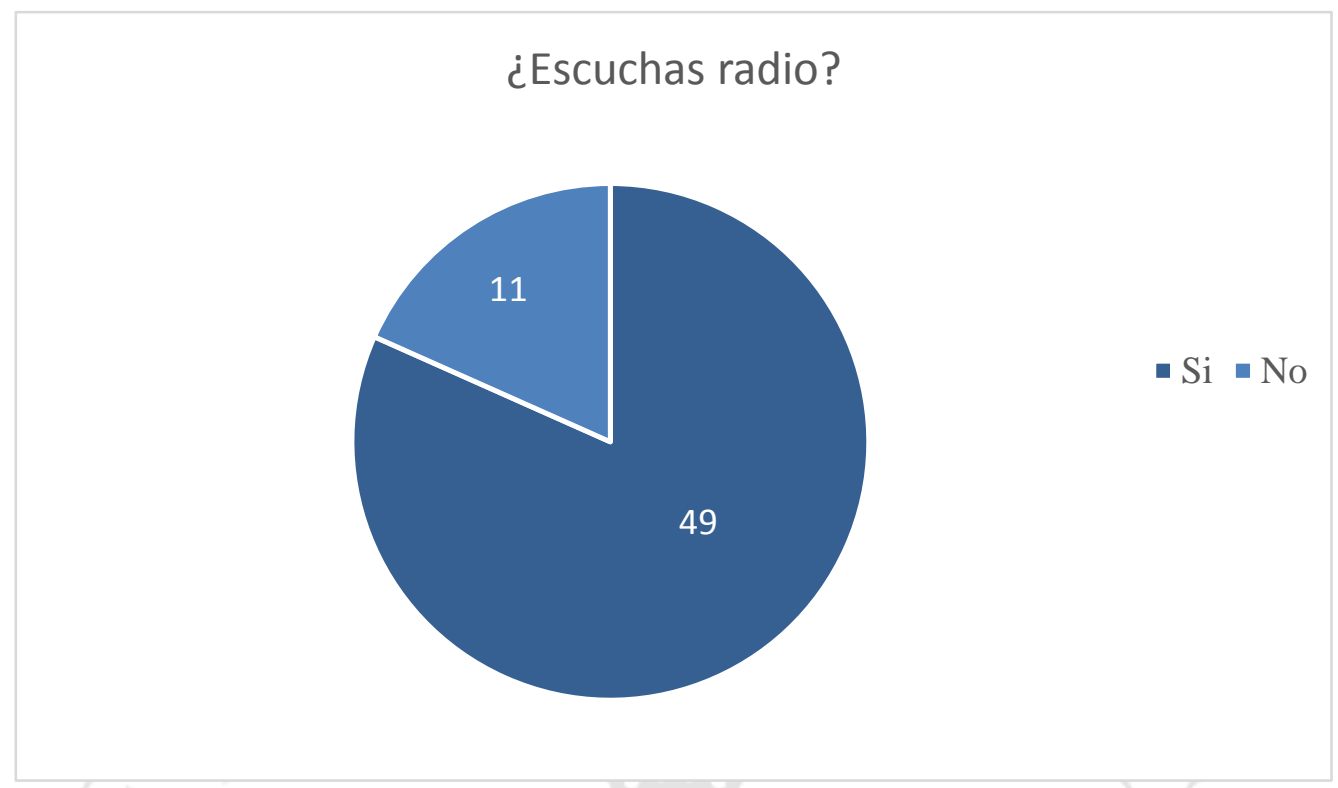

$\begin{array}{rrr}\text { Si } & \mathbf{4 9} & 81.7 \% \\ \text { No } & \mathbf{1 1} & 18.3 \%\end{array}$

7. ¿Con qué frecuencia escuchas radio?

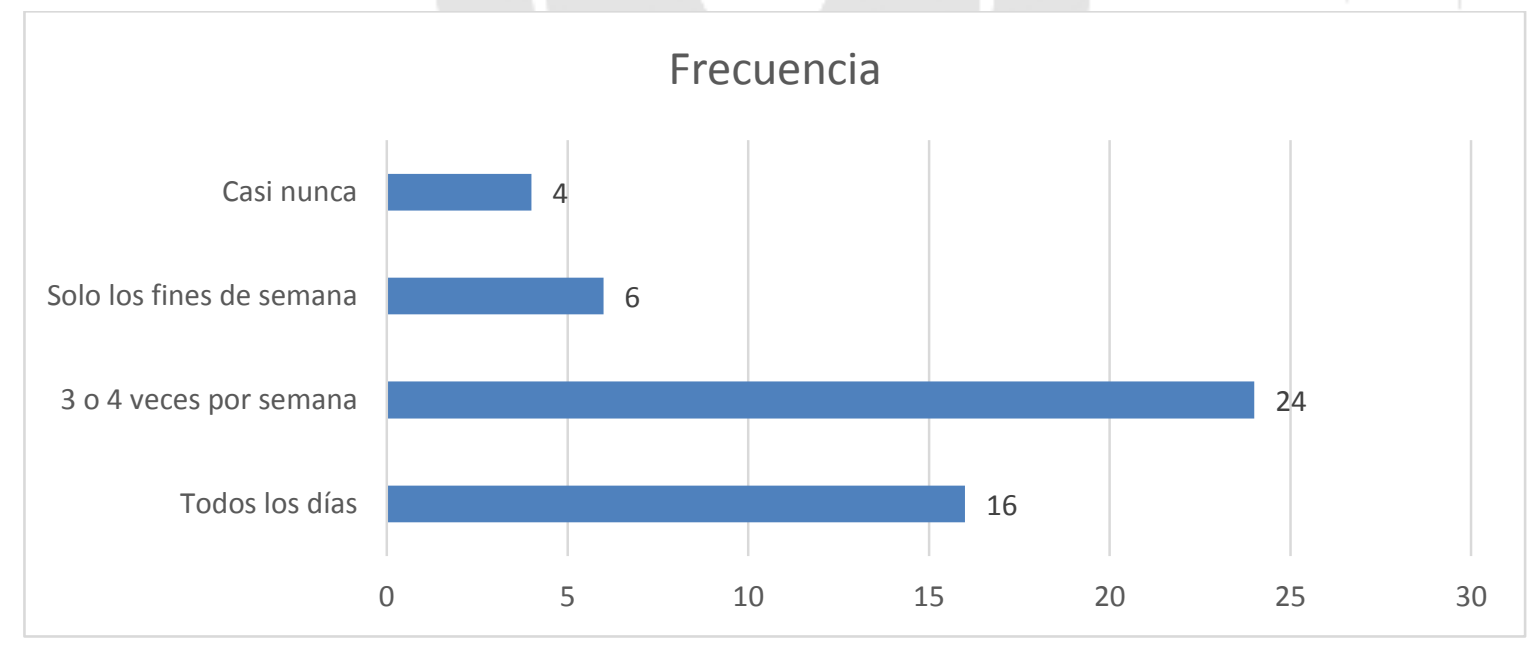

Todos los días $\quad \mathbf{1 6} \quad 32.7 \%$

3 o 4 veces por semana $\quad \mathbf{2 4} 49 \%$

Solo los fines de semana $\quad \begin{array}{ll}6 & 12.2 \%\end{array}$

Casi nunca $\quad \mathbf{4} \quad 8.2 \%$ 
8. ¿En dónde sueles escuchar radio?

\section{¿En dónde sueles escuchar radio?}

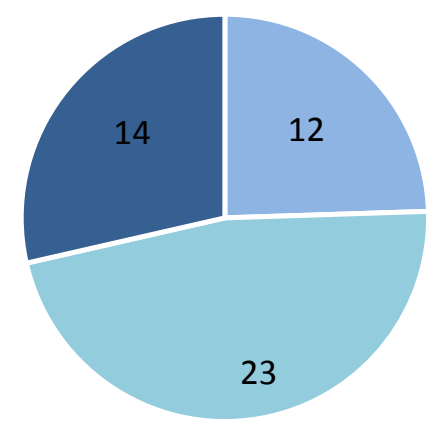

- En mi casa - En el carro - En la calle

$\begin{array}{rrr}\text { En mi casa } & \mathbf{1 2} & 24.5 \% \\ \text { En el carro } & \mathbf{2 3} & 46.9 \% \\ \text { En el trabajo } & \mathbf{0} & 0 \% \\ \text { En la calle } & \mathbf{1 4} & 28.6 \%\end{array}$

$\begin{array}{lll}\text { En la universidad } & \mathbf{0} & 0 \%\end{array}$

9. De lunes a viernes ¿a qué hora escuchas radio? 


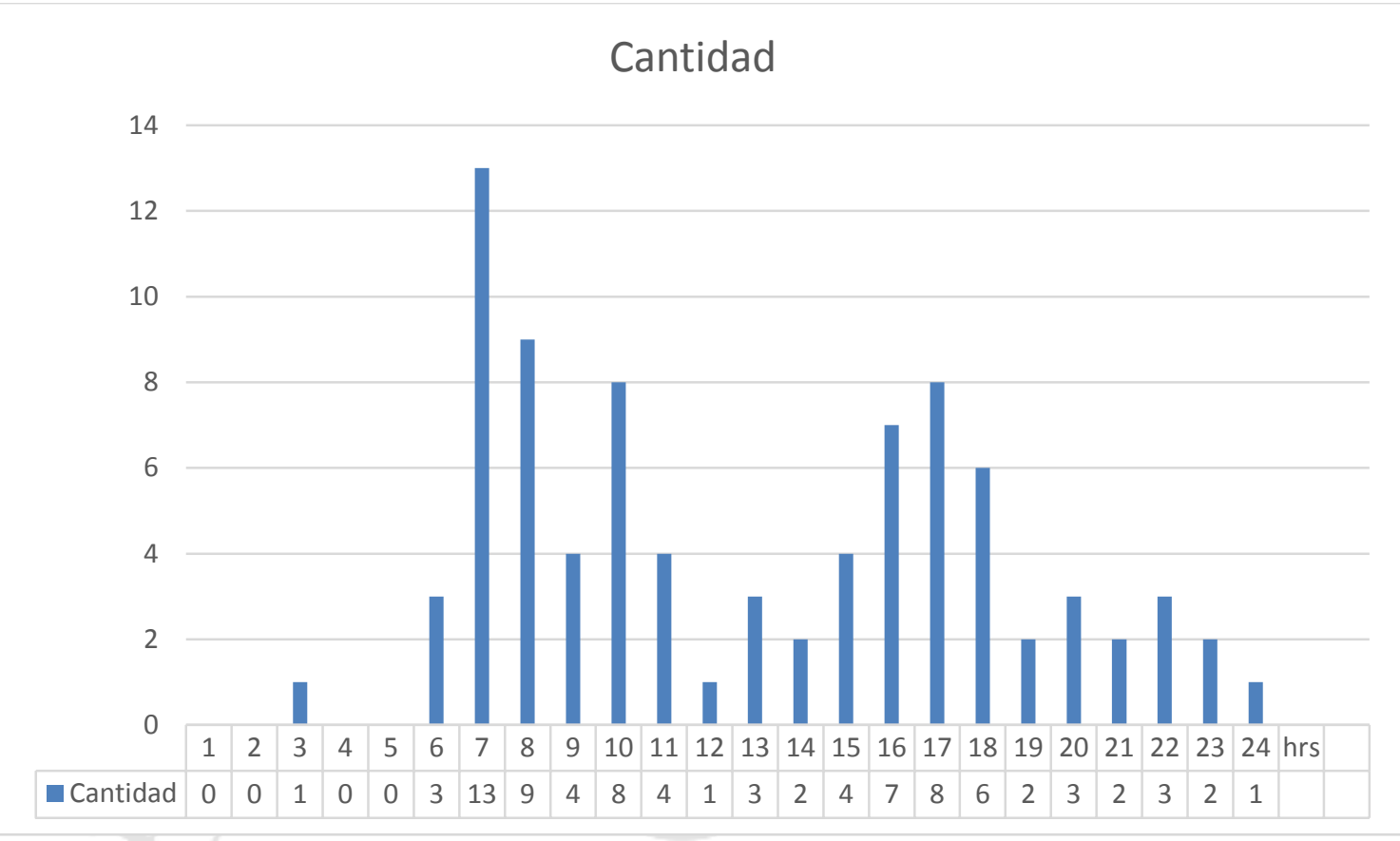

10. ¿Qué haces mientras escuchas radio?

¿Qué haces mientras escuchas radio?

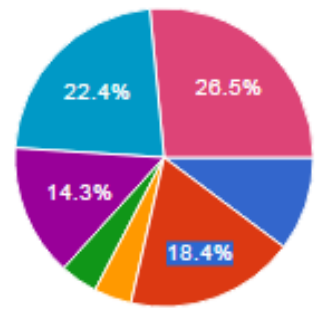

$\begin{array}{rrr}\text { Estudio/hago trabajos } & \mathbf{5} & 10.2 \% \\ \text { Descanso } & \mathbf{9} & 18.4 \% \\ \text { Trabajo } & \mathbf{2} & 4.1 \% \\ \text { Como } & \mathbf{2} & 4.1 \% \\ \text { Solo escucho radio } & \mathbf{7} & 14.3 \% \\ \text { Me transporto } & \mathbf{1 1} & 22.4 \% \\ \text { Otro } & \mathbf{1 3} & 26.5 \%\end{array}$

11. ¿Sueles participar en la radio mediante comentarios en redes sociales?

$$
\begin{array}{rrr}
\text { Si } & \mathbf{7} & 14.3 \% \\
\text { No } & \mathbf{4 2} & 85.7 \%
\end{array}
$$

12. Las veces que has comentado fue para: 


\section{La veces que has comentado fue para:}

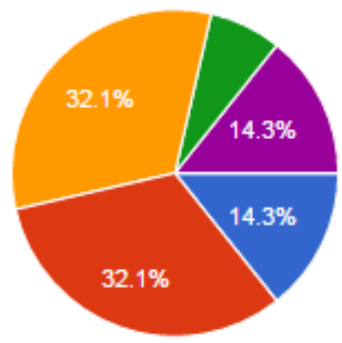

$\begin{array}{rrr}\text { Pedir una canción } & \mathbf{4} & 14.3 \% \\ \text { Participar de un concurso } & \mathbf{9} & 32.1 \% \\ \text { Dar tu opinión sobre el tema } & \mathbf{9} & 32.1 \% \\ \text { Comentar que te gusta la radio } & \mathbf{2} & 7.1 \% \\ \text { Otro } & \mathbf{4} & 14.3 \%\end{array}$

13. ¿Alguna vez has llamado a una radio?

$$
\begin{array}{ccc}
\text { Si } & \mathbf{1 7} & 34.7 \% \\
\text { No } & \mathbf{3 2} & 65.3 \%
\end{array}
$$

14. ¿Alguna vez has llamado a una radio?

La veces que has llamado fue para:

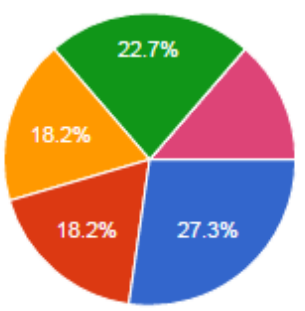

$\begin{array}{rlr}\text { Pedir una canción en especial } & \mathbf{6} & 27.3 \% \\ \text { Participar de un concurso vía telefónica } & \mathbf{4} & 18.2 \% \\ \text { Dar tu opinión sobre el tema } & \mathbf{4} & 18.2 \% \\ \text { Mandar saludos } & \mathbf{5} & 22.7 \% \\ \text { Consultar sobre algún tema } & \mathbf{0} & 0 \% \\ \text { Denunciar algún suceso } & \mathbf{0} & 0 \% \\ \text { Otro } & \mathbf{3} & 13.6 \%\end{array}$


15. ¿Sueles escuchar radio por internet?

$\begin{array}{ccc}\text { Si } & \mathbf{1 7} & 34.7 \% \\ \text { No } & \mathbf{3 2} & 65.3 \%\end{array}$

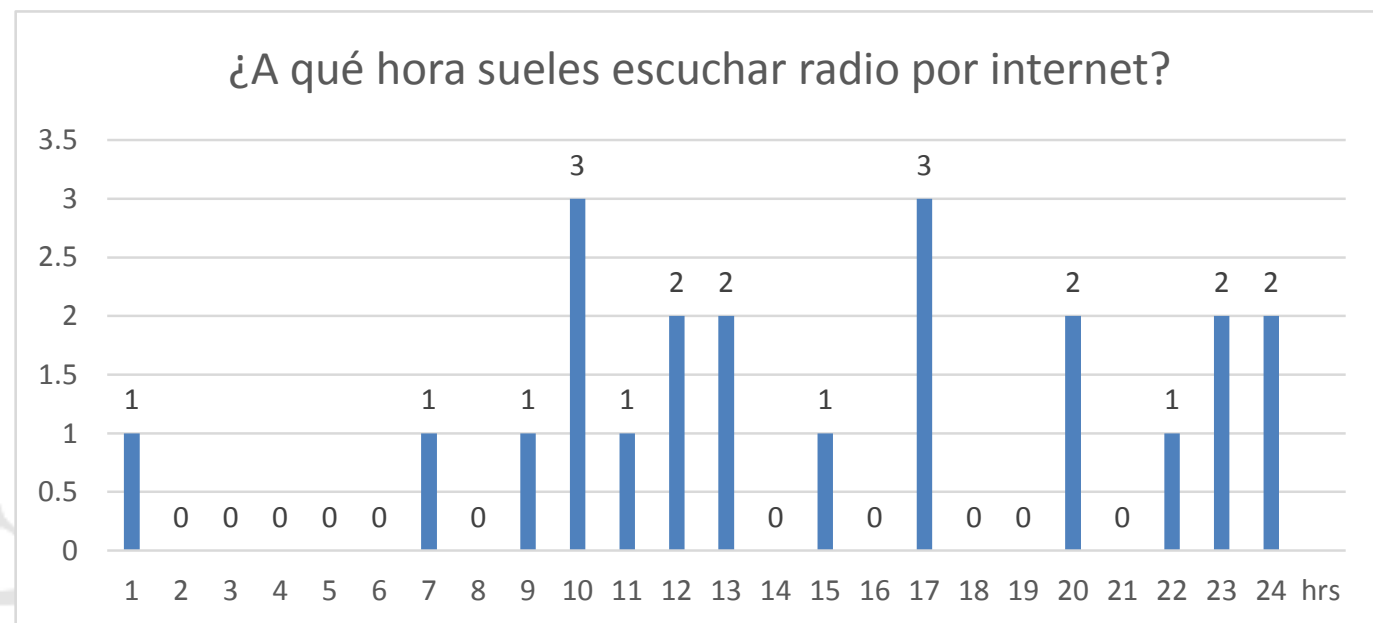

16. ¿A qué hora sueles escuchar radio por internet?

17. ¿En dónde sueles escuchar radio online?

$\begin{array}{rrr}\text { Casa } & \mathbf{1 5} & 88.2 \% \\ \text { Universidad } & \mathbf{0} & 0 \% \\ \text { Trabajo } & \mathbf{1} & 5.9 \% \\ \text { Carro } & \mathbf{0} & 0 \% \\ \text { Calle } & \mathbf{1} & 5.9 \% \\ \text { Otro } & \mathbf{0} & 0 \%\end{array}$

18. ¿Usas alguna aplicación para escuchar radio online?

$$
\begin{array}{rrr}
\text { Si } & \mathbf{4} & 23.5 \% \\
\text { No } & \mathbf{1 3} & 76.5 \%
\end{array}
$$

19. ¿Escucharías un programa de radio que trate temas relacionados a nuestra espiritualidad?

$$
\begin{array}{rrr}
\text { Si } & \mathbf{2 6} & 43.3 \% \\
\text { No } & \mathbf{4} & 6.7 \%
\end{array}
$$


20. ¿Te gustaría que una radio pase música del MVC?

$\begin{array}{rrr}\text { Si } & \mathbf{5 3} & 88.3 \% \\ \text { No } & \mathbf{0} & 0 \%\end{array}$

Me da igual $\quad 5 \quad 8.3 \%$

21. ¿Cuánto debería durar este programa?

1 hora $\mathbf{1 0} \quad 37 \%$

2 horas $\quad 7 \quad 25.9 \%$

3 horas $518.5 \%$

Todo el día $\quad \mathbf{5} \quad 18.5 \%$ 


\section{ANEXO 4: \\ LINKS RELACIONADOS}

Artistas o grupos:

- http://ictys.org/presentacion/

- https://www.facebook.com/athenas.venica/

- https://www.facebook.com/Vox-Lumini-13237696588/?fref=ts

- https://www.facebook.com/LaCimaOficial/?fref=ts

- https://www.facebook.com/SiervasMusica/?fref=ts

- https://www.facebook.com/takillakkta.org/?fref=ts

Radio católica juvenil:

- http://www.tres.fm./ 